Florida International University

FIU Digital Commons

$11-2-2015$

\title{
Determinants and Disparities of Survival in Triple- Negative Breast Cancer Patients: A Population- Based Retrospective Longitudinal Cohort Design Utilizing the Cox Proportional Hazard Analytical Model
}

Michael C. Belcon

Florida International University, Michael.Belcon@fiu.edu

DOI: $10.25148 /$ etd.FIDC000206

Follow this and additional works at: https://digitalcommons.fiu.edu/etd

Part of the Epidemiology Commons

\section{Recommended Citation}

Belcon, Michael C., "Determinants and Disparities of Survival in Triple-Negative Breast Cancer Patients: A Population-Based Retrospective Longitudinal Cohort Design Utilizing the Cox Proportional Hazard Analytical Model" (2015). FIU Electronic Theses and Dissertations. 2311.

https://digitalcommons.fiu.edu/etd/2311

This work is brought to you for free and open access by the University Graduate School at FIU Digital Commons. It has been accepted for inclusion in FIU Electronic Theses and Dissertations by an authorized administrator of FIU Digital Commons. For more information, please contact dcc@fiu.edu. 


\section{FLORIDA INTERNATIONAL UNIVERSITY \\ Miami, Florida}

\section{DETERMINANTS AND DISPARITIES OF SURVIVAL IN TRIPLE-NEGATIVE BREAST CANCER PATIENTS: A POPULATION-BASED RETROSPECTIVE LONGITUDINAL COHORT STUDY DESIGN UTILIZING THE COX PROPORTIONAL HAZARD ANALYTICAL MODEL}

A dissertation submitted in partial fulfillment of the requirements for the degree of DOCTOR OF PHILOSOPHY

in

PUBLIC HEALTH

by

Michael C. Belcon 
To: Interim Dean Mark L. Williams

Robert Stempel College of Public Health \& Social Work

This dissertation, written by Michael C. Belcon, and entitled Determinants and Disparities of Survival in Triple-negative Breast Cancer Patients: A Population-based Retrospective Longitudinal Cohort Study Design Utilizing the Cox Proportional Hazard Analytical Model, having been approved in respect to style and intellectual content, is referred to you for judgment.

We have read this dissertation and recommend that it be approved.

Changwon Yoo

Vukosava Pekovic

Quentin Felty

Nasar U. Ahmed, Major Professor

Date of Oral Dissertation Defense: November 2, 2015

The dissertation of Michael C. Belcon is approved

Interim Dean Mark L. Williams Robert Stempel College of Public Health\& Social Work

Dean Lakshmi N. Reddi

University Graduate School

Florida International University, 2015 


\section{DEDICATION}

This undertaking is dedicated to my loving family for their unstinting support during this long, difficult, but delightful journey. 


\section{ACKNOWLEDGMENTS}

I wish to acknowledge the Florida International University (FIU) for financial support it provided that has helped me to complete this endeavor. I also acknowledge the database access support granted by the Surveillance, Epidemiology and End Results (SEER) program that was necessary for the completion of this dissertation. I wish to thank all my teachers, especially those of my dissertation committee, for their generous advice, support and guidance during this often challenging educational process, but in the end, their helping to turn this into a delightful quest is also fitting to recognize. I especially acknowledge, my major professor, Dr. Nasar Ahmed, who has been a special mentor and source of inspiration and support throughout my educational sojourn at FIU. He has helped me in ways too numerous to detail. Many of my student-colleagues have also motivated me in countless ways during our shared journey. Finally but not least, I wish to especially thank Anshul Saxena who has been of invaluable assistance to me with his keen knowledge of statistical analysis. 


\author{
ABSTRACT OF THE DISSERTATION \\ DETERMINANTS AND DISPARITIES OF SURVIVAL IN TRIPLE-NEGATIVE \\ BREAST CANCER PATIENTS: A POPULATION-BASED RETROSPECTIVE \\ LONGITUDINAL COHORT STUDY DESIGN UTILIZING THE COX \\ PROPORTIONAL HAZARD ANALYTICAL MODEL
}

by

Michael C. Belcon

Florida International University, 2015

Miami, Florida

Professor Nasar U. Ahmed, Major Professor

A significant racial disparity in breast cancer mortality exists among women in the United States. Triple-negative breast cancer (TNBC) is a breast cancer phenotype that may explain, in part, this disparity between white and African American women. The objective of this study was to determine the predictors of survival in TNBC and nontriple-negative breast cancer (NTNBC) patients.

Data on 168,756 female patients with a diagnosis of invasive breast cancer in the Surveillance Epidemiology and End Results (SEER) program were stratified based on breast cancer receptor phenotypes in this retrospective longitudinal cohort study design. Multiple logistic regressions were used for exploring predictors of treatment which showed that not receiving surgery as standard treatment was associated (odds ratio: 95\% CI) with TNBC (OR 1.151: 1.042, 1.177), uninsured (OR 3.552: 3.206, 3.937) and African American (OR 1.804: 1.702, 1.912) while not receiving radiation was associated with TNBC (OR 1.151: 1.113, 1.190), uninsured (OR 1.318; 1.217, 1.429). Cox's hazard 
models were used, regressing age, race, ethnicity, marital status, health insurance status, histological tumor grade, and treatment status on survival time, the outcome measure. Analysis revealed that the mean survival time is lower for TNBC $[15.60$ ( \pm 10.29)] months compared with NTNBC $[16.01( \pm 10.18)](\mathrm{p}<0.0001)$, a difference though small is statistically significant. The independent determinants of survival in TNBC were: young age at diagnosis $[(\beta=0.033$, HR $1.033(1.026,1.041)]$; being African American [( $\beta=0.182$, HR $1.200(1.117,1.289)]$, being married $[(\beta=-0.362$, HR 0.697 (0.658, 0.737)]; higher tumor histological grades [ $\beta=1.034$, HR 2.812 (2.159,3.661)]; uninsured $[(\beta=0.541$, HR $1.717(1.481,1.992)]$; no surgery $[(\beta=2.156$, HR 8.633 (8.152, 9.143)], or no radiation treatment $[(\beta=0.489$, HR $1.630(1.535,1.73)]$. African American race, uninsured status, higher grade at diagnosis, inadequate treatment are independent predictors of poor survival among breast cancer patients; importantly, TNBC had a lower survival than that of NTNBC patients. A higher proportion of TNBC patients had a diagnosis at younger age, with higher tumor grade and was of the African American race. The survival disparity in African American patients may be partially explained by disproportionately higher TNBC cases among them, as well as, rates of not receiving standard treatments. 


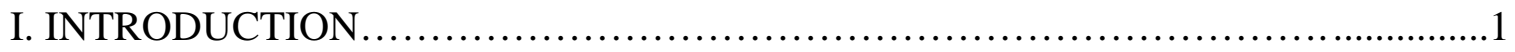

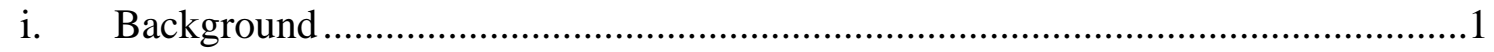

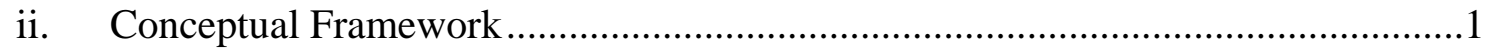

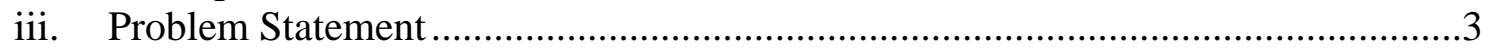

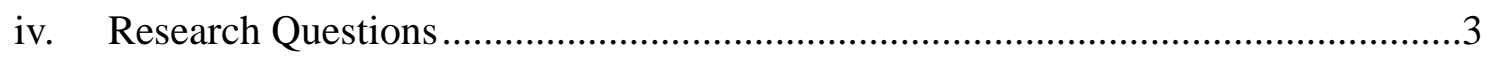

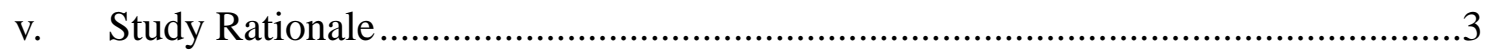

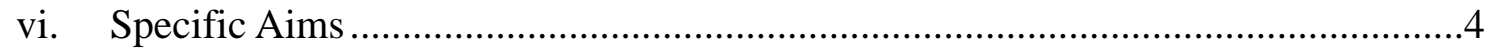

vii. Potential Contribution to Current Body of Knowledge ............................................

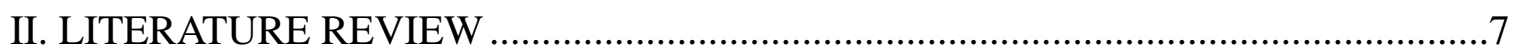

i. Breast Cancer Epidemiology …………………...........................................10

ii. Breast Cancer Risk Factors .............................................................................17

iii. Breast Cancer Receptor Biology and Phenotypes ...............................................25

iv. Breast Cancer Clinical Stages and Grades..............................................................34

v. Consensus Standard Treatment of Breast Cancer .................................................36

vi. Epidemiology of Triple-Negative Breast Cancer.......................................................45

vii. Triple-Negative Breast Cancer Knowledge Gaps and Unmet Needs .....................57

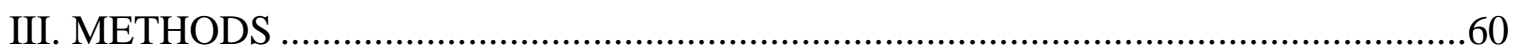

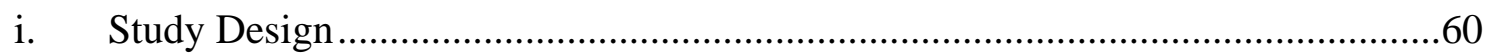

ii. Population Representative Sample …………….............................................60

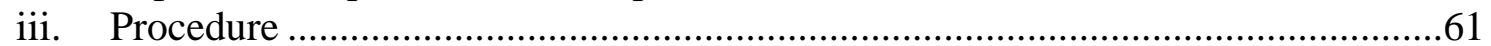

iv. Statistical Analysis .......................................................................................63

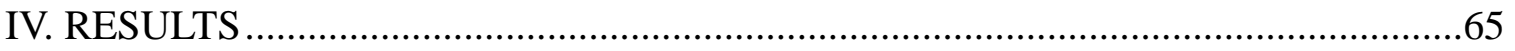

i. Demographics and Patient Characteristics........................................................65

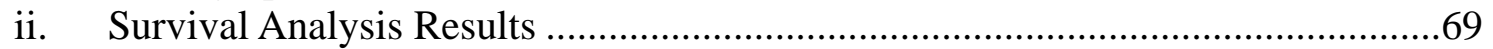

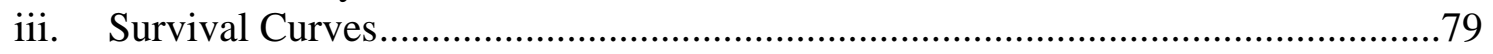

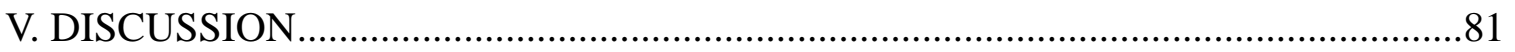

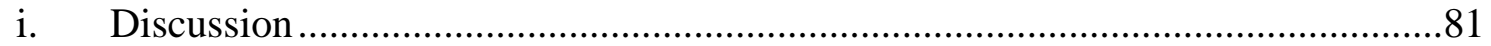

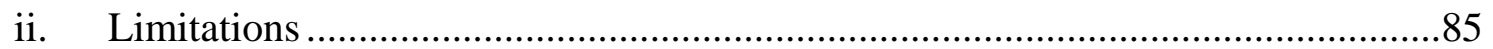

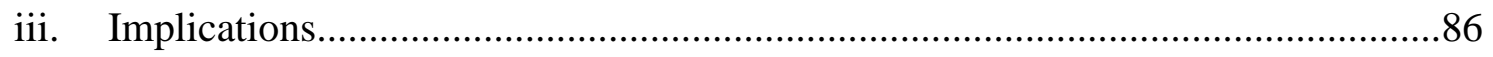

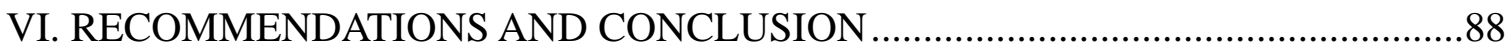

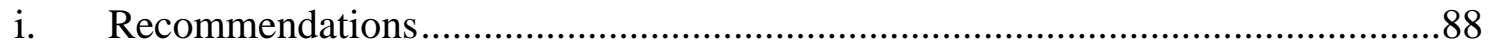

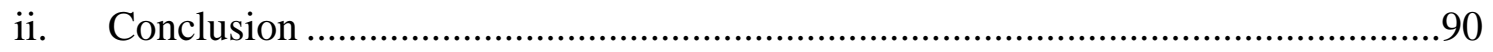

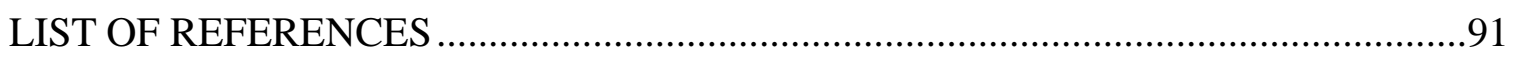

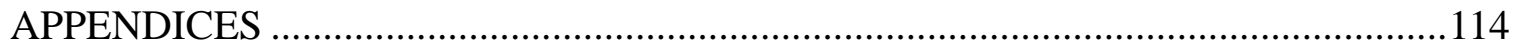




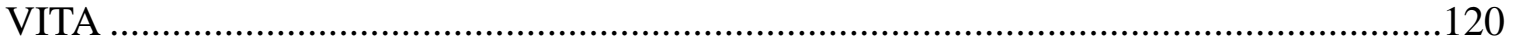




\section{LIST OF TABLES}

TABLE

PAGE

1. Age-specific breast cancer incidence rates per 100,000 (2008-2012).......11

2. Percentage of women diagnosed/died from breast cancer by age groups.....14

3. Risk factors for breast cancer......................................17

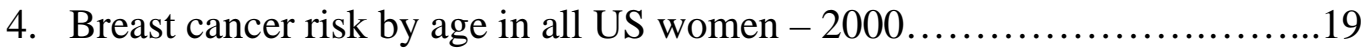

5. Incidence of breast cancer in the population $-2012 \ldots \ldots \ldots \ldots \ldots \ldots \ldots \ldots$

6. Determinants of breast cancer development............................23

7. Stratification of breast cancer risk factors by degree of risk...............25

8. Features of breast cancer molecular subtypes.........................26

9. List of selective cellular receptors and markers in breast cancer cells........28

10. AJCC - TNM breast cancer classification by stage........................35

11. Tumor grade and relative prognosis.................................36

12. Specific treatment of breast cancer by subtype..........................39

13. Treatment of breast cancer by receptor and menopausal status.............42

14. Invasive TNBC age-distribution among case patients...................48

15. Race/Ethnic distribution of invasive TNBC year $2010 \ldots \ldots \ldots \ldots \ldots \ldots \ldots . . . . . . .51$

16. Breast cancer subtypes selected from SEER database.....................61

17. Frequency of known breast cancer subtypes..........................62

18. Frequencies of age categories for TNBC and NTNBC $\ldots \ldots \ldots \ldots \ldots \ldots \ldots 6$

19. Frequencies of other demographic variables..........................67

20. Frequencies of clinical variables: grades, treatment, insurance status........68

21. Survival time for NTBC and TNBC .................................71 
22. Cox regression survival analysis of variables.........................72

23. Logistic regression analysis for surgery/no surgery and other variables......74

24. Logistic regression analysis for radiation/no radiation and other variables...75

25. Cox proportional hazard results TNBC and NTNBC $\ldots \ldots \ldots \ldots \ldots \ldots \ldots \ldots . . .78$ 


\section{LIST OF FIGURES}

FIGURE

PAGE

1. Conceptual framework for breast cancer survival study $\ldots \ldots \ldots \ldots \ldots \ldots \ldots \ldots . .2$

2. Top ten cancer sites: 2012, male and female United States - all races...........9

3. Age-specific female breast cancer incidence and mortality rates....................15

4. Breast cancer age-adjusted mortality rates by race/ethnicity $2000-2012 \ldots \ldots . .20$

5. Breast cancer survival from the Carolina Breast Cancer Study................50

6. Survival curve function by breast cancer subtypes (TNBC and NTNBC) .....73

7. Survival function curves for TNBC and race.............................. 79

8. Survival function curves for NTNBC and race.......................... 80 


\section{SYMBOLS}

\&

$\%$

$\pm$

$\geq$

$\leq$

$>$

$<$

$=$

$\beta$

And

Percent

Plus or minus

Greater than or equal to

Less than or equal to

Greater than

Less than

Equal to; the same as

Beta, Beta coefficient 


\section{ABBREVIATIONS AND ACRONYMS}

AJCC American Joint Committee on Cancer

BCS breast conserving surgery

BMI body mass index

cAMP cyclic adenosine monophosphate

CDC Centers for Disease Control and Prevention

GDP guanine diphosphate

EGF epidermal growth factor

EGFR epidermal growth factor receptor

ER estrogen receptor

ERBB2 erb-b2 tyrosine kinase 2 (humans), Avian erythroblastic leukemia viral oncogene

FDA Federal Drug Administration

HER2 human epidermal receptor type 2

OR odds ratio

PARP poly (ADP-ribose) polymerase

PDQ Presentation Display Quality

PR progesterone receptor

S.D. Standard deviation

SERM selective estrogen receptor modulator

SES Socioeconomic status

SEER Surveillance Epidemiology and End Results Program

TNBC triple-negative breast cancer 
NTNBC non-triple-negative breast cancer

VS

Versus 


\section{DEFINITIONS}

Adjuvant therapy

This is used for prophylaxis against potential recurrence or spread and after surgery and includes (1) radiation therapy to regional lymph nodes and to chest wall after modified radical mastectomy, (2) Systemic therapy with endocrine agents for $\mathrm{ER}+, \mathrm{PR}+$, chemotherapy, and monoclonal antibodies especially for HER2+ breast cancer and can be combined with chemotherapy.

Targeted neoadjuvant therapy Treatment administered to shrink tumor size after needle biopsy but before other surgery of any kind

Race and Ethnicity

The definition of race and ethnicity used in this undertaking is based on the US Office of Management and Budget's definition of race and ethnicity contained in the Federal Register Notice, October 30, 1997 and operationalized in the US Census Bureau publication “Race” revised July 8, 2013. The terms African American and Black are used interchangeable, especially as used in cited studies. In this same classification ethnicity is defined as Hispanic/Latino and non-Hispanic/non-Latino. 


\section{CHAPTER I}

\section{INTRODUCTION}

\section{i. Background}

After skin cancer, breast cancer is the most common form of cancer amongst women in the United States (CDC, 2009) and the second leading cause of cancer death in women after lung cancer (SEER Cancer Statistics Factsheets: Breast Cancer, 2015). In general, white women have a higher incidence and lower mortality rate that African American women with breast cancer (American Cancer Society (ACS). Cancer Facts and Figures. 2013-2014)). However, for women younger than 45 years the incidence of breast cancer is higher in African American women than white women (NAACCR, 2011; Howlader, et al., 2011). Compared with white women, the mortality rate among African American women is not only higher for younger age groups but is higher for all age groups (American Cancer Society (ACS). Cancer Facts and Figures. 2013-2014). Recently, the discovery that triple-negative breast cancer also may have a significantly higher mortality in African American, raises the possibility that this subset of breast cancer may partly explain the persistent disparity in breast cancer mortality.

\section{ii. Conceptual Framework}

The conceptual framework of this study is based on the Harvard TREC model of multilevel interactions of factors that influence cancer risks and predictors of survival (Harvard Transdisciplinary Research in Energetics and Cancer Center). These factors include genetic, behavioral, structural, sociological and biological factors that are 
interrelated and linked to the development of cancer and its outcome. The framework encompasses disparities among these factors that alter the differential potential for development of cancer (Kilboume et al., 2006). Once cancer develops there are other factors including socioeconomic correlates that influence cancer pathophysiology, health care access, and response to treatment that influences survival. The present study envisioned this model to link predictive factors such as age, race, marital status, tumor grade, tumor stage, health insurance availability and treatment provided, all of which in turn affect prognosis and ultimately the outcome of survival (Figure 1).

Figure 1: Conceptual framework for breast cancer survival study.

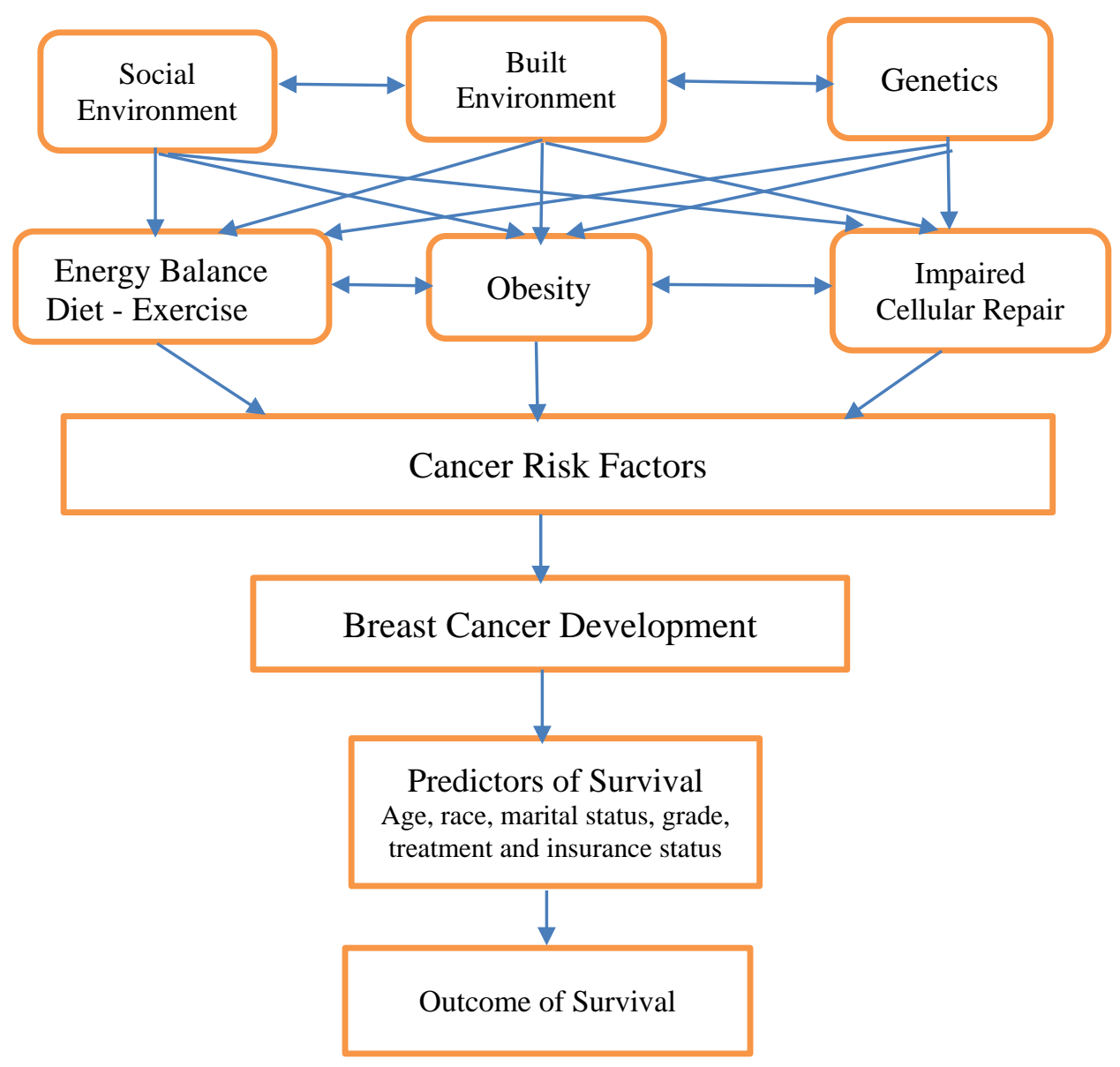




\section{iii. $\quad$ Problem Statement}

African American women have higher mortality from breast cancer than white women do and recent evidence suggests that one subset of breast cancer, TNBC, may be so lethal as to partially explain this higher mortality. Therefore, to better understand these observations, there is a need to better estimate: (a) the magnitude of survival in TNBC compared to NTNBC patients in the population, (b) the racial disparity in survival among TNBC patients, and (c) the predictors of survival among TNBC and NTNBC patients.

\section{iv. $\quad$ Research Questions}

Research Question 1: Is survival lower in TNBC patients compared to NTNBC patients? Research Question 2: Are there racial/ethnic disparities in survival in TNBC patients? Research Question 3: Are there clinical and sociodemographic variables that predict survival among TNBC and NTNBC patients?

\section{v. Study Rationale}

African American women have the highest mortality rate among all racial and ethnic groups. TNBC is a very lethal subset of breast cancer. Smaller population studies have suggested that mortality differences among racial groups do exist among TNBC patients, but no large scale population study has examined survival differences between racial and ethnic groups among TNBC patients using survival analysis statistical methods (Boyle, 2012). Could lower TNBC survival explain the higher mortality seen in overall breast cancer? If so, what are the variables that explain this poorer survival? 
Although the Carolina Breast Cancer study explored survival differences among basal-like, liminal A and luminal B breast cancer subsets (Carey et al, 2006), no largescale population study has yet evaluated survival among TNBC and NTNBC patients using survival analysis statistical methods (Boyle, 2012).

The ultimate rationale of this study then is to better estimate and define some of the epidemiological factors that may predict the high mortality and low survival of TNBC in certain racial and ethnic groups in the population from a large population database.

No large scale study has yet explored the epidemiological determinants that define the differences of TNBC and NTNBC patients using Cox proportional hazard methods of statistical analysis (Boyle, 2012).

It is the purpose of this study to provide data on these unanswered questions. Furthermore, the epidemiology of TNBC compared to NTNBC is still not well-defined currently. In fact, the burden of TNBC is only now being explored in the literature and needs to be better understood. It is one of the prerogatives of this study to better define the relative prevalence of TNBC in these population subsets and the factors contributing to TNBC survival. In the end, the purpose of this study is to evaluate which clinical and socioeconomic determinants have the biggest impact on TNBC survival.

\section{vi. Specific Aims}

The long term goal of this study is to close the existing epidemiologic information gaps in breast cancer, specifically between TNBC and NTNBC patients. The study can achieve this by providing a better understanding of the existing survival disparity and by identifying the possible predictors of survival among TNBC. In the broader context, the 
study's goal is for the study results to form the basis of effective public health programs and policies that would narrow the disparities that exist among minorities with breast cancer.

Specific Aim 1: The main aim of this study is to evaluate survival differences between racial and ethnic groups among TNBC patients from a large national database.

Hypothesis 1: Survival is lower in African American patients compared with NonHispanic white women.

Specific Aim 2: To compare the survival between TNBC and NTNBC so as to determine if survival is lower in TNBC compared to NTNBC patients.

Hypothesis 2: Survival is lower in TNBC patients compared with survival in NTNBC patients.

Specific Aim 3: To examine if treatment, clinical and sociodemographic factors predict survival in both TNBC and NTNBC patients.

Hypothesis 3: Treatment, clinical and sociodemographic characteristics predict survival in TNBC and NTNBC patients.

vii. Potential Contribution to Current Body of Knowledge

Since TNBC has such a poor prognosis, knowledge of the impact of this breast cancer subset on the overall mortality of breast cancer may have a significant impact on the overall knowledge of breast cancer survival in the general population. While awareness of factors affecting survival among breast cancer patients appears to be better understood 
in the general population, why TNBC is disproportionately lethal compared to NTNBC patients especially in the minority population, is not well understood. What are the factors contributing to survival in TNBC patients? What is the prevalence of TNBC among minority populations estimated from larger population databases? What other epidemiological factors distinguish TNBC from NTNBC and how significant are they as contributors to survival? Answering some of these questions can add substantial information to our current body of knowledge. The need for answers and results that this study can provide is compelling. 


\section{CHAPTER II}

\section{LITERATURE REVIEW}

The conceptual framework of this study encompasses behavioral, structural, biological and socioeconomic constructs that influence not only the risk factors for development of breast cancer but also the predictors of survival following the development of breast cancer (Kilbourne et al, 2006). These factors are not well delineated for TNBC and other breast cancer subsets and there remains significant gaps in available knowledge about the epidemiology of this disease and its subsets.

The overarching objective of this study is to address the epidemiologic information gaps among TNBC and NTNBC patients and the factors influencing survival in this population. An understanding of breast cancer is therefore essential in this process. In that direction, it is important to first understand that there is significant heterogeneity among breast cancers, each with unique therapeutic and prognostic implications (Goldhirsh et al., 2011; Esposito, Criscitiello, \& Curigliano, 2015). Up to 27\% of all breast cancers in some studies are considered triple-negative (Carey et al., 2006; Dawson, Provenzano, \& Caldas, 2009; Morris et al., 2007; Kaplan, \& Malmgren JA, 2008). Triplenegative breast cancer (TNBC) is a phenotype which is clinically negative for expression of the estrogen and progesterone receptors (ER and PR) and lacks overexpression of the HER2/neu protein (Boyle P, 2012). (Note: HER2/neu has been referred to as HER2 or human epidermal receptor type 2 and more recently, erb-b2 tyrosine kinase2 and v-erb-b2 avian erythroblastic leukemia viral oncogene homolog 2 (ERBB2). HER2 will be used in this discourse to denote the same entity). 
On an immunohistochemical level, TNBC shares salient features with basal-like breast cancer with which it is often confused but there is up to $30 \%$ discordance between the two (Nielsen et al., 2004; Kreike et al., 2007; Bertucci, et al., 2008; Cleator, Heller, \& Coombes, 2007). So the distinction should be made that the term TNBC refers to the immunohistochemical classification of breast cancers lacking ER, PR, and HER2 protein over expression, a phenotypic manifestation of genetic expression, while the basal-like subtype is defined by gene expression microarray analysis.

Clinically, TNBC differs from other subtypes of breast cancers in its predilection to younger women especially those who are African American and carries significantly different therapeutic and prognostic implications. A pattern is developing about TNBC from the smaller population studies currently available, one aspect of which is that women with TNBC tend to be disproportionally premenopausal and African American.

TNBC carries a worst prognosis than other subsets of breast cancer (Rastelli \& Crispino, et al., 2008). In this group, the disease tends to be diagnosed at a more advanced stage, with more lymph node involvement, larger tumor size, higher tumor grade and with more mitotic activity and cell growth fraction as measured by Ki-67 nuclear protein index; TNBC metastasizes earlier and to distant organs, especially visceral organs, as well as brain metastasis. Women with TNBC also tend to have earlier breast cancer recurrence, within 3 years of treatment. Reliance on common forms of treatment for TNBC has been relatively ineffective. This is especially so for hormonal manipulation including selective estrogen receptor modulators (SERM) and aromatase inhibitors and to a lesser extent radiotherapy and currently available biological therapy (Langland, Horgan, Dodwell \& Smith, 2013). 
Breast conserving surgery and chemotherapy have been the mainstay of treatment, thus far. The efficacy of biological therapy in TNBC is still uncertain but is currently in clinical trials (Tinoco, Warsch, Glück, Avancha, \& Montero, 2013). Because of poor responses to standard therapeutic interventions there has been a recent focus on more novel forms of treatment for TNBC including EGF receptor, alpha B crytallin, PARP inhibitors and Cyclin E therapeutic approaches (Crown, Oshaughnessy, \& Gullo, 2012; Malin et al., 2013). A consensus is developing that TNBC is a breast cancer subset with unique clinical, therapeutic and prognostic challenges compared to other subsets.

Figure 2: Top ten cancer sites 2012: male and female, United States - all races.

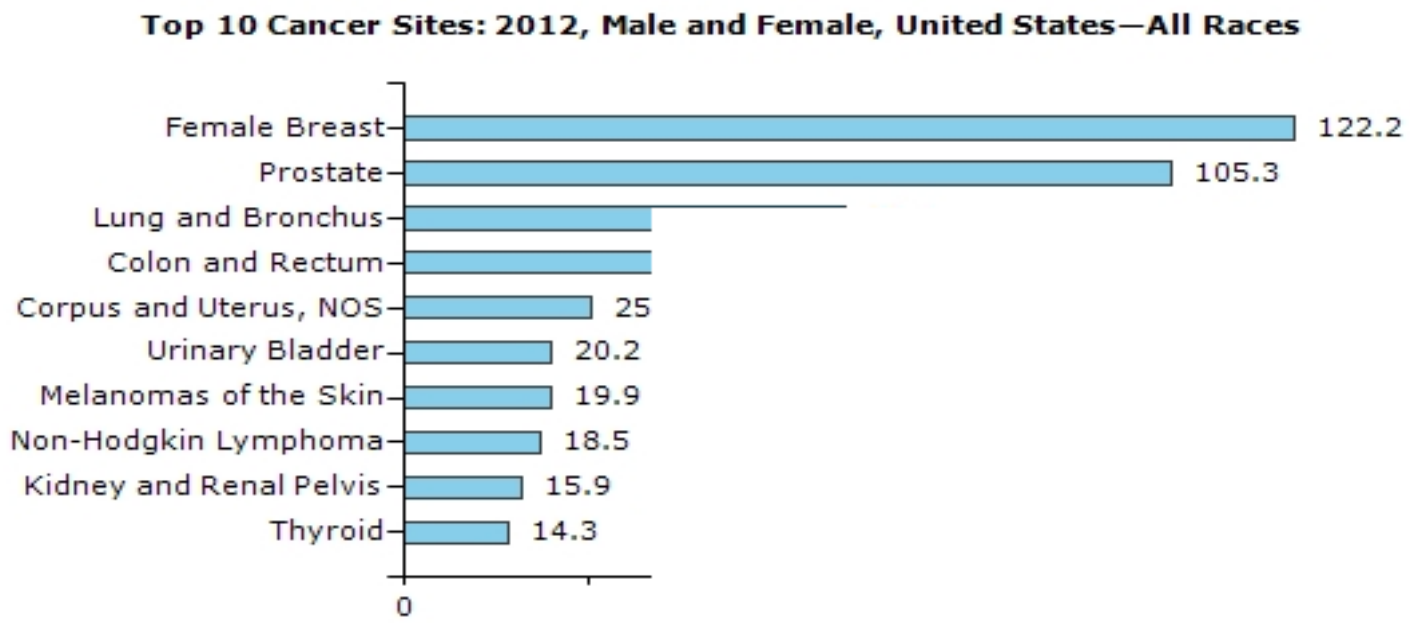

Taken from: U.S. Cancer Statistics Working Group. United States Cancer Statistics: 1999-2012 Incidence and Mortality Web-based Report. Atlanta: U.S. Department of Health and Human Services, Centers for Disease Control and Prevention and National Cancer Institute; 2015. Available at: www.cdc.gov/uscs.

Despite this, little is known about the epidemiology of TNBC from large scale population studies. The incidence, prevalence, mortality rate, mean age at diagnosis, racial and ethnicity profile for TNBC has been inferred from smaller population studies. Many of 
the factors affecting survival in TNBC are still to be better delineated. It is the purpose of this dissertation to better clarify some of the factors affecting survival of TNBC patients utilizing the large national database in the Surveillance, Epidemiology and End Results (SEER) program and Cox proportional hazard analytic model (Cox DR, 1972).

TNBC is but one subset of breast cancer and an overview of the entirety of breast cancer as a whole is essential to place the TNBC subset in its broader perspective. Much is known of breast cancer as a whole, while TNBC is only now being elucidated. In addition, much of what is known about the epidemiology of TNBC is based on the proportion of epidemiological indices of breast cancer overall as it relates to its subsets. Therefore, knowledge of breast cancer epidemiology is important to fully understand the epidemiology of TNBC.

\section{i. Breast Cancer Epidemiology}

Since the goal of this study is to address the existing epidemiologic information gaps in breast cancer, specifically between TNBC and NTNBC patients, clearly, an overview of what is known, or unknown about breast cancer epidemiology provides an essential perspective to better understand the intricacies of its subsets, TNBC and NTNBC.

After skin cancer, breast cancer is the most common cancer amongst both men and women in the United States (CDC. Breast Cancer Rates by Race and Ethnicity 1999 - 2011, 2014). Figure 1 is from data published in 2015 which excludes skin cancer, and shows breast cancer as having the highest incidence among 10 of the most common cancers in the population. Thirty two percent of all cancer cases diagnosed in women are due to breast cancer (American Cancer Society, 2012). 
Table 1: Age-specific breast cancer incidence rates per 100,000 (2008-2012).

\begin{tabular}{|c|c|c|}
\hline Age at Diagnosis & Non-Hispanic White & Black \\
\hline $20-24$ & 1.3 & 2.0 \\
\hline $25-29$ & 8.5 & 11.8 \\
\hline 5.139-34 & 26.6 & 34.3 \\
\hline $35-39$ & 59.4 & 68.2 \\
\hline $40-44$ & 122.0 & 123.4 \\
\hline $45-49$ & 191.8 & 183.5 \\
\hline $50-54$ & 227.2 & 225.4 \\
\hline $55-59$ & 268.8 & 278.2 \\
\hline $60-64$ & 353.6 & 341.6 \\
\hline $65-69$ & 437.9 & 397.8 \\
\hline $70-74$ & 460.1 & 422.8 \\
\hline $75-79$ & 469.9 & 420.8 \\
\hline $80-84$ & 438.2 & 408.1 \\
\hline $85+$ & 362.1 & 364.0 \\
\hline
\end{tabular}

From:

Howlader N, Noone AM, Krapcho M, Garshell J, Miller D, Altekruse SF, Kosary CL, Yu M, Ruhl J, Tatalovich Z,Mariotto A, Lewis DR, Chen HS, Feuer EJ, Cronin KA (eds). SEER Cancer Statistics Review, 1975-2012, National Cancer Institute. Bethesda, MD, http://seer.cancer.gov/csr/1975_2012/, based on November 2014 SEER data submission, posted to the SEER web site, April 2015.

Table 1 shows data from 2008 - 2012, where the breast cancer age-adjusted incidence is 122.2 per 100,000 adjusted to the 2000 U.S. standard. It is estimated in 2015 that 231,840 women in the US will be diagnosed with breast cancer and 40,290 women 
will die from the disease in that same year (SEER Cancer Statistics Factsheets: Breast Cancer, 2015). Based on 2008 - 2012 data, the lifetime probability of a US woman developing breast cancer is 1:8. Put another way, $12.3 \%$ of women in the United States will be diagnosed with breast cancer in their lifetime, the highest among all cancers by site (Howlader et al., 2012).

The overall age-adjusted annual incidence of breast cancer from 2008 - 2012 is 124.8 per 100,000 , slightly higher among whites $(128.3$ per 100,000$)$ compared to African-Americans (124.3 per 100,000).

Before age 45 years, African-American women have a higher incidence of breast cancer compared to non-Hispanic whites, but after age 45 there is a crossover of incidence in which the incidence of overall breast cancer is higher in non-Hispanic white women compared to African-American women (NAACCR, 2011, Howlader, et al., 2011). This data is tabulated in Table 1.

Until quite recently, trends indicated that breast cancer incidence increased over the past four decades. Between 1999 and 2009 the incidence decreased by 2\% per year but most of that incidence decrease occurred in women age 50 and older. Before that, the rate of increase was most rapid in the 1980s, mainly as a result of increased early detection through mammography. By year 1999, the incidence started to decrease particularly among women 50 years and older (ACS - American Cancer Society, 2010). In addition to a decrease in actual breast cancer cases detected, this recent decrease in incidence may also be due to a low adherence to mammography screening (Clarke et al., 2013), although a decreased use of hormonal replacement therapy a decade before may have been a contributing factor (Zbuk \& Anand, 2012). 
The prevalence of breast cancer in 2012 is estimated at 2,975,314 indicating a significant burden of breast cancer in the US population. The risk of developing breast cancer increases with age with the 10-year risk put at 1 in 71 for a woman at age 40 years, 1 in 42 at age 50 years, and 1 in 29 at age 60 years (Altekruse et al,. 2010). This can be stated another way. Data from 2008-2012 show the percentage of women diagnosed with breast cancer increases from $0 \%$ in those under age 20 years to $25.6 \%$ in those 55 - 64 years (See Table 2). The peak incidence occurs in the 55 - 64 age-group. But the incidence of breast cancer between ages 35 - 44 years is not trivial, with $10.9 \%$ of all cases occurring before age 45 years and fully $32.5 \%$ or $1 / 3$ of all cancer cases occurring before the peak incidence age group (Howlader et al., 2014).

Despite the passage of time, the disease is still very lethal among US women. After lung cancer (26.8\% of cancer deaths), breast cancer is still the second leading cause of death among US women accounting for 6.8\% of all cancer deaths (CDC NCHS, 2014. From 2005 - 2011 data, the five-year survival rate for breast cancer is $89.4 \%$, worst for distant metastasis (Stage IV) at the time of diagnosis at, 25.9\% (SEER Cancer Statistics Factsheets: Breast Cancer, 2014). From the same data, it is estimated that 40,290 women will die from breast cancer in the year 2015.

Between 2008 and 2012, the overall age-adjusted mortality rate of breast cancer was 21.9 per 100,000 with 32.4 per 100,000 in African-Americans compared to 23.9 per 100,000 among White women (SEER Cancer Statistics Factsheets: Breast Cancer, 2015). While two of the leading causes of death - heart disease and stroke - have had a substantially decreased mortality (60\% decrease) between 1950 and 2005, cancer 
mortality has decreased only slightly (5\%) from 193.9 to 183.8 per 100,000 during those years (NCHS, 2009) and the burden is particularly weighty for the minority populations.

Table 2: Percentage of women diagnosed/died from breast cancer by age groups.

\begin{tabular}{|c|c|c|}
\hline Age (years) & Percentage Diagnosed & Percentage who died \\
\hline$<29$ & 0.0 & 0.0 \\
\hline $20-34$ & 1.8 & 0.9 \\
\hline $35-44$ & 9.1 & 5.1 \\
\hline $45-54$ & 21.6 & 14.3 \\
\hline $55-64$ & 25.6 & 21.9 \\
\hline $65-74$ & 21.9 & 21.0 \\
\hline $75-84$ & 14.2 & 20.5 \\
\hline$>84$ & 5.7 & 16.4 \\
\hline
\end{tabular}

Data from 2008- 2012. From: Howlader, et al., 2014

Epidemiology of Breast Cancer in US Racial and Ethnic Minority Populations: In the period 2008 -2012, the age-adjusted incidence of breast cancer was 124.8 per 100,000. For African Americans it was 124.4 per 100,000, White 127.9 per 100,000, Asian/Pacific Islanders 96.3 per 100,000, American/Alaska natives 82.0 per 100,000. For Hispanics it was 92.1 per 100,000 and Non-Hispanics 130.1 per 100,000. African Americans have a 33\% higher risk of dying from cancer than Whites (Ries L, et al., 2006) and about 2.8 times as much mortality risk compared to Asian American/Pacific Island (AA/PI) women (34.6 versus 12.3 per 100,000) (Stewart et al., 2004).

Between 2008 -2012, there was a racial gradient in female breast cancer death rates with the highest among African American women (30.2 per 100,000), followed by 
White, American Indian/Alaska natives, Hispanics and Asian American/Pacific Island women (21.3, 15.0, 14.5 and 11.4 per 100,000 respectively). Age-adjusted to 2000 US standard population, the breast cancer mortality rate in 2000 among African Americans was 33.8 compared to 25.0 per 100,000 in 2009.

Figure 3: Age-specific breast cancer incidence and mortality rates.

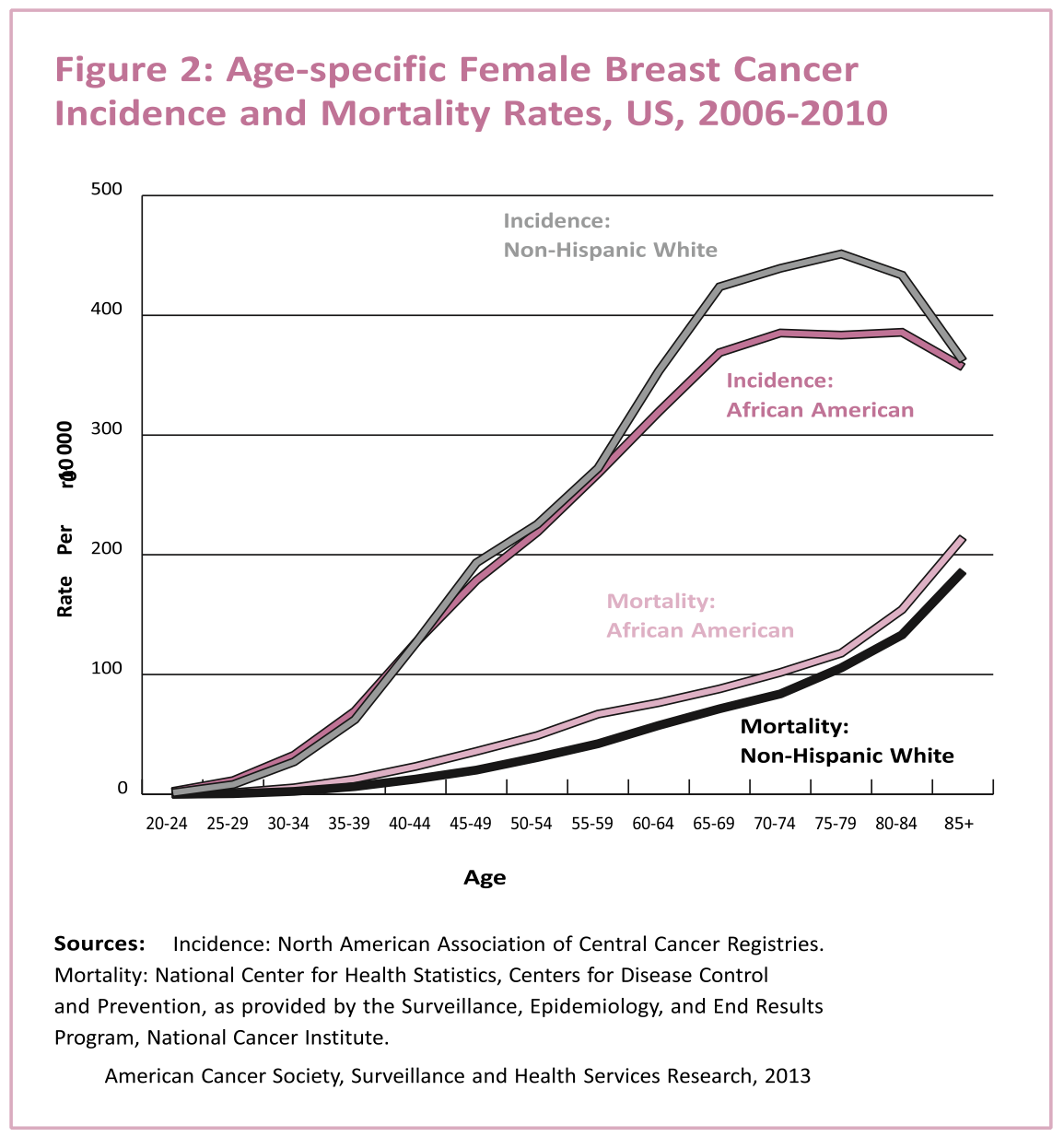

Age Disparity in Breast Cancer Incidence: In women, the incidence of breast cancer increases with age and doubles every 10 years until menopause when the rate of increase slows. Approximately 25\% of breast cancers affect women under the age of 50 years, 
with $50 \%$ occurring between the ages of 50 and 69 years and the remaining $25 \%$ developing in women who are 70 years or older.

The trend of change in incidence and mortality with age, although similar for both races, shows that breast cancer tends to occur at a younger age in African Americans with separation of, and higher mortality rates between, the races in all age groups. The average age of breast cancer diagnosis in African American women is 46 years, compared to 57 years for white women (CDC, 2010; (Retsky et al., 2005; Howlader et al., 2012). Disparity in Lethality: Figure 2 shows the breast cancer incidence and mortality rates by age among Non-Hispanic whites and African American women. Recent research suggests that in African American women breast cancer appears to be more aggressive and lethal than in White women. Analysis of data from the Women's Health Initiative Study revealed that African American women had more high-grade and estrogen receptor negative tumors, at a rate five times as much as White women. Both findings together indicate that these aggressive breast cancers are more difficult to treat and are associated with poorer outcomes (Chlebowski et al., 2003; Li et al., 2002; Miller et al., 2002).

These same studies also confirmed that African American women are more likely to be diagnosed with late-stage disease than white women are (45 percent compared with 33 percent) (Leserman et al., 1993). This observation was also demonstrated with other ethnic minority groups. In one study by Lantz et al. (2000), African American and Hispanic women were less likely to be diagnosed with early-stage breast cancer than were White women $(P<0.001)$. After controlling for study site, age, and individual socioeconomic factors, the odds of early detection were still significantly less for 
Hispanic women (odds ratio $[\mathrm{OR}]=0.45,95 \% \mathrm{CI}=0.31-0.64$ ) and African Americans women ( $\mathrm{OR}=0.72,95 \% \mathrm{CI}=0.54-0.96)$ than for White women (Lantz et al., 2000).

ii. Breast Cancer Risk Factors

Table 3: Risk factors for breast cancer.

\begin{tabular}{|l|l|c|}
\hline \multicolumn{1}{|c|}{ FACTOR } & \multicolumn{1}{|c|}{ FACTOR DETAIL } & $\begin{array}{l}\text { Relative } \\
\text { Risk }\end{array}$ \\
\hline Age & Over age 50 & $>4.0$ \\
\hline Gender & Female > Males & $>4.0$ \\
\hline Family history & $\begin{array}{l}\text { Breast cancer in first-degree relatives, particularly if } \\
\text { BRCA1 or BRCA2 }\end{array}$ & $>4.0$ \\
\hline Personal history & $\begin{array}{l}\text { Previous breast cancer in ipsilateral or contralateral } \\
\text { breast }\end{array}$ & $>4.0$ \\
\hline $\begin{array}{l}\text { Hormonal } \\
\text { Influence }\end{array}$ & $\begin{array}{l}\text { Long menstrual history: early menarche and late } \\
\text { menopause } \\
\text { Menstrual }\end{array}$ & $\begin{array}{l}\text { Nulliparous or first full-term pregnancy at age 40 or } \\
\text { older. } \\
\text { Postmenopausal hormone therapy use }\end{array}$ \\
\hline Parity & $\begin{array}{l}\text { Not having breastfed or having breastfed for less than } \\
\text { 12 months (i.e., total for all births) }\end{array}$ & $>4.0$ \\
\hline Breast feeding & $\begin{array}{l}\text { Particularly post-menopausal obesity. Overweight } \\
\text { women were 60\% more likely to die from breast } \\
\text { cancer than were normal-weight women (Calle, } \\
\text { Rodriguez, Walker-Thurmond \& Thun, 2003); a } \\
\text { higher risk of breast cancer has been associated with } \\
\text { weight gain after menopause (Lahmann, Lissner, } \\
\text { Gullberg, Olsson, \& Berglund, 2003); }\end{array}$ & $>4.0$ \\
\hline Obesity & $\begin{array}{l}\text { Moderate to heavy alcohol intake (i.e., }>1 \text { drink/day), } \\
\text { estrogens, chest radiation }\end{array}$ & $2.1-4.0$ \\
\hline $\begin{array}{l}\text { Environmental } \\
\text { exposure }\end{array}$ & $\begin{array}{l}\text { Abnormal breast biopsy } \\
\text { brevious breast }\end{array}$ & $2.1-4.0$ \\
\hline
\end{tabular}

Adapted from: Hulka \& Moorman, 200 
To best appreciate factors predicating survival is to understand the known risk factors for developing breast cancer. The number one risk factor for developing breast cancer is female gender (ACS, 2011). Breast cancer is gender specific. The disease has an overwhelming predilection for women. While it does occur in men, almost all cases occur in women. Consistent epidemiological data has repeatedly shown that about $99.5 \%$ of people developing breast cancer are female and less than $0.5 \%$ are male (ACS, 2011).

Besides sex, generally, the risk factors for breast cancer are based on several other factors including age, familial or genetic factors, environmental, endocrinological and host factors (such as breast density and proliferative breast disorders) (Table 3).

Age and Race: The life time risk of a woman developing breast cancer is about 1:8 or $12.5 \%$. By decades, the 10 year risk increases to about $25 \%$ in the $4^{\text {th }}$ decade and $35 \%$ in the $5^{\text {th }}$ decade of life (SEER, 2011). Age is the single most important risk factor for the development of breast cancer. Table 4 shows the percentage risk of developing breast cancer for various age groups in the year 2000.

This percentage risk increases with age and is highest after age 80 years old. Table 5 shows the incidence of breast cancer as a function of age for various racial and ethnic groups. The average age of breast cancer diagnosis in African American women is 46, compared to 57 years for Whites (Retsky et al., 2005; Howlader, et al., 2012).

For the general population the incidence of breast cancer increases from age 40 to over age 70 and after which it levels off. For African Americans the breast cancer incidence is higher than Whites between age 40 and age 50 years. After age 50 years the incidence is higher in Whites than African Americans. 
Table 4: Breast cancer risk by age in all US women - 2000.

\begin{tabular}{|c|c|}
\hline $\begin{array}{c}\text { Age Group } \\
\text { (Years) }\end{array}$ & $\begin{array}{c}\text { Breast Cancer Risk } \\
(\%)\end{array}$ \\
\hline$<30$ & 0.004 \\
\hline $30-39$ & 0.43 \\
\hline $50-49$ & 1.44 \\
\hline $60-59$ & 2.65 \\
\hline $70-79$ & 3.65 \\
\hline$>80$ & 4.73 \\
\hline
\end{tabular}

After: Ries et al. SEER Cancer Statistics Review, 1975-2003. Bethesda, MD: National Cancer Institute, 2006.

This crossover in incidence between white women and African American women with breast cancer as a function of age-groups has not been observed in comparisons with other racial and ethnic groups (Figure 3).

Table 5: Incidence of breast cancer in the population - 2012*

$\begin{array}{ccccccc}\begin{array}{c}\text { Age } \\ \text { Group }\end{array} & \begin{array}{c}\text { All } \\ \text { Races }\end{array} & \text { White } & \text { Black } & \begin{array}{c}\text { Asian/Pacific } \\ \text { Islander }\end{array} & \begin{array}{c}\text { American } \\ \text { Indian/Alaska } \\ \text { Native }\end{array} & \text { Hispanic } \\ 25-29 & 9.1 & 8.4 & 12.4 & 8.2 & - & 6.0 \\ 30-34 & 27.4 & 26.2 & 32.8 & 23.9 & 13.4 & 20.2 \\ 35-30 & 60.1 & 59.1 & 66.1 & 51.5 & 33.1 & 45.9 \\ 40-44 & 121.3 & 121.0 & 126.0 & 106.7 & 49.4 & 91.1 \\ 45-49 & 184.5 & 185.1 & 180.2 & 169.8 & 84.6 & 138.8 \\ 50-54 & 219.4 & 219.3 & 225.1 & 184.5 & 129.0 & 169.6 \\ 55-59 & 254.6 & 254.6 & 266.4 & 203.0 & 122.7 & 201.3 \\ 60-64 & 327.8 & 331.1 & 328.5 & 289.9 & 239.4 & 308.7 \\ 65-69 & 418.1 & 426.1 & 385.8 & 289.9 & 239.4 & 321.9 \\ 70-74 & 440.1 & 451.2 & 398.4 & 264.2 & 289.4 & 308.7 \\ 75-79 & 442.6 & 454.5 & 400.9 & 234.2 & 273.6 & 310.4 \\ 80-84 & 407.3 & 414.9 & 369.5 & 229.1 & 290.2 & 278.4 \\ 85+ & 332.9 & 333.7 & 329.0 & 182.5 & 147.9 & 244.5\end{array}$

*(Incidence per 100,000 by Age, Race and Hispanic Ethnicity, 2012).

Taken from: U.S. Cancer Statistics Working Group. United States Cancer Statistics: 1999-2012 Incidence and Mortality Web-based Report. Atlanta: U.S. Department of Health and Human Services, Centers for Disease Control and Prevention and National Cancer Institute; 2015. Available at: www.cdc.gov/uscs. 
Interestingly, age-adjusted mortality rates for breast cancer are higher in African

American than whites for all age-groups.

Familial Considerations: First degree relatives (mother, siblings, etc.) of index breast cancer cases are at highest risk for getting breast cancer independent of known genetic factors. Second degree relatives (aunts, grandmothers, cousins) are at a lower risk.

Figure 4. Breast cancer age-adjusted mortality rates by race/ethnicity 2000 - 2012.

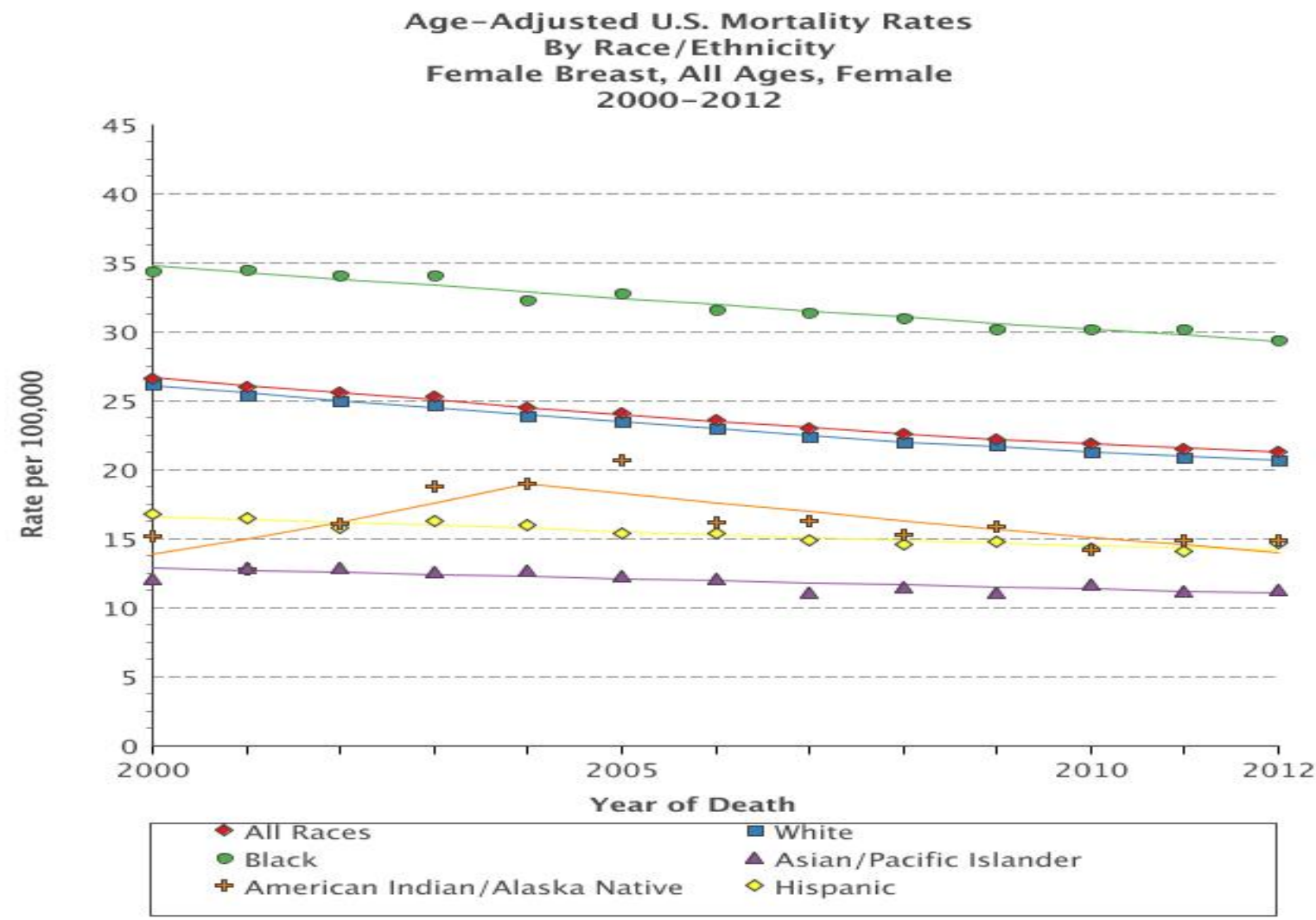

Cancer sites include invasive cases only unless otherwise noted.

Rates for American Indian/Alaska Native are based on the CHSDA (Contract Health Service Delivery Area) counties.

Hispanics and Non-Hispanics are not mutually exclusive from whites, blacks, Asian/Pacific Islanders, and American Indians/Alaska Natives.

Mortality source: US Mortality Files, National Center for Health Statistics, CDC.

Rates are per 100,000 and are age-adjusted to the 2000 US Std Population (19 age groups - Census P251130). Regression lines are calculated using the Joinpoint Regression Program Version 4.2.0, April 2015, National Cancer Institute. 
Genetic Factors: To some extent the familial risk of developing breast cancer is related to the mode of gene inheritance, known or unknown. A number of such breast cancer genes (oncogenes) have been identified including BRAC1, BRCA2, erb-B2, p53, c-myc, cyclin D-1, and CDK-1, the presence of which may convey increased risk of developing breast cancer. Mutations of BRCA 1 and 2 suppressor genes are the more commonly known of these which are frequently tested among women at risk in the population and have been shown to be inherited in an autosomal dominant fashion (King et al., 2003).

Environmental Factors: A number of putative environmental factors have been found to be related to breast cancer development. High among these is ethanol intake which has been shown consistently in controlled, as well as in pooled and meta-analytic studies (Longnecker, 1994; Smith-Warner et al., 1998; Key et al., 2006; Tjonneland et al., 2003). Alcohol consumption and breast cancer has been fairly well researched. Earlier studies have had methodological issues that made firm conclusions regarding the association difficult, but later studies, as well as, pooled and meta-analytic studies consistently showed a risk-association which is dose-dependent and independent of beverage type. In a more recent review of a large number of studies, alcohol consumption of up to 24 grams (2 drinks) per day increases the risk of developing breast cancer by $21 \%$ (McDonald J, Goyal A \& Terry MB, 2013). Risk assessment modeling shows a stratified risk for developing breast cancer which depends on the quantity of chronic alcohol ingestion in both animals and humans (Boyle \& Boffetta, 2009; Key et al., 2006). Other putative environmental risk factors for breast cancer include exposure in utero to the pesticide DDT (Cohn et al., 2015), which needs further studies for confirmation. 
Endocrinological Factors: Early menarche before age 12, late menopause after age 55, late or no pregnancy and limited breast feeding have been cited as risk factors for developing breast cancer. Delayed childbearing, low fertility and decreased physical activity may also increase the risk of breast cancer (ACS, 2004). Among Black women parity may have a dual effect on breast cancer risk (Palmer, et al., 2003).

Avoidance of combination hormonal replacement therapy appears to be a prudent way to reduce cancer risk at this time based on current data. Based on an analysis of current data the US Preventative Service Task Force has recommended that combination HRT (estrogen and progestins) be avoided among post-menopausal women for routine prevention of chronic disease (Moyer et al., 2012). Interestingly women who use SERMs may be at a lower risk of developing breast cancer but the evidence is preliminary and inconclusive such that definitive recommendations cannot be made at this time (Cummings et al., 2009).

While routine use of tamoxifen cannot be advocated as a primary prevention measure, there is good evidence that among high risk individuals from an ongoing US follow up study, this agent reduced the risk of breast cancer by $49 \%$ (Vogel, 2001). In another multicenter international study, the risk reduction seen in the group taking this drug was 32\% compared to placebo (Cruzik et al., 2007). Adverse effects with the drug may preclude routine use among women. The risk of endometrial cancer appears to be higher among women on long-term tamoxifen therapy (Curtis et al., 1996). However, in postmenopausal women who have had a hysterectomy and are high risk for breast cancer chemoprophylaxis with tamoxifen may be a consideration (Cuzick et al., 2014). Table 6 provides an interpretation of the various determinants of breast cancer. 
Table 6: Determinants of breast cancer development.

\begin{tabular}{|c|c|c|}
\hline General Risks & Specific Risk Factors & Interpretation \\
\hline Age & $\begin{array}{l}40-49 \text { years }-20 \% \\
50-59-30 \% \\
60-70-35 \%\end{array}$ & Increases with age in all subgroups \\
\hline Race & $\begin{array}{l}\text { Whites ( }>40 \text { years) } \\
\text { Blacks ( }<40 \text { years) }\end{array}$ & $\begin{array}{l}\text { After age } 40 \text { years whites at higher } \\
\text { risk }\end{array}$ \\
\hline Family History & $\begin{array}{l}\text { First degree } \\
\text { (Mother, Sister) }\end{array}$ & $\begin{array}{l}\text { Second degree relatives (aunts, } \\
\text { grandmothers, cousins, etc.) }\end{array}$ \\
\hline Genetic & BRCA I and II Genes & 5\% Cases overall \\
\hline Host Factors & Dense breast (Mammography) & $\begin{array}{l}\text { Histological correlates } \\
\text { a. Fibroadenoma with complex } \\
\text { features, } \\
\text { b. Hyperplasia without atypia } \\
\text { c. Sclerosing adenomas } \\
\text { d. Solitary papillomas } \\
\text { e. Atypical Hyperplasia, (lobular } \\
\text { and ductal) } \\
\text { f. Lobular carcinoma in situ } \\
\text { Truncal Obesity }\end{array}$ \\
\hline \multirow[t]{2}{*}{ Environmental } & Hormonal exposure & $\begin{array}{l}\text { Oral contraceptives and hormonal } \\
\text { replacement } \\
\text { Early menarche before age } 12 \\
\text { Late menopause after age } 55\end{array}$ \\
\hline & Carcinogens & $\begin{array}{l}\text { Alcohol, excessive radiation } \\
\text { exposure }\end{array}$ \\
\hline $\begin{array}{l}\text { Previous } \\
\text { Cancers }\end{array}$ & Breast cancer in one breast & $\begin{array}{l}\text { Gynecological cancer, ovary, } \\
\text { cervix, endometrial } \\
\text { Colon Cancer }\end{array}$ \\
\hline
\end{tabular}

Host factors: A number of host factors have been implicated in breast cancer risk association (Goodwin, 2008; McPherson, Steel \& Dixon, 2000). This is especially so for radiological and histological abnormalities that has been cited as identifiable risk factors for breast cancer (Amir, Freedman, Seruga \& Evans, 2010). These include dense breast tissue on mammography and histological features on pathologic examination of breast tissue including fibroadenoma with complex features, hyperplasia without atypia, 
sclerosing adenomas, solitary papillomas, atypical lobular and ductal hyperplasia and lobular carcinoma in situ (Guray, 2006). Obesity, especially truncal redistribution of fat, is putative causation factor for breast cancer (Morimoto et al., 2002) and has been suggested to be a significant risk factor for TNBC as well, in a comprehensive and detailed evaluation by Pierobon \& Frankenfeld, in a meta-analytical study (Pierobon \& Frankenfeld, 2013) as well as, other smaller but representative studies.

Previous Cancers: Previous occurrence of breast cancer in one breast is an extremely high risk factor for the development of breast cancer in the same or the other breast (Chen, Thompson, Semenciw, \& Mao, 1999). The development of colon and some gynecological cancers such as ovarian, cervical and endometrial cancers is a known risk for the development of breast cancer (McPherson, Steel, \& Dixon JM, 2000), particularly in hereditary conditions like Lynch syndrome (Lynch, Lynch, Lanspa, \& Snyder, 2009). For asymptomatic individuals in the population, these same determinants for cancer development can be stratified by degree of risk a priori in the general population.

This type of classification may then have implications for screening with specific measures such as mammography and MRI. But more importantly, this initial step can also have implications for assessment of prognosis before proceeding to the next step, establishing the diagnosis with measures such as ultrasonography and ultrasound guided biopsy. Perhaps the greatest benefit arising directly from and assessment of risk and risk stratification is the altering of modifiable risks by the institution of primary or secondary prevention measures which have a better likelihood of altering the course of the disease process. Table 7 is a display of breast cancer stratification into different levels of risk namely: moderate risk, slightly higher risk and highest risk. 
Table 7: Stratification of breast cancer risk-factors by degree of risk.

\begin{tabular}{|c|c|c|}
\hline Highest Risk & Moderate Risk & Slightly Lower Risk \\
\hline \multirow[t]{8}{*}{$\begin{array}{l}\text { Breast cancer } \\
\text { in one breast }\end{array}$} & $\begin{array}{r}\text { Age - } 50-59 \\
40-49 \\
60-70\end{array}$ & $\begin{array}{l}\text { Family history - second degree relatives } \\
\text { (aunts, grandmothers, cousins }\end{array}$ \\
\hline & $\begin{array}{l}\text { Family history } \\
\text { First degree }\end{array}$ & $\begin{array}{l}\text { Histological lesions - Fibroadenoma with } \\
\text { complex features, hyperplasia without } \\
\text { atypia, Sclerosing adenomas, solitary } \\
\text { papillomas. } \\
\text { Dense breast on mammogram }\end{array}$ \\
\hline & $\begin{array}{l}\text { Genetic trait } \\
\text { BRCA 1, } 2\end{array}$ & $\begin{array}{l}\text { Early menarche before age } 12 \\
\text { Late menopause after age } 55\end{array}$ \\
\hline & $\begin{array}{l}\text { Breast Lesions } \\
\text { Atypical hyperplasia } \\
\text { Lobular carcinoma in } \\
\text { situ }\end{array}$ & Overweight or obese especially truncal \\
\hline & & $\begin{array}{l}\text { Excessive radiation - following disease } \\
\text { treatment }\end{array}$ \\
\hline & & $\begin{array}{l}\text { Family history of colon cancer, or } \\
\text { gynecological cancer ( ovary, cervix, } \\
\text { endometrial) }\end{array}$ \\
\hline & & Race - whites, blacks under age 40 \\
\hline & & $\begin{array}{l}\text { Chemicals - alcohol, oral contraceptive } \\
\text { and hormonal replacement therapy }\end{array}$ \\
\hline
\end{tabular}

\section{iii. Breast Cancer Receptor Biology and Phenotypes}

The main aim of this study is to evaluate survival in breast cancer phenotypes. An understanding of the receptors that distinguish these phenotypes is therefore essential and the biological behavior of breast cancer receptors then becomes important in predicting the factors that determine the lethality, poor treatment response and survival of these cancers. Normal breast tissues contain receptors that are involved in signaling processes which mediate various aspects of cell function and directly influence breast cancer growth, proliferation, treatment and prognosis (Buxant, Engohan-Aloghe, \& Noel, 2010). 
Table 8: Features of breast cancer molecular subtypes.

\begin{tabular}{|c|c|c|c|}
\hline $\begin{array}{l}\text { Molecular/Genetic } \\
\text { Subtype }\end{array}$ & Frequency & $\begin{array}{l}\text { Usual Receptor } \\
\text { Phenotypes }\end{array}$ & Clinical Features \\
\hline Luminal A & $40 \%$ & ER+ PR+ HER2- & $\begin{array}{l}\text { Better prognosis, less recurrence, } \\
\text { responsive to endocrine treatment }\end{array}$ \\
\hline Luminal B & $20 \%$ & $\mathrm{ER}+\mathrm{PR}+\mathrm{HER} 2+$ & $\begin{array}{l}\text { Younger age than A, larger tumor } \\
\text { size, lymph node positive, Grade } \\
\text { II, IV. }\end{array}$ \\
\hline TNBC & $15 \%$ & ER- PR- HER2- & $\begin{array}{l}\text { Heterogeneity with basal-like (p53 } \\
\text { mutations), BRCA-1, younger, } \\
\text { Black, poorer prognosis }\end{array}$ \\
\hline HER2 enriched type & $15 \%$ & ER- PR- HER2+ & $\begin{array}{l}\text { Lymph node +, Grade III, IV, } \\
\text { Younger age, poor prognosis }\end{array}$ \\
\hline Basal-Like & $10 \%$ & Unclassifiable & Mixed features. \\
\hline Claudin-low & $12 \%$ & $\begin{array}{l}\text { High } \\
\text { heterogeneity, } \\
\text { ER+ }\end{array}$ & $\begin{array}{l}\text { Mixed features, moderate } \\
\text { prognosis }\end{array}$ \\
\hline
\end{tabular}

Adapted from: Esposito, Criscitiello, \& Curigliano, 2015).

TNBC is defined as breast cancer that relatively lacks all of estrogen, progesterone receptor-expression and HER2 over-expression (Gluz, Liedtke, Gottschalk, Pusztai, \& Harbeck, 2009). These protein molecules are receptors that are the phenotypic representation of genes that are expressed on breast cancer cells that interact with other 
protein molecules to carry out specific cell function when activated or inhibited (Rastelli \& Crispino, 2008). ER, PR and HER2 is their current annotation in the medical literature. Occurring with $40 \%$ frequency among all breast cancers and the histological cellular appearance of the inner lining of mammary ducts and well- or fairly well-differentiated tumor cells, they tend to express ER+, PR+ mutations and do not over express HER2 mutations, respond to hormonal manipulation and in general, carry a better prognosis (Rastelli \& Crispino, 2008). The Luminal B category tends to have all three receptors (Table 8). Of the few that that are HER2-, they tend to have high mitotic rates (high ki67). Luminal B also originate in ductal tissue and express ER+ and PR+ mutation but with cells that tend to express p53 genetic mutations as well (Ma et al, 2003). The larger tumor size and lymph node involvement at diagnosis tend to put these in a fair to poor prognosis than Luminal A (Zorka et al., 2014).

In addition, at diagnosis, histologic grades tend to be in the fair to poorly differentiated categories (Zorka et al., 2014). This study will focus on the category in this classification in which cancer cells do not express estrogen, progesterone and do not over express HER2 receptor mutations (ER-, PR-, HER2 -) (Yanagawa et al., 2012). These TNBC tend to overlap with the basal-like immonohistochemical category with which there is significant discordance (Gazinska et al., 2013). Hormonal, other cellular receptors and biomarkers are shown in Table 9.

Specific receptors for the steroid hormones, estrogen and progesterone mediate breast tissue cell growth and function through many different signaling pathways. In some breast cancers, estrogen and progesterone receptors (ER+ and PR+) are overexpressed on malignant cells. ER occur in $65-70 \%$ of breast cancers (Nadji et al., 
2005; Gown et al., 2008) and ER+, PR+ breast cancer cells tend to represent the vast majority of breast cancer cells. On the other hand, TNBC (ER-, PR- and HER2-) occur in about $10-25 \%$ of breast cancers from a consensus of multiple small studies and carry a worst prognosis than other breast cancer subsets (Rastelli \& Crispino, 2008).

Table 9: List of selective cellular receptors and markers in breast cancer cells.

RECEPTOR ACRONYM RECEPTOR ROLE

\begin{tabular}{|c|c|}
\hline ER+ & Estrogen receptor \\
\hline PR+ & Progesterone receptor \\
\hline HER2/NEU (ERBB2) & Human epidermal growth factor receptor 2 \\
\hline EGFR (HER1) & Epidermal growth factor receptor 1 \\
\hline CK5/6 & Cytokeratin 5/6 \\
\hline $\mathbf{P} 21$ & $\begin{array}{l}\text { Involve both tumor suppression and oncogenic } \\
\text { modulation* }\end{array}$ \\
\hline KI-67 & Proliferation marker of cell mitotic activity \\
\hline TOP2 ALPHA & Topoisomerase II alpha \\
\hline AR & Androgen receptor \\
\hline P53/63/73 & Tumor Suppressor genes \\
\hline CXCR7 & Chemokine-receptor 7 \\
\hline
\end{tabular}

*Gartel AL. Is p21 an oncogene? Molecular Cancer Therapeutics, 5, 1385, 2006.

The estrogen-estrogen receptor complex activates messenger proteins through a process involving protein activator (AP-1) and specificity protein (SP-1) leading to 
protein transcription and cell proliferation (Heldring et al., 2003), for both normal cellular processes of tissue growth, as well as, oncogenic-tumor suppressive processes (Ma, et al, 2003). Because breast cancer cell receptors are so intimately involved in cell proliferation, treatment and clinical prognosis some knowledge of cell receptor structure and function is necessary.

Structure of Cell Receptors: Cell receptors are structurally part of the cell membrane (Lodish, et al., 2000, Section 5.1). The cell membrane is a molecular mosaic principally consisting of a bilayer of phospholipid molecules interspersed with other molecules including cholesterol, protein and long-chained carbohydrate molecules (Lodish et al., 2000, Section 15.5). The phospholipid bilayer consists of structural macromolecules, the base of which have phosphate moieties dangling intracellularly, while at the other end a fatty acid chain extending extracellularly (Lodish et al., 2000, Section 5.1). Lipid soluble or hydrophobic ligands can readily cross these bipolar cell membranes. However, water soluble or hydrophilic ligands usually bind to specific receptors in order to be transported across the cell membrane and into the cytosol (Lodish et al., 2000, Section 15.1).

Cell receptors are proteins and each have: (1) a surface membrane or ligandbinding domain, (2) a hydrophobic transmembrane domain and (3) an internal intracellular domain that extends into the cytosol region. Transmembrane protein cell receptors can bind to other chemicals, as well as other proteins, forming a receptor-ligand complex (Lodish et al., 2000, and Section 20.1). Once the receptor-ligand complex is formed, the conformational structure of the cell membrane is altered leading to a cascade of biochemical changes and the activation or inhibition of signaling pathways (first and second messengers). Within the cells are nuclear membrane protein receptors that 
structurally possess an $\mathrm{N}$-terminal transactivation domain, a middle DNA binding region containing a zinc finger domain and a C-terminal ligand binding domain. It is this $\mathrm{C}$ terminal region that binds to its specific ligand which then binds to promoter elements in specific genes that are then activated. Nuclear protein receptors bind to ligands such as adrenal hormones including estrogen and progesterone (Zhou \& Zingerland, 2014).

Cell receptors can also be ion channel, G-protein or enzyme-linked receptors. For hormone receptors, such as estrogen, that act as growth, oncogenic or tumor suppressive triggers in the breast cancer cells, the process starts at the transmembrane molecular structure specific for the estrogen molecule. The bound estrogen-receptor complex causes a conformational change in the integral membrane proteins activating the G-proteins which releases guanine diphosphate (GDP) that is phosphorylated to form guanine triphosphate (GTP). The process of conformational change of the integral membrane is called signal transduction. Other ligand-receptor binding associated with a specific enzyme in its intracellular domain, such as tyrosine kinase causes phosphorylation of tyrosine residues in the intracellular domain which can then transmit the signal to the intracellular second messenger (Lemmon \& Schlessinger, 2011).

Enzyme-linked receptor activation also occurs with epidermal growth factors (EGF), such as HER2. The hormonal pathways often utilize either the phosphatidylinositol or G- coupled receptor pathways involving cyclic adenosine monophosphate (cAMP) and GDP/GTP phosphorylation pathways (second messenger pathway). The second messenger activates proteins and calcium ions from stores in the endoplasmic reticulum. The activated proteins travel in the cytosol to the nuclear membrane where they bind with receptors and pass into the nucleus activating 
transcription factors, enabling transcription of proteins. Intracellular binding to regulatory DNA sequences activate transcription genes directly or through transcription regulatory molecules (Lodish et al., 2000 Section 20.1). The enzyme RNA polymerase separates the double stranded DNA helix forming a nucleotide complement to the DNA segment called mRNA. The mRNA serves as a template for the synthesis of protein molecules from amino acids in the cytosol through a process called translation.

Ligands like EGF after binding with their specific receptor, induces dimerization and autophosphorylation of the epidermal growth factor receptor (EGRR) which in turn activates intracellular second messenger signaling pathways. Some of these pathways leads to cell division which are mediated by mitogen activated protein kinases (MAPK), aberrations of which leads to uncontrolled cell proliferation as seen in some cancers including breast cancer (Lodish, 2000, Section 20.1). Complicating this complex process are gene modulators, such as Toll-like receptors which act as an on-off switches that can amplify the signal leading to induction or suppression of genes and their responses that are referred to as toll-gate modulation of gene expression and have implications for treatment of cancers including breast cancer (Wang, 2008). Biologic Influences of Breast Cancer Subsets among Racial Groups: Are there differences in rates of mammary tumor growth, response to chemotherapy, and chemoprevention and are there biologic differences particularly hormonal influences such as sex hormones and adrenocorticosteroid hormones - between African Americans and white women? Based on current data, definitive answers to these questions are not yet available. 
However, recent research seem to suggest that in African Americans women breast cancer appears to be more aggressive and lethal than in White women. It is established that African American women are also more likely to present with breast cancer at a younger age than White women (Chlebowski et al., 2005). Analysis of data from the Women's Health Initiative study revealed that African American women had more high-grade and estrogen receptor negative tumors, at a rate five times higher than for White women. Both findings make these aggressive breast cancers more difficult to treat and are associated with poorer outcomes (Chlebowski et al., 2003; Li et al., 2002; Miller B, et al., 2002).

Adding to this are early genetic studies that address differential susceptibilities. Mutations in the TP53 gene were more common in African American women than in White women with breast cancer, based on a recent population-based study. Mutations in the TP53 tumor suppressor gene are associated with cancers that grow faster, are more likely to spread, and have a poorer prognosis (Jones et al., 2004). TNBC through HER2 activation is known to stimulate breast cancer cellular growth and is amplified and/or over expressed in about $20-25 \%$ of invasive breast cancers. These cancers tend to grow faster, spread more rapidly, recur more often, and have a poorer prognosis than other breast cancers (Weiss et al., 2006).

New data on cancer biology point to a critical role of gene expression in the development of cancer. Cancer can be described as the uncontrolled growth of abnormal cells. Usually a network of signals that promotes cell division through oncogenes, control cell growth by slowing or stopping cell division at the right time (tumor suppressor genes), or repairing DNA damage. DNA damage can affect gene amplifications, gene 
deletions, point mutations, loss of heterozygosity, chromosomal re-arrangements, and an abnormal number of chromosomes (NCBI, 2005; Dickson et al., 2000). Moreover, breast cancer development can be triggered by mutations of the signals in the network that controls cell division, and can be associated with genetic predisposition (e.g., mutations in the BRCA1 and BRCA2 genes), exposure to some environmental factor (e.g., radiation exposure of the chest), or both. While large-scale studies of variation in network signaling among races are lacking, a better understanding of cancer biology and how it differentially affects certain races point out the necessity for a better understanding of the role of human genetics in breast cancer biology. Interaction of Race, SES and Biology in Breast Cancer Survival: Once a diagnosis of invasive breast cancer is made survival becomes dependent on a number of factors. Some of these factors are similar to known risk factors for developing the disease. These include: disease stage at diagnosis, time since diagnosis, race and ethnicity and socioeconomic factors.

By definition the longer one lives after diagnosis the higher the survival rate for that breast cancer subset. Among women who survived 5 years after diagnosis, the 5 years survival rate is $87 \%$ ( $85 \%$ for black women). For women surviving 10 years following diagnosis, the 5 year survival is $77 \%$. There is clear evidence that earlier diagnosis leads to longer survival. If the disease is diagnosed when localized to the breast there is a $97 \%$ five-year survival. However, if the disease has spread to distant sites the five year survival is only $23 \%$ indicating that the stage at diagnosis predicts survival.

Race and ethnicity also play a major role in survival. However, race and ethnicity may be more complex as risks of survival than currently understood. They may be 
intertwined with income, treatment and health insurance availability, genetic and environmental factors. Still race and ethnicity is one independent factor that influences breast cancer survival. Black women 5 year survival is $74 \%$ compared to white women 85\% (Howlader et al., 2012)). African American women tend to be diagnosed at a more advanced stage of the disease than white women. Moreover, even when compared to women diagnosed at the same stage of the disease the outcomes of African American women are still poorer.

Lack of health insurance certainly plays a role in this lower breast cancer survival among black women. This may be a surrogate for income since among black women, five- year survival is lower among low income black women when compared to higher income black women. Moreover, there is a gradient of 5-year survival based on income such that lower income women irrespective of race also have a lower 5-year survival than higher income women. Disparities in treatment options offered women of different races, access to medical care and co-morbid conditions also appear to directly influence racespecific five year survival.

\section{iv. Breast Cancer Clinical Stages and Grades}

The main aim of this study is to evaluate the factors that predict survival in breast cancer and its phenotypes. The extent of spread of breast cancer cells to a large extent clearly is expected to determine survival. In fact, estimation of prognosis has been correlated with the extent of breast cancer disease based on clinical evaluation at the time of diagnosis (Tot et al, 2011). The extent of spread of breast cancer cells to a large extent determines 
survival. Estimation of prognosis has been correlated with the extent of breast cancer disease based on clinical evaluation at the time of diagnosis. The determination of the extent of breast cancer is called staging. The stage or extent of disease also aids treatment and guides prognostication. Treatment of breast cancer is complex. It depends on tumor size ( $<2 \mathrm{~cm}, 3-5 \mathrm{~cm},>5 \mathrm{~cm}$ ), hormonal receptor status (ER+, PR+, HER2, triple negative), patient age (premenopausal vs. postmenopausal), stage (disease extent), grade and gene type. Below (Table 10) is a grid of AJCC breast cancer stage classification (Breast. In: Edge SB, Byrd DR, Compton CC, et al, eds.: AJCC Cancer Staging Manual. 7th Ed. New York, NY: Springer, 2010, pp 347-376).

Table 10: AJCC - TNM breast cancer classification by stage.

\begin{tabular}{|c|c|c|c|c|}
\hline Stage & Explanation & Tumor Size & Nodes & Metastasis \\
\hline I & $\begin{array}{l}\text { Small and limited to breast or } \\
\text { sentinel lymph node N0 or N1mi } \\
\text { A. } \quad<2 \mathrm{~cm} \text {, no lymph nodes } \\
\text { B. } \quad<2 \mathrm{~cm} \text {, local lymph nodes } \\
\text { cancer cell cluster }<0.2 \\
\text { mm }\end{array}$ & $\begin{array}{l}\text { T1mi } \\
\text { Ta } \\
\text { Tb } \\
\text { Tc }\end{array}$ & $\begin{array}{l}\text { N0 } \\
\text { N1 }\end{array}$ & $\begin{array}{l}\text { M0 } \\
\text { (No clinical metastasis) }\end{array}$ \\
\hline II & $\begin{array}{l}\text { Larger tumors with spread to } \\
\text { regional lymph nodes } \\
\text { A. Less than } 2 \mathrm{~cm} \\
\text { B. More than } 2 \mathrm{~cm} \text { but }<5 \\
\text { cm, }<3 \text { local lymph } \\
\text { nodes }\end{array}$ & $\mathrm{T} 2$ & $\begin{array}{l}\text { N2 } \\
\text { N2a } \\
\text { N2b }\end{array}$ & M0 \\
\hline III & $\begin{array}{ll}\text { A. } & \text { Larger and operable, }< \\
& 9 \text { regional lymph nodes } \\
\text { B. } & \text { Larger and inoperable } \\
\text { C. } & \text { Spread to }>9 \text { regional } \\
& \text { lymph nodes }\end{array}$ & T3 & $\begin{array}{l}\text { N3 } \\
\text { N3b } \\
\text { N3c } \\
\text { N3d }\end{array}$ & M0 \\
\hline IV & $\begin{array}{l}\text { Metastasized to bones, liver, } \\
\text { lungs, etc. }\end{array}$ & $\begin{array}{l}\text { T4a } \\
\text { T4b } \\
\text { T4c } \\
\text { T4d }\end{array}$ & & $\begin{array}{l}\text { M1 } \\
\text { (Distant Metastasis } \\
\text { Clinically) }\end{array}$ \\
\hline
\end{tabular}

Even though this has been found simplistic as a guide to treatment (Veronesi et al., 2009) it is still useful for prognostication. 
Histological Grade: The Nottingham Grading System is considered the gold standard of histological breast cancer grading (Elson \& Ellis, 1991). In this system, tumor grade classification is founded on the histological characterization of cancer cells based on degree of homology and differentiation from normal breast terminal-duct lobular tissue (Table 11). Tumor grade has been correlated with prognosis and a number of breast cancer characteristics (Rakha et al., 2010) but breast cancer grading is principally used for prognostic assessment.

Table 11: Tumor grade and relative prognosis.

\begin{tabular}{|c|c|c|}
\hline Grade & Differentiation & Prognosis \\
\hline $\mathbf{1}$ & Well differentiated & Better \\
\hline $\mathbf{2}$ & Moderately differentiated & Fair \\
\hline $\mathbf{3}$ & Poorly differentiated & Poor \\
\hline $\mathbf{4}$ & Undifferentiated & Poorest \\
\hline
\end{tabular}

v. Consensus Standard Treatment of Breast Cancer

The main aim of this study is to evaluate the factors that predict survival in breast cancer and its phenotypes. One of the factors determining breast cancer survival is the treatment administered following diagnosis. Who is treated and with what is a major determinant of breast cancer survival. The standard of care for breast cancer treatment has and continues to change over the course of history. The current approach will be summarized below.

First some definitions:

1. Adjuvant therapy: This is used for prophylaxis against potential recurrence or spread and after surgery and includes (1) radiation therapy to regional lymph 
nodes and to chest wall (locoregional radiation therapy), (2) Systemic therapy with endocrine agents for ER+, PR+, chemotherapy, and monoclonal antibodies especially for HER2+ breast cancer which can be combined with chemotherapy.

2. Targeted neoadjuvant therapy: This is administered to shrink tumor size after needle biopsy but before other surgery of any kind (Metzger-Filho \& de Azambuja, 2011).

History of Breast Cancer Treatment: In 1882 William Halstead introduced into the United States what then became the accepted standard treatment for breast cancer for almost a century, the radical mastectomy (Rankin J., 2006). The degree of node dissection, including axillary node dissection, became more extensive over time. As early as 1962 in Europe (Kaae \& Johansen, 1962; Kaae \& Johansen, 1969), there was an indication of no difference in breast cancer outcome between the radical mastectomy and the combination of BCS and radiation by the McWhirter method.

In the US, Fisher first reported the effectiveness of limited mastectomy plus radiation therapy compared to the radical mastectomy for early stage breast cancer in studies beginning in 1971 (Fisher B, Montague E, Redmond C, Barton B, et al, 1977). Still it took some time for the BCS plus radiation therapy to become the mainstay of treatment for early stage breast cancer of all subtypes, which it still is today. In 1975 Fisher et al. (1975) and Bonadonna et al. (1975) reported the effectiveness of adjuvant chemotherapy after surgery to increase breast cancer survival (Fisher et al., 1975; Bonadonna, Brusamolino, Valagussa, \& Veronesi, 1975). Even before the discovery of hormone receptors, ovarian hormone suppression through oophorectomy and ovarian ablation was used to improve breast cancer survival from 1940 to 1960 (Love \& Philips, 
2004; Singh, 2012; Prowell \& Davidson, 2007). With the discovery of the estrogen receptor and its use to predict risk of breast cancer recurrence, the next major step in endocrine therapy occurred when the FDA approved the use of the selective estrogen receptor modulator (SERM) tamoxifen in 1977. In 1986 it was reported that tamoxifen could be effectively given prophylactically against breast cancer recurrence when administered for five years after surgery in postmenopausal women and increase survival (Delozier et al., 1986).

In the early part of this century, molecular profiling was used to classify breast cancers into genetic subtypes and predict the risk of early breast cancer recurrence (Sorlie et al., 2001). This has led to the use of endocrinological treatment as adjuvant therapy for Luminal A breast cancer subsets which has significantly improved breast cancer outcomes (Goldhirsch et al., 2011). Moreover, combination systemic therapy proved to be effective for Luminal B, HER2+ and TNBC subsets as adjuvant therapy in enhancing breast cancer survival (Goldhirsh et al., 2011).

Today surgery, radiation and multimodal systemic treatment are now accepted as the current standard of care for breast cancer based on a variety of factors (NCI, 2015). These factors include tumor size, stage of disease, patient's age and menopausal status, breast cancer cell receptor status, gene type (BRCA mutation), and tumor histologic grade. Stage is one of the single most important factors determining optimal breast cancer treatment. In 1979 the American Joint Committee on Cancer (AJCC) staging recommendations utilized the previously established TNM system in its first manual, a summary of which was shown in Table 11 (Breast. In: Edge SB, Byrd DR, Compton CC, et al, eds.: AJCC Cancer Staging Manual. 7th Ed. New York, NY: Springer, 2010, pp 347- 
76). The evolution of breast cancer treatment from surgery, radiation therapy, chemotherapy, endocrine therapy and to biological therapy over the years have brought us to the present and has become the mainstay of breast cancer treatment currently. Current Standard of Care Treatment: The NCI sponsored ESMO expert consensus treatment guidelines and the St Galen International Breast Cancer Conference (2011) Expert Panel on breast cancer treatment by subsets is summarized in Table 12 (Aebi, Davidson, Gruber \& Cardoso, 2008; Goldhirsh et al., 2011).

Table 12: Specific treatment of breast cancer by subtype.

\section{Breast Cancer Subset Classification Specific Treatment}

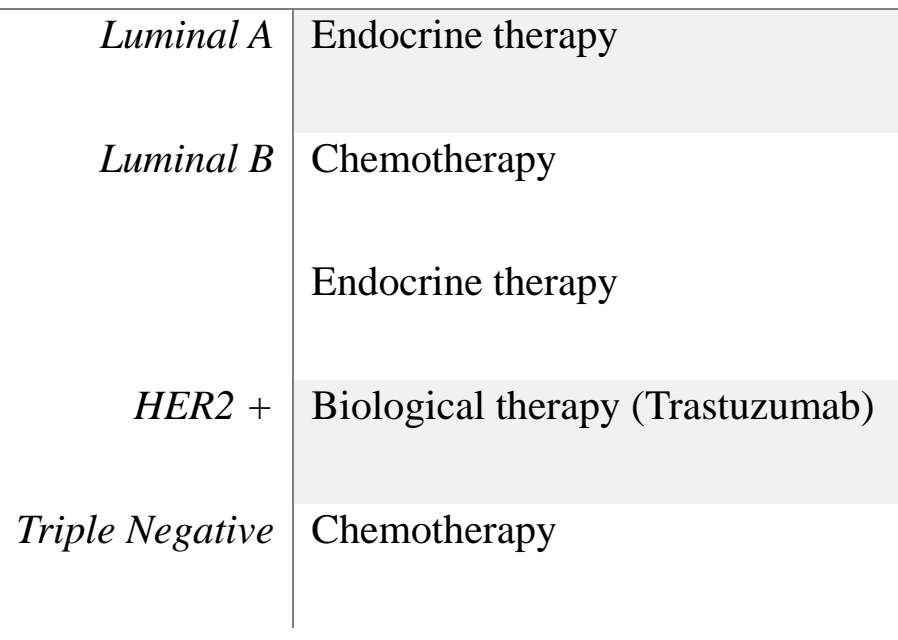

This summary in Table 12 below excludes the treatment of inflammatory breast cancer and recurrent breast cancer. It also excludes the standard neoadjuvant or adjuvant systemic therapy given in conjunction with initial surgical plus locoregional radiotherapy, which is considered standard initial treatment for early breast cancer. Invasive TNBC and 
NTNBC comprehensive treatment options based on menopausal and hormonal cell receptor status are summarized separately in Table 13.

Surgery: In general, for earlier stage invasive breast cancer (Stage I, II, IIIB and IIIC) and small tumor size $(<5 \mathrm{~cm})$, BCS has evolved as the accepted surgical approach for breast cancer primarily because it results in the best survival and quality of life (Fisher et al., 2006; Cao, Olson \& Tyldesley, 2013). The BCS procedure of choice for earlier stage disease is the "lumpectomy" in which the tumor is removed with or without regional lymph node dissection together with radiation therapy (Solin, 2010). A partial mastectomy is also considered BCS surgery for larger sized tumors (Rahman, 2011) and is often utilized based on cell receptor status and may even show improved survival over a total mastectomy (Parker, Lin \& Shen, 2014). The BCS has supplanted the radical mastectomy as the standard surgical procedure that was performed before the 1990s for most stages of breast cancer (Loukas et al., 2011). Since then, data has suggested that the survival rates from radical mastectomy were no different than that of combined BCS and radiation therapy for earlier stage disease (Anderson et al., 2009).

Besides this lack of outcome-difference between the BCS and more disfiguring aggressive surgeries, BCS also offers the benefit of a better quality of life, wellbeing, less fear of loss of femininity, sexual desirability, less depression and a sense of isolation (Moyer A et al., 1997; De Haes, Van Oostrom, \& Welvaart K, 1986; Nissen et al., 2001; Ganz, Rowland, Desmond, Meyerowitz, \& Wyatt., 1998). Post-surgery, women had more positive body image with BCS than otherwise (Steinberg, Juliano, \& Wise, 1985; Mock et al., 1993. The loss of chest wall muscle mass and muscle strength was also less with BCS than radical mastectomy (Wellisch \& Dimatteo, 1989; Crosbie et al., 2010). 
There are still some surgical indications for total mastectomy. The National Comprehensive Cancer Network guidelines for mastectomy indications include the following: prior radiation therapy to the breast or chest wall, when radiation therapy is contraindicated by pregnancy (except patients in the third trimester who can receive radiation postpartum), inflammatory breast cancer, diffuse suspicious or malignantappearing microcalcifications, widespread disease that is multicentric, located in more than one quadrant, and cannot be removed through a single incision with negative margins and a positive pathologic margin after repeat re-excision and suboptimal cosmetic outcome. Some relative indications for mastectomy as opposed to BCS, include active connective tissue disease involving skin, like scleroderma or systemic lupus erythematosus (SLE), breast tumors greater than $5 \mathrm{~cm}$ in diameter and focally positive surgical margins (NCCN, 2014).

Systemic Therapy: Radiation, endocrine, biological and chemical agents are systemic forms of therapy, which when administered after surgical treatment, are broadly considered adjuvant therapy (Chew et al., 2001). Adjuvant therapy as previously defined is secondary therapy following initial therapy with the goal of suppressing or preventing spread of neoplastic residues or micrometastasis (Hortobagyi et al., 2001).

Radiation is indicated as adjunctive therapy for BCS or mastectomy depending on lymph node involvement and/or the size of the primary breast lesion $(>5 \mathrm{~cm})$ and even for metastatic breast cancer (Clarke et al., 2005). Radiation can be administered either as an external beam or internally as brachytherapy. Externally administered radiation can be applied focally or extensively and is considered the standard of care for radiation therapy. Brachytherapy is usually applied locally by interstitial or intracavitary radioactive pellets. 
Intracavitary brachytherapy is now becoming the approach of choice for locally administered therapy, although its efficacy versus external beam therapy still has not been adequately established (Smith et al, 2013). Radiation can be administered at various stages before or after surgery, all of which carries specific risks and benefits.

Because TNBC is relatively unresponsive to hormonal manipulation, systemic therapy is the treatment of choice following surgery and locoregional radiotherapy for TNBC, and for advanced stage breast cancer with widespread metastasis. Systemic therapy is also indicated for inoperable breast cancer where the disease is too extensive at the time of diagnosis (Cardoso et al., 2012).

Chemotherapy drugs for breast cancer is always evolving and currently includes agents such as Adriamycin, cyclophosphamide, cisplatin, vinblastine, 5-fluorouracil (5FU), epirubicin, paclitaxin, doceaxel, vinorelbine, capecitabine, and gemcitabine.

Endocrine therapy is often employed when breast cancer cell receptors indicate cancer is amenable to this type of therapy, which is, with the presence of estrogen, progesterone and androgen receptors (Burnstein et al, 2014).

Table 13: Treatment of early breast cancer by receptor and menopausal status.

\begin{tabular}{|c|c|c|c|}
\hline $\begin{array}{l}\text { ER+/PR+ } \\
\text { (Premenopausal) }\end{array}$ & $\begin{array}{l}\text { ER+/PR+ } \\
\text { (Postmenopausal) }\end{array}$ & HER2+ & $\begin{array}{l}\text { Triple } \\
\text { Negative }\end{array}$ \\
\hline $\begin{array}{l}\text { Surgery } \\
\text { Locoradiation }\end{array}$ & $\begin{array}{l}\text { Surgery } \\
\text { Locoradiation }\end{array}$ & $\begin{array}{l}\text { Surgery } \\
\text { Locoradiation }\end{array}$ & $\begin{array}{l}\text { Surgery } \\
\text { Locoradiation }\end{array}$ \\
\hline $\begin{array}{l}\text { Endocrine Therapy } \\
\text { (SERM) }\end{array}$ & $\begin{array}{l}\text { Endocrine Therapy } \\
\text { (Aromatase Inhibitors) }\end{array}$ & Monoclonal Antibody & Chemotherapy \\
\hline $\begin{array}{l}\text { Examples: } \\
\text { Tamoxifen } \\
\text { Toremifene } \\
\text { Fulvestrant }\end{array}$ & $\begin{array}{l}\text { Examples: } \\
\text { Anastrozole } \\
\text { Letrozole } \\
\text { Exemestane }\end{array}$ & $\begin{array}{l}\text { Examples: } \\
\text { Trastuzumab } \\
\text { Bevacizumab }\end{array}$ & $\begin{array}{l}\text { (? Biological } \\
\text { therapy) }\end{array}$ \\
\hline
\end{tabular}


For premenopausal women with breast cancer and the appropriate receptor status, endocrine therapy includes the now outdated oophorectomy and the more recent SERM, such as tamoxiphen, toremifene and fulvestrant. For postmenopausal women and the appropriate receptor status aromatase inhibitors, such as anastrozole, letrozole and exemestrane, are often utilized for specific treatment. Table 13 summaries use of endocrine therapy based on menopausal and cell receptor status. Biological therapy is quickly becoming a useful and effective form of treatment for many forms of cancers including colorectal, renal cell and non-small cell lung cancers (Shih \& Lindley, 2006). As systemic therapy for breast cancer, its effectiveness is being studied currently. Agents such as trastuzmab have found widespread utility for HER2 positive breast cancer (Goldhirsh et al, 2011). Trastuzmab inhibits the HER2 up-regulation by direct HER2 degradation and antibody-dependent cellular cytotoxicity (Vu \& Claret, 2012). The effectiveness of bevacizumab, an inhibitor of angiogenesis through inhibition of vascular endothelial growth factor, for TNBC and other breast cancer phenotypes is less encouraging, except for as adjunctive treatment in combination with other agents for select forms of breast cancer and particularly metastatic breast cancer (Valachis et al., 2010; Smith et al., 2011).

Treatment of Triple-Negative Breast Cancer: The main aim of this study is to evaluate the factors that predict survival in breast cancer and its phenotypes and treatment is one of those factors. In general, the treatment outcome for TNBC compared to other subsets of breast cancer is poorer irrespective of treatment administered (Dent et al., 2007). The use of standard protocols for treating Luminal A and B, subsets of breast cancer has not met 
with the same success in treating TNBC (Andre \& Zielinski, 2012). BCS plus radiation, has shown a low recurrence rate for TNBC compared to NTNBC in some studies, with higher rates of recurrence in others (Freedman et al., 2009; Haffty et al., 2006; Schwartz et al., 2005). Unlike Luminal A and Luminal B classes of breast cancer where endocrine therapy has been found relatively effective, in the basal-like breast cancer analogues, including TNBC, endocrine therapy has had poor outcomes either as separate or as adjuvant form of treatment (Hudis \& Gianni, 2011). Systemic therapy especially chemotherapy shows the best promise in treating TNBC (Andre \& Zielinski, 2012). Moreover, because clinical trials involving systemic therapy are still ongoing, definitive consensus protocols have not been clearly established but are evolving. Despite the paucity of available supportive data on effective treatments for TNBC, a consensus is developing about a reasonable approach to treating TNBC in the face of these many limitations. Current recommended treatment for TNBC is systemic chemotherapy following BCS and locoradiation therapy (Schwartz et al., 2006).

This is also the recommendation of the National Cancer Institute expert consensus for TNBC treatment (National Cancer Institute National, 2015). BCS surgery in conjunction with locoradiation therapy has been found to be as effective in TNBC as nonTNBC with the same rates of recurrence (Freedman, Anderson, Li, \& Nicolaou, 2009). Despite this, recent data suggested that in actuality patients with TNBC were undergoing more extensive mastectomy at a higher rate than other breast cancer subtypes (Lizarraga, Schroeder, Weigel, \& Thomas, 2015).

Systemic therapy as currently used, is also evolving with the use of taxanes, anthracycline and platinum salts (Isakoff, 2010; Yadav, Sharma, Chanana, \& Jhamb, 
2014). For earlier stages, anthracycline-based regimens (like doxorubicin) followed by docetexel is currently being utilized by some (Yadav et al, 2014). Some experts prefer the combination of docetaxel and cyclophosphamide (Martin et al, 2010). For higher stages of TNBC with metastasis, platinum compounds (cisplatin or carboplatin) and PARP inhibitors (gemicitabine or olaparib) are being utilized (Niu, Sangal \& Quan, 2014). Angiogenesis inhibitors like bevacizumab have not been as effective as they are in colon and lung cancers (Cameron et al, 2013). Newer regimens are currently in trials including the biological EGFR inhibitors (Ueno \& Zhang, 2011), as well as PARP (O’Shaughnessy et al., 2014), alpha B-crystallin (Altundag et al., 2007) and cyclin dependent kinase inhibitors (Ueno \& Zhang, 2011).

For the purpose of this study, the accepted standard of care for early stage TNBC will be the NCI recommended standard of care. The SEER database only contains surgical procedures and radiation therapy as breast cancer treatment options. As a result with these limitations in mind and for the purpose of this study, appropriate treatment of TNBC will include BCS plus radiation therapy.

\section{vi. Epidemiology of Triple-Negative Breast Cancer}

The main aim of this study is to evaluate the factors that predict survival in breast cancer and its phenotypes, and it requires an understanding of the epidemiology of these phenotypes. As will be discussed later in the next section on "Knowledge Gaps," the epidemiology of TNBC is not well known (Gierach, Burke, Anderson, 2010; Boyle, 2012) and the burden of TNBC in the general population is still unclear (Dolle et al., 
2009). This is not surprising since the distinction between breast cancer molecular subtypes was only first reported in 2000 (Perou et al., 2000). Most of the currently known TNBC epidemiological estimates have been based on relatively small datasets rather than large population studies like the one here. Except for one study (Howlader et al., 2014) most of the current epidemiological estimates of incidence, prevalence and mortality of TNBC are based on findings from small samples, observational studies, limited geographical areas, hospital or state cancer registry datasets (Carey et al., 2006; Bauer et al., 2007; Lund et al., 2009; Moran, et al., 2006). This makes generalizability to the larger population difficult.

Incidence and Prevalence: Only one large population-based study has estimated agespecific incidence rates for TNBC but that study was based on one-year study-data only (Howlader et al., 2014). The authors reported age-specific incidence rates for TNBC for the year 2010 among 50,571 known breast cancer subtypes using SEER registries representing $28 \%$ of the US population. The peak incidence rate was 69.5 per 100,000 in non-Hispanic Blacks between ages 65 and 69 years compared to 36.8 per 100,000 in nonHispanic whites, 23.6 per 100,000 in Non-Hispanic Asians/Pacific islanders and 32.6 per 100,000 among Hispanics.

In studies greater than one year study duration, but smaller population datasets, the proportion of breast cancer patients with TNBC represented between about $10-20 \%$ of invasive breast cancers (Carey et al., 2006; Dawson, Provenzano, \& Caldas, 2009; Morris et al., 2007). While trends in overall breast cancer incidence and prevalence are well-known and reported (ACS, 2012) that is not the case with TNBC (Boyle, 2012). One population-based study (Howlader et al, 2014) provided reasonably good estimates 
of TNBC in various population subsets. In that study, non-Hispanic black women had the highest incidence of TNBC across all age groups with the widest disparity occurring between ages $64-69$ years compared to other racial groups.

Age Distribution: A number of studies have reported that younger age at diagnosis is a putative risk factor for TNBC. In a descriptive study utilizing data from the California Cancer Registry of 375, 761 invasive breast cancer patients, Amirikia et al. (2011) found that women, age less than 44 years had higher incidence rates of TNBC than all other breast cancers (Amirikia et al., 2011). In a cohort study, Bauer et al. (2007) also using data from the California Cancer Registry compared 6370 TNBC women with 44,704 women with other cancer subsets found an association between TNBC and being younger than 40 years old [OR $1.53(95 \%$ CI $1.37-1.70)$ ].

In a smaller rural West Virginia Hospital-based registry descriptive study, among 620 breast cancer patients 117 had TNBC (Vona-Davis et al., 2008). They found patients with TNBC were younger (44.5\%) than those with other receptor subtypes (26.7\%) p < 0.0004. In a prospective cohort study from Toronto (Dent et al., 2007), of 180 TNBC cases among 1601 invasive breast cancers, the mean age at diagnosis was significantly younger for the triple-negative group compared with other breast cancers (53.0 versus 57.7 years, respectively; $P<0.0001)$.

Another, the Carolina Breast Cancer Study (Carey et al., 2006) has reported age distribution estimates confirming the young age distribution of basal-type breast cancer compared other molecular subsets. One large population-based study yielded useful age distribution estimates (Howlader et al., 2014.). Results of that study showed that TNBC tends to occur in younger ages at diagnosis compared to other molecular subtypes (Table 
14). In that study, as in the present study, hormonal receptor status (HR+) consisted of combined $\mathrm{ER}+/ \mathrm{PR}+$ status. The same study, suggests that the incidence of TNBC is not only higher in younger premenopausal African American women but remains higher in all age and racial/ethnic groups, including those in postmenopausal white women. This is not the case with overall breast cancer incidence versus age-comparisons, where there is a crossover of incidence and where breast cancer incidence becomes higher in white women compared to African American women after age 50 years (NAACCR, 2011, Howlader et al., 2011).

Table 14: Invasive TNBC age-distribution among case patients.

\begin{tabular}{|c|c|c|c|c|}
\hline $\begin{array}{c}\text { Age Group } \\
\text { (Years) }\end{array}$ & $\begin{array}{c}\text { TNBC } \\
\text { (Cases) }\end{array}$ & $\begin{array}{c}\text { TNBC } \\
\text { (\% Cases) }\end{array}$ & $\begin{array}{c}\text { HR+/HER2+ } \\
\text { (Cases) }\end{array}$ & $\begin{array}{c}\text { HR+/HER2+ } \\
\text { (\% Cases) }\end{array}$ \\
\hline $\mathbf{5 0}$ & 1616 & 15.2 & 1528 & 14.4 \\
\hline $\mathbf{5 0}-\mathbf{6 4}$ & 2540 & 13.2 & 2066 & 10.7 \\
\hline $\mathbf{6 5}-\mathbf{7 4}$ & 1151 & 10.4 & 939 & 8.5 \\
\hline $\mathbf{7 7 5}$ & 866 & 9.3 & 707 & 7.2 \\
\hline
\end{tabular}

Data for $2010(\mathrm{~N}=6193)$. Taken from: Howlader et al., 2014.

Mortality: Few studies on disparities in TNBC mortality rates have also been reported previously. A few small studies have reported that proportionally, the mortality of TNBC is increased for this subset of breast cancer compared to all other breast cancer subtypes (Carey et al.; Dent et al; and Solie et al., 2003) but mortality rates from large populations have not been reported for TNBC. 
One of the largest studies reported so far, with $\mathrm{N}=9908$ TNBC patients, found that elderly patients $\geq 70$ years old with TNBC showed an increased early mortality within the first two years of diagnosis compared to younger individuals $<70$ years old which could be attributed in part to a lower rate of loco-regional radiotherapy in the elderly compared to younger age-groups (Zhu, Perez, Hong, Li \& Xu, 2015).

Trends: While trends in overall breast cancer incidence, prevalence and mortality are well known (ACS, 2012) that is not the case with TNBC and other breast cancer subsets (Boyle, 2012). Data on secular trends and changes in epidemiological indices over time still has to be better delineated for TNBC and other subsets.

Survival: It has been reported in some smaller studies that survival in TNBC is worse than in other subsets. In part, this may be due to the finding that TNBC tends to be first diagnosed at a late stage of the disease (Morris et al., 2014). Even when it is diagnosed earlier, TNBC responds poorly to conventional modes of therapy, is insensitive to endocrine therapy and currently available monoclonal antibodies (Oakman C, Viale G and Di Leo A, 2010). It is a more aggressive cancer with a higher Ki67 index of cellular proliferation and higher mitotic rates than other breast cancer subsets (Carey et al., 2006). It also has a higher rate of recurrence (Dent et al., 2007) and readily metastasizes to distant sites (Liedtke et al., 2008) and visceral organs including the brain than other breast cancer subsets (Hicks et al., 2006; Dent et al., 2007).

In one study the five-year relative survival of TNBC compared to other breast cancers was 14\% higher (Bauer et al., 2007). In another, the five year survival was $81 \%$ compared to 94\% for ER/PR+HER2- breast cancers (Kaplan \& Malmgren, 2008). 
Overall survival is worst with TNBC compared to other subsets (hazard ratio 1.8 (95\% CI 1.06 - 3.2) (Onitilo, Engel, Greenlee \& Mulesh, 2009).

Disease-free survival was also worst compared to other subtypes (hazard ratio 1.5 [(95\% CI 0.8 - 3.0)] (Kaplan \& Malmgren, 2008). TNBC has double the recurrence rate compared to other breast cancer subsets (Billar et al., 2010). In one study, (Dent et al., 2007), the risk of recurrence of TNBC is higher the first 3-5 years after diagnosis.

BRCA1 genotype is strongly associated with TNBC with about $20 \%$ of women with TNBC having the BRAC1 genotype, while the converse association found that $48 \%$ of BRAC1 mutations carriers have TNBC, compared to $12 \%$ in non-carriers of the mutation (Lee et al., 2011).

Figure 5: Breast cancer survival from the Carolina Breast Cancer Study.

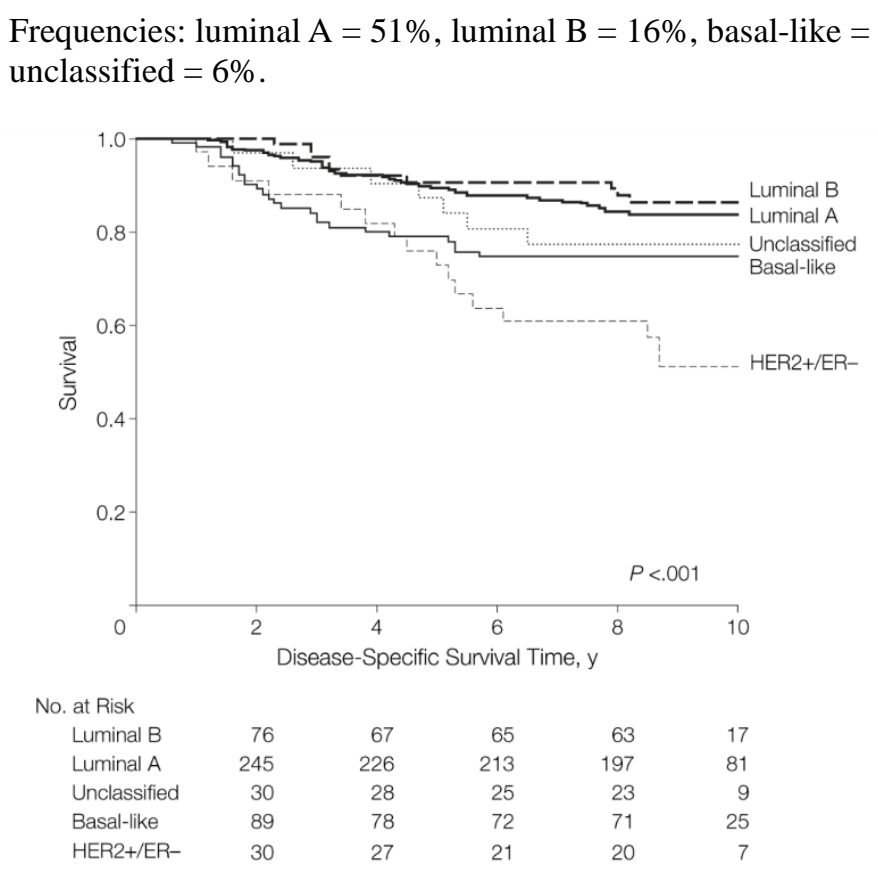

Taken from: Carolina Breast Cancer study (Carey et al., 2006). 
Survival estimates for selective breast cancer subtypes has been reported in the Carolina Breast Cancer study (Carey et al., 2006). The data from that study is shown in Figure 5 which illustrates the findings that the disparity in survival for basal-like breast cancer is worse than that for other subsets. Compared with other women with breast cancer the likelihood of death within five years of diagnosis was increased for basal-like breast cancer [hazard ratio 3.2, (95\% CI: 2.3- 4.5); p < 0.001].

Preliminary one-year survival rates for the year 2010 were reported in one study in abstract form showing no difference in survival rates among ethnicities. The authors emphasized that follow-up data greater than one year was needed to reach more meaningful conclusions (Rushton, Zhang \& Song, 2014).

Race and Ethnicity: The prevalence of TNBC was estimated as 26\% in African American women compared to $16 \%$ in white women (Carey et al., 2006).

Table 15: Racial/ethnic distribution of invasive TNBC year 2010.

\begin{tabular}{|l|l|l|}
\hline Race/Ethnicity Group & Cases & Cases (\%) \\
\hline Non-Hispanic Whites & 3850 & 10.7 \\
\hline Non-Hispanic Blacks & 1183 & 22.5 \\
\hline Non-Hispanic Asian/ Pacific Islander & 376 & 9.7 \\
\hline Hispanic & 727 & 14.7 \\
\hline Total & 6193 & 100 \\
\hline Taken from: Howlader et al., 2014. & & \\
\hline
\end{tabular}


Among premenopausal women in the same study the frequencies were $39 \%$ among African American women and 16\% in the rest of the sample of non-African American women ( $<$ 0.001). Population-based prevalence data per 100,000 has not been reported. Recent data suggests that Hispanic women also may be at higher risk of TNBC than that reported in white women (Howlader et al., 2014; Lara-Medina et al., 2011). The disparities in risk, incidence, mortality, and survival between Hispanic and non-Hispanics have not been well-studied. In contrast, the disparity data in TNBC-disease risk between racial groups is only slightly clearer, and again not definitively so. See table 15 which shows the race/ethnic distribution of TNBC in year 2010 case-based analysis. In some studies, African American women have up to a 3 times greater risk of developing TNBC than does other population subsets (Lund et al., 2009). In the study by Carey et al., (2006), it was estimated that TNBC occurs in 39\% of African American women compared to 16\% among white women (p 0.001) (Carey et al., 2006). The study by Morris, et al., (2007) yielded a similar disparity with 20.8\% among African American women compared to $10.4 \%$ among white women (p <0.0001). Moran et al., (2008), showed a $21 \%$ versus $8 \%$ disparity $(\mathrm{p}<0.001)$. A smaller study showed a $28 \%$ versus 12\% disparity ( $<<0.001)$ (Sturtz et al., 2014).

In one population- based study, it was estimated that $47 \%$ of breast cancer in African American women were TNBC while only 22\% was the case in white women, p<0.001 (Lund, et al., 2009). Even in an international study involving women of African ancestry, the racial disparity persisted (Stark et al., 2010). Premenopausal women tend to be at greatest risk of developing TNBC and up to 39\% of all African American premenopausal women have TNBC (Carey et al., 2006). 
Genetic and Histologic Disparity: TNBC patients tend to have breast cancer with higher histologic grades, Ki 67 and higher mitotic indices (Carey et al., 2006). Breast cancer in women with BRCA-1 mutation is more likely to be TNBC (Sorlie et al., 2003). It has been reported that up to $75 \%$ of breast cancers that develop in BRCA1 mutations carriers are triple-negative (Bayraktar et al., 2011; Atchley et al., 2008; Musolino et al., 2007). Atchley et al. (2008) found an incidence of 51\% triple-negative among BRCA1 mutation carriers. The converse is also significant in that other studies suggest that in a population of TNBC patients, the proportion of BRCA1 mutation in certain patient population is 10 - 30\% (Evans et al., 2011; Gonzalez-Angulo et al., 2011). Only studies of small sizes have demonstrated this high prevalence of BRCA1 mutation among TNBC patients. Risk Factors: Only a few risk factors for TNBC have been clearly delineated in the literature. They include younger age at diagnosis (Amirikia et al., 2011), Black race (Bauer et al., 2007; Carey et al., 2006; Kurian et al., 2010), Hispanic ethnicity (Bauer et al., 2007), high BMI (Stead et al., 2009; Kwan et al., 2009; Vona-Davis, et al., 2008), delayed age at menarche (Phipps et al., 2011), higher parity (Kwan et al., 2009; Shinde et al., 2010; Phipps et al., 2011), reduced breastfeeding (Kwan et al., 2009; Shinde et al., 2010), oral contraceptive use (Dole et al., 2009), BRCA1 mutation, and premenopausal status (Carey et al., 2006; Sorlie et al., 2003).

In contrast with other breast cancer subtypes, high parity and young age at first birth, lack of breast feeding and early age of menarche are risk factors for TNBC (Millikan et al., 2008; Phipps et al., 2011; Yang et al., 2007) especially among African American women (Ambrosone et al, 2015). TNBC patients tend to live in counties with 
higher poverty levels, as shown in the only large one-year study to demonstrate this geographic disparity (Howlader et al., 2014).

Weight and Obesity: In the study by Kwan et al. (2009), the investigators also found that more women with the TNBC subset tended to be overweight than those with the luminal A subset $[\mathrm{OR}=1.82(95 \%$ CI $1.03-2.81)]$ and to be obese if premenopausal with OR 1.97 (95\% CI 1.03 - 3.77). The smaller Appalachian-based study by Vona-Davis et al. (2008), found that $49.6 \%$ of women with TNBC were obese compared to $35.8 \%$ of those with non-TNBC women being $<50$ years $(\mathrm{p}<0.0004)$. An Atlanta-based study consisting of the Atlanta arm of a multicenter population-based case control study of breast cancer risk factors with patients from Metropolitan Atlanta, Georgia comprising Cobb, Fulton or DeKalb counties, (Trivers et al., 2009) found that women with TNBC were more likely to be obese than normal/underweight ( $\mathrm{OR}=1.89$, 95\% CI 1.22-2.92).

Genetics and BRCA1 Mutation: This has been discussed previously. It was reported that up to $75 \%$ of breast cancers that develop in BRCA1 mutations carriers are triple-negative (Bayraktar et al., 2011; Atchley et al., 2008; Musolino et al., 2007). Atchley et al. (2008) found an incidence of 51\% triple-negative among BRCA1 mutation carriers. The converse is also significant in that studies also suggest that in a population of TNBC patients the prevalence of BRCA1 mutation is 10 - 30\% (Evans, et al., 2011; GonzalezAngulo, et al., 2011).

Endocrinological Factors: The study by Li et al. (2013) was based on data collected from cancer registries in the Seattle, Puget Sound area, yielded 1056 study patients and 941 randomly selected controls. 180 TNBC patients were extracted and included for analysis. An inverse relationship was observed between breastfeeding, age at first menarche, and 
age at first live birth when TNBC was compared with controls (Li et al., 2012). Early age at menarche, shorter duration of breast-feeding, younger age at full-term pregnancy were risk factors for basal-like TNBC in the Carolina Breast Cancer Study (Carey et al., 2006). In the Women Health Initiative study (Phipps et al., 2011) among parous women having three or more births versus one birth was associated with TNBC (Hazard Ratio $=1.46$, 95\% CI 0.82-2.63. High parity and early age at first birth were also risk factors in TNBC compared to other breast cancer subsets where nulliparity and delayed age at first birth were risk factors (Yang et al., 2005). The study by Kwan et al. (2009) found that the TNBC subset tended to not have breastfed if the parity was $\geq 3$ (OR=1.68, 95\% CI 1.00 2.81). In the study by Shinde et al. (2010) women with TNBC had a shorter duration of breastfeeding per child (OR=0.93, 95\% CI 0.90-0.97) and a higher parity (OR=1.12, 95\% CI 1.06-1.20) than non-TNBC women (Shinde et al., 2010). Using data from the cancer registries in the Seattle, Puget Sound area, a case control study of 187 TNBC patients by Dolle et al. (2009), oral contraceptive use for equal or greater than one year duration in patients less than 45 years was associated with a 2.5 -fold increased risk of TNBC compared to controls 95\% CI 1.4 - 4.3 (Dolle et al., 2009). Socioeconomic Factors and Poverty: Dunn et al. (2010) reviewed the influence of socioeconomic status among different subsets of breast cancers; however, it is clear that the effect of socioeconomic factors on TNBC status has not been well studied. Bauer et al. (2007) exploring data from the California Cancer Registries found that women with TNBC were at higher risk of having a lower socioeconomic status as measured by poverty level. Andaya et al. (2012) reported on the disparities in socioeconomic status among various breast cancer receptor subsets besides TNBC. They found that high 
poverty areas tended to have a greater prevalence of one component of TNBC, HRnegative tumors compared to more affluent areas. This was also observed among young, non-Hispanic black women and non-Hispanic Asian/Pacific Islander women with regional and distant stage (Andya et al., 2012).

In a comprehensive review of mortality data Vona-Davis et al. (2009) found that social deprivation was associated with poor prognosis in another component of TNBC, ER- breast cancer (Vona-Davis \& Rose, 2009). While not about TNBC itself, the results are illustrative of the influence of social factors on prognosis in breast cancer subsets. Environmental Risk Factors: Among 184,418 postmenopausal women aged 50-71 years in the National Institutes of Health-AARP Diet and Health Study (1995-2003), Lew et al. (2009) performed assessments of multivariate relative risks of alcohol exposure among women with various breast cancer receptors, including estrogen receptorpositive/progesterone receptor-positive, estrogen receptor-positive/progesterone receptornegative, and estrogen receptor-negative/progesterone receptor-negative tumors and found that the relative risks for breast cancer from alcohol exposure were 1.46 (95\% CI: $1.12,1.91)$ for $>35$ g versus $0 \mathrm{~g} /$ day, 1.13 (95\% CI: $0.73,1.77)$ for $>20 \mathrm{~g}$ versus $0 \mathrm{~g}$ /day, and 1.21 (95\% CI: $0.79,1.84)$ for $>20$ g versus 0 g/day, respectively.

On the other hand Kabat et al. (2011) evaluated the association between smoking and alcohol intake among TNBC and other subsets of breast cancer (Kabat et al., 2011). They found that cigarette smoking was not associated with TNBC, whereas drinkers had a reduced risk compared to non-drinkers among TNBC. In contrast, both cigarette smoking and alcohol exposures showed slightly positive associations with ER+ breast cancer: for women with $\geq 40$ pack-years of smoking, the HR was 1.24, 95\% CI 1.06-1.44; 
for women consuming $\geq 7$ servings of alcohol per week the HR was 1.26, 95\% CI 1.061.50. Intakes of spirits such as wine and hard liquor were also significantly positively associated with ER+ breast cancer. Li et al. (2010) also found that the risk per drink per day of alcohol was statistically significantly lower for ER-PR- breast cancer than it was for $\mathrm{ER}+\mathrm{PR}+$ breast cancer (multivariable adjusted difference in $\mathrm{HRs}=0.74,95 \% \mathrm{CI}=$ 0.58 to $0.93, P=.010)$ (Li et al, 2010 .

Histological Grades and Stage of Triple-Negative Breast Cancer: TNBC patients tend to have breast cancer with higher histologic grades and higher mitotic indices.

Premenopausal women tend to be at greatest risk of developing TNBC and 39\% of premenopausal African American women have TNBC (Carey et al., 2006). Breast cancers in women with BRCA-1 mutation are more likely to be TNBC (Sorlie et al., 2003). In addition, TNBC tend to be diagnosed at a more advanced stage of disease compared to controls (OR 2.2, 95\% CI 1.0 - 4.9) (Boyle P, 2012).

vii. Triple Negative Breast Cancer Knowledge Gaps and Unmet Needs

Given that the main aim of this study is to evaluate the factors that predict survival in the breast cancer phenotype TNBC, the review of the literature indicates that much remains unknown about TNBC. While the molecular and clinical correlates of TNBC are still being delineated, the epidemiology of TNBC is clearly not well known (Gierach, Burke, \& Anderson, 2010; Boyle, 2012) and the burden of TNBC in the general population is still very unclear (Dolle et al., 2009). Specific, accurate and up to date information from 
large population studies on the incidence, prevalence and mortality of TNBC in the US is still lacking (Boyle, 2012).

Knowledge of the age, race, and ethnic group distribution, as well as, other demographic and socioeconomic profiles of the TNBC population is still in its infancy and is yet to be clearly delineated (Sturtz et al., 2014); this even though race, BMI and other risk factors have been identified in smaller limited studies (Stead et al., 2009). Epidemiological correlates such as high BMI have been identified as possible independent risk factors for TNBC, especially for African American women (Bauer et al., 2007; Carey et al., 2006) but methodological issues involving available studies makes firm conclusions on the association difficult.

Oral contraceptive use may also confer an increased risk of developing TNBC as opposed to NTNBC (Dolle et al., 2009). Clearly, more work is still to be done regarding the identification of major epidemiological determinants of survival in TNBC patients (Trivers et al., 2009). Furthermore, apart from the absence of endocrinological biomarkers, such as ER, PR and HER2/neu, there are no specific biomarkers that distinguish TNBC from NTNBC. Moreover, no other biomarkers have been found to correlate with TNBC as yet, although molecular signaling defects have been proposed as a differentiating factor (Suba Z, 2014). Early work on the identification of biomarkers for the broader basal-like breast cancer subset is in progress (Choo \& Nielsen, 2010). Once identified, these biomarkers may prove to be useful in the evaluation and treatment of patients with TNBC and its correlates (Hudis \& Gianni, 2011).

Until identification and characterization of potential biomarkers are available haracterization of risk factors will remain critical in determining who in the general 
population is at greater risk for developing breast cancer and its subsets, such as TNBC. From smaller population studies, the finding that higher rates of TNBC tends to occur among selective population groups such as African Americans, Hispanics/Latinos, those with high BMI, specific hormonal exposures and lower socioeconomic groups, are indicative of the uniqueness of this subset of breast cancer patients that warrant further intense and multidisciplinary investigation.

The uniqueness of this breast cancer subset extends to studying the effectiveness of screening for breast cancer with mammography in TNBC perhaps from earlier age groups than is recommended for other breast cancer subsets (Amirikia et al., 2011). Effective screening and early diagnosis of such patients using mammography are still problematic. Preliminary results show that there is some indication that mammography has low rates of TNBC detection compared to NTNBC (Bauer et al., 2007; Carey et al., 2006). This deserves further study especially if it turns out that the high mortality rates seen in African American women with breast cancer is related to the lethal TNBC subset. A validated risk model for TBNC has not been developed, as is the case with the Gail model for breast cancer and will be useful for individual clinical applications including screening. Even effective treatment of TNBC is still in its infancy with many unmet needs yet to be fulfilled (Pal, Childs \& Pegram, 2011; Hudis \& Gianni, 2015). Disparities in treatment administered may also help to explain disparities in outcome among TNBC compared to NTNBC patients but has not been adequately studied. Studies linking socioeconomic factors such as poverty, education level, income level and health insurance status to TNBC status, are also lacking in the literature. 
Helping to confirm specific risk factors for TNBC that may enhance survival in these patients will also close a significant knowledge gap that exists and fulfill many unmet needs. It is the purpose of this study to help explore and establish the role of identifiable determinants of TNBC survival from a large population-database, especially among African American women. Knowledge of the impact of TNBC and comparisons with NTNBC still remains elusive today, further study of this breast cancer subset may help to close the existing knowledge gaps and fulfill a significant unmet need.

\section{CHAPTER III}

\section{METHODS}

\section{i. Study Design}

This is a retrospective longitudinal cohort study design, a form of longitudinal epidemiologic observational designs, which utilizes the methodologically validated Surveillance Epidemiology End Result (SEER) database (Merrill \& Capocaccia, 2000).

\section{ii. Population Representative Sample}

The population representative sample for this study was obtained from the SEER programs of the National Cancer Institute (SEER - Overview of the SEER Program, 2015). The data collected includes cancer incidence, prevalence and survival from nine population-based cancer registries across the USA since 1973 and are updated annually. Data on TNBC became available from 2010 in SEER. The SEER population-base currently represents $28 \%$ of the US population and the data collected includes patient demographics, primary tumor origin, morphology, stage at diagnosis, course of initial 
treatment and follow-up data. The database has a population coverage that includes $26 \%$ African Americans, 38\% Hispanics, 44\% American and Alaska Natives, 50\% Asians and 67\% of Hawaiian/Pacific Islanders. Comprehensive mortality data are obtained from the National Center for Health Statistics and its population data from the US Census Bureau. The original 9 registries included Connecticut, Detroit, Hawaii, Iowa, and Utah (1993) then Atlanta and Seattle-Puget Sound (1974) were added. These registries expanded in 2000 to include Greater California, including Los Angeles, Louisiana, New Jersey, New Mexico, Utah, Hawaii, Iowa and Kentucky. Specific registries comprise Georgia Center for Cancer Statistics that includes Atlanta (1975), rural Georgia (1992) and Greater Georgia (2000). California’s Greater Bay Area Cancer Registry includes San FranciscoOakland and San Jose-Monterey (1992). Data of indigenous peoples are obtained from the Arizona Indians, Cherokee Nation and Alaska Native Tumor Registry (1992).

Even though rural Georgia and some major rural state registries are included, the population represented in the SEER database tends to be more urban than rural and as a result has a higher proportion of foreign-born individuals than the general U.S. population. Because of its comprehensiveness and stringent validation however, SEER data are taken to represent cancer incidence for the entire United States (SEER Overview of the SEER Program SEER, 2015).

Table 16: Breast cancer subtypes selected from SEER database.

\begin{tabular}{|l|c|c|}
\hline BREAST SUBTYPE (Data from 2010 - 2012) & Frequency & Percent \\
\hline Her2+/HR+ & 17668 & 1.3 \\
\hline Her2+/HR- & 7889 & 0.6 \\
\hline Her2-/HR+ & 123437 & 8.9 \\
\hline
\end{tabular}




\begin{tabular}{|l|c|c|}
\hline Triple Negative & 19762 & 1.4 \\
\hline Unknown & 58860 & 4.2 \\
\hline Breast Cancer from other years (not 2010 -2012) & 1158364 & 83.6 \\
\hline Total & 1385980 & 100.0 \\
\hline
\end{tabular}

iii. $\quad$ Procedure

From the SEER database, 1,385,980 cases of breast cancer from 1973 - 2012 years were identified, from which 227,616 breast cancer cases diagnosed between the years 2010 to 2012 were extracted (See Table 16). The years 2010, 2011 and 2012 are the years for which TNBC data are currently available from the SEER database. From these, 168,756 cases had identifiable breast cancer molecular subtypes, while 58,860 cases of unknown breast cancer molecular subtype were excluded from the analysis. The breast cancer subtypes were then stratified into five phenotypes: Her2+/HR+, Her2+/HR-, Her2-/HR+ and TNBC, where HR was defined as the ER/PR phenotype. Cases with the phenotypes Her2+/HR+, Her2+/HR-, Her2-/HR+ were defined as NTNBC and compared with TNBC in the analysis.

Table 17: Frequency of known breast cancer subtypes.

\begin{tabular}{|l|l|l|}
\hline Breast Cancer Subtype & Frequency & Percent \\
\hline NTBC & 148994 & 88.29 \\
\hline TNBC & 19762 & 11.71 \\
\hline & 168756 & 100.00 \\
\hline
\end{tabular}

Selection Criteria: Female sex, year of diagnosis 2010 - 2012 inclusive, age of diagnosis 20 - 90 years inclusive, tumor receptors status - (ER, PR, HER2) and data on hormonal 
receptors; race (black, white or other); Hispanic/Latino ethnicity, marital status, tumor grade at diagnosis, treatment, insurance status and recorded survival time $>1$ month using SEER cause of death code.

Exclusion criteria: Males, missing values, death from other causes other than having the breast cancer cause of death code (treated as censoring in the analysis) were excluded. Predictor Variables: Age, race (Black or White), ethnicity (Latino/Hispanic, nonHispanic), marital status, health insurance status, histological tumor grade, and treatment were the regression independent variables. It was found that there were nineteen SEER geographic variables which made inclusion into the Cox models complex, hence geographic localities were excluded in the model.

Outcome Variables: Breast cancer survival was the dependent or outcome variable.

\section{iv. Statistical Analysis}

The study aim is to evaluate the association between breast cancer phenotypes and specific predictor variables in a large sample of female breast cancer patients. Means \pm $\mathrm{SD}$, frequencies and associated percentages of continuous demographic variables among TNBC and NTNBC cases were subjected to z-testing. Categorical variables were assessed using Chi-Square tests.

Using SPSS software version 21 (SPSS Inc., Chicago, Illinois) Cox proportional hazard models evaluated factors predicting survival time (outcome variable) among TNBC and NTNBC. The Cox hazard model is a semiparametric, in contrast to the alternative Kaplan-Meier non-parametric, survival method, that can evaluate multiple variables simultaneously. Predictor variables in the model were age categories, age at first 
diagnosis, race, ethnicity, marital status, grade, surgery, radiation, and insurance status and were also subjected to logistic regression analysis to examine predictors of receiving or not receiving standard treatment.

The model for the effect on TNBC of the predictor variables and repeating the process for the effect on NTNBC alone of the other predictive variables were run separately. The results of the stratified analysis were presented in a combined table for ease of reading. For the analytical models, categories with fewer cases were combined, in particular - the combination of American Indian/Alaska Native, and Asian/Pacific Islander as “Other” Races.

The Cox survival results are summarized as the hazard ratio (HR) with associated 95\% confidence interval (CI) with two sided tests of significance $(\mathrm{p} \leqslant 0.05)$. 


\section{CHAPTER IV}

\section{RESULTS}

The main aim of this study was to close the epidemiological gaps and evaluate the factors that predict survival in the breast cancer phenotype TNBC. In this study, the proportion of TNBC among breast cancer subsets is $11.71 \%$. For African Americans the proportion is $21.6 \%$ compared to $10.8 \%$ in whites. Some of the other patient characteristics and demographic information determined in this study are as follows:

i. Demographics and Patient Characteristics Age: Table 18 shows the age distribution of cases in the data set. TNBC cases were younger (mean age $58.67 \pm 13.57$ years) than NTNBC cases (mean age $61.51 \pm 13.57$ years). Among TNBC cases $8.4 \%$ are less than 40 years old while $4.5 \%$ of NTNBC cases are less than 40 years old a disparity of $4 \%$ point. Similarly $53.6 \%$ of TNBC cases are 59 years or less compared to $44.7 \%$ of NTNBC cases a disparity of $9 \%$ point.

The peak proportion of TNBC (20.01\%) occurs in the $<40$ age group while in NTNBC the peak proportion (90.45\%) occurs in the $70-79$ age group again demonstrating that TNBC is a disease of younger women than is the case for NTNBC. The difference in mean age at diagnosis between NTNBC and TNBC cases was 2.843 years, (95\% CI: 2.623, 3.063), p < 0.0001.

Table 19 shows other demographic variables among the study population including: Race/Ethnicity: A greater proportion of TNBC cases are African American (21.55\%)) than white women (10.84\%), a disparity difference in frequency of $10.71 \%(\mathrm{p}<0.001)$. However, at $\mathrm{p}=0.05$ level of significance, for frequency of TNBC among Hispanic 
(13.13\%) and non-Hispanic (11.76\%) ethnicity, the difference was not statistically significant $\mathrm{p}=0.07$.

Table 18: Frequencies of age categories for TNBC and NTNBC.

\begin{tabular}{|l|c|c|c|c|}
\hline Age Categories & NTNBC & TNBC & Total & P-value \\
\hline$<\mathbf{4 0}$ years & $\begin{array}{c}5976(79.99 \%) \\
(4.5)\end{array}$ & $\begin{array}{c}1495(20.01 \%) \\
(8.4)\end{array}$ & 7471 & $<0.001$ \\
\hline $\mathbf{4 0 - 4 9}$ years & $\begin{array}{c}21172(86.19 \%) \\
(16.1)\end{array}$ & $\begin{array}{c}3391(13.81 \%) \\
(19.1)\end{array}$ & 24563 & $<0.001$ \\
\hline $\mathbf{5 0 - 5 9}$ years & $\begin{array}{c}31701(87.22 \%) \\
(24.1)\end{array}$ & $\begin{array}{c}4645(12.78 \%) \\
(26.1)\end{array}$ & 36346 & $<0.001$ \\
\hline $\mathbf{6 0 - 6 9}$ years & $\begin{array}{c}35247(89.34 \%) \\
(26.8)\end{array}$ & $\begin{array}{c}4205(10.66 \%) \\
(23.7)\end{array}$ & 39452 & $<0.001$ \\
\hline $\mathbf{7 0 - 7 9}$ years & $\begin{array}{c}23344(90.45 \%) \\
(17.8)\end{array}$ & $\begin{array}{c}2466(9.55 \%) \\
(13.9)\end{array}$ & 25810 & $<0.001$ \\
\hline $\mathbf{2 8 0}$ years & $\begin{array}{c}14068(90.01 \%) \\
(10.7)\end{array}$ & $\begin{array}{c}1561(9.99 \%) \\
(8.8)\end{array}$ & 15629 & $<0.001$ \\
\hline Total & $\begin{array}{c}131508 \\
(100.0)\end{array}$ & $\begin{array}{c}17763 \\
(100.0)\end{array}$ & 149271 & \\
\hline Mean Age (S.D) & $\begin{array}{c}61.51(13.57) \\
\text { Values in red and parenthesis are relative percentages within columns }\end{array}$ & & \\
\hline \\
Values in black and parentheses are relative percentages within rows
\end{tabular}

Other Races: The proportion of "other" women with TNBC was 9.75\% while for white women it was 10.84 which was statistically significant difference at $\mathrm{p}=0.05$ level.

Similarly, compared to African American women (21.55\%), TNBC in the “other” racial group, defined as the combination of American Indian/Alaska Native, and Asian/Pacific Islander, was smaller, a difference that was statistically significant. The findings show that $19.8 \%$ of TNBC cases compared to $9.8 \%$ of NTNBC are of African American cases, a disparity difference of $10.0 \%$. However, among Hispanics there is no difference between NTNBC (10.4\%) and TNBC (11.7\%) cases. 
Marital Status: The proportion of TNBC among married women (11.55\%) was not different statistically from that of unmarried women (12.37\%).

There was no disparity in frequencies based on marital status (Table 19).

Table 19: Frequencies of other demographic variables.

\begin{tabular}{|c|c|c|c|c|}
\hline & NTNBC & TNBC & Total N & P-value \\
\hline $\mathbf{N}$ & 131508 & 17763 & 149271 & \\
\hline $\begin{array}{l}\text { Mean Age at } \\
\text { Diagnosis (S.D) }\end{array}$ & 61.51 (13.57) & 58.67 (14.11) & 149271 & $<0.001$ \\
\hline \multicolumn{5}{|l|}{ Race } \\
\hline White & $\begin{array}{c}106155(89.16 \%) \\
(81.3)\end{array}$ & $\begin{array}{c}12910(10.84 \%) \\
(73.1)\end{array}$ & 119065 & $<0.001$ \\
\hline Black & $\begin{array}{c}12727(78.44 \%) \\
(9.8)\end{array}$ & $\begin{array}{c}3497(21.55 \%) \\
(19.8)\end{array}$ & 16224 & $<0.001$ \\
\hline Other & $\begin{array}{c}11617(90.25 \%) \\
(8.9)\end{array}$ & $\begin{array}{c}1255 \text { (9.75\%) } \\
(7.1)\end{array}$ & 12872 & $<0.001$ \\
\hline \multicolumn{5}{|l|}{ Ethnicity } \\
\hline Non-Hispanic & $\begin{array}{c}117800(88.24 \%) \\
(89.6)\end{array}$ & $\begin{array}{c}15692(11.76 \%) \\
(88.3)\end{array}$ & 133492 & $<0.001$ \\
\hline Hispanic & $\begin{array}{c}13714(86.87 \%) \\
(10.4)\end{array}$ & $\begin{array}{c}2072(13.13 \%) \\
(11.7)\end{array}$ & 15786 & $<0.070$ \\
\hline \multicolumn{5}{|l|}{ Marital Status } \\
\hline Unmarried & $\begin{array}{c}52692(87.63 \%) \\
(54.2)\end{array}$ & $\begin{array}{c}7437(12.37 \%) \\
(52.4)\end{array}$ & 60129 & $<0.001$ \\
\hline Married & $\begin{array}{c}71330(88.45 \%) \\
(45.8)\end{array}$ & $\begin{array}{c}9317(11.55) \\
(47.6)\end{array}$ & 80647 & 0.001 \\
\hline
\end{tabular}

Other = American Indian/Alaska Native, Asian/Pacific Islander Values in red and parenthesis are relative percentages within columns Values in black and parentheses are relative percentages within rows

Tumor Grade: For tumor histological grade at the time of diagnosis, the peak prevalence of TNBC was for Grade IV (31.91\%) with Grade III (28.28\%) a close second. For NTNBC the peak prevalence occurred at Grade I (98.83\%) and Grade II (95.21) a close 
second. This indicates that a greater proportion of women with TNBC have higher histological tumor grades (IV and III) at the time of diagnosis than women with NTNBC (grades I and II) and frequency of tumor histological grade disparity (Table 20).

Table 20: Frequencies of clinical variables: grades, treatment, insurance status.

\begin{tabular}{|c|c|c|c|}
\hline Clinical & NTNBC & TNBC & P-value \\
\hline \multicolumn{4}{|l|}{ Tumor Grades } \\
\hline Grade I & $\begin{array}{c}31719 \text { (98.83\%) } \\
\text { (25.3) }\end{array}$ & $\begin{array}{c}376(1.17 \%) \\
(2.2)\end{array}$ & $<0.001$ \\
\hline Grade II & $\begin{array}{c}59215(95.21 \%) \\
(47.3)\end{array}$ & $\begin{array}{c}2981(4.79 \%) \\
(17.7)\end{array}$ & $<0.001$ \\
\hline Grade III & $\begin{array}{c}33807 \text { (71.72\%) } \\
(27.0)\end{array}$ & $\begin{array}{c}13330(28.28 \%) \\
(79.0)\end{array}$ & $<0.001$ \\
\hline Grade IV & $\begin{array}{c}414(68.09 \%) \\
(0.3)\end{array}$ & $\begin{array}{c}194(31.91 \%) \\
(1.1)\end{array}$ & $<0.001$ \\
\hline \multicolumn{4}{|l|}{ Surgical Status } \\
\hline Performed & $\begin{array}{c}121095(88.25 \%) \\
(92.8)\end{array}$ & $\begin{array}{c}16129(11.75 \%) \\
(91.8)\end{array}$ & $<0.001$ \\
\hline Not performed & $\begin{array}{c}9462(86.81 \%) \\
(7.2)\end{array}$ & $\begin{array}{c}1438(13.19 \%) \\
(8.2)\end{array}$ & $<0.001$ \\
\hline \multicolumn{4}{|l|}{ Radiation } \\
\hline Performed & $\begin{array}{c}63767(88.87 \%) \\
(50.5)\end{array}$ & $\begin{array}{c}7986(11.13 \%) \\
(47.4)\end{array}$ & $<0.001$ \\
\hline Not Performed & $\begin{array}{c}62414(87.59 \%) \\
(49.5)\end{array}$ & $\begin{array}{c}8846(12.41 \%) \\
(52.6)\end{array}$ & $<0.001$ \\
\hline \multicolumn{4}{|l|}{ Insurance Status } \\
\hline Uninsured & $\begin{array}{c}2294(83.42 \%) \\
(1.8)\end{array}$ & $\begin{array}{c}456(16.58 \%) \\
(2.6)\end{array}$ & $<0.001$ \\
\hline Insured & $\begin{array}{c}125406(88.08 \%) \\
(98.2)\end{array}$ & $\begin{array}{c}16970(11.92 \%) \\
(97.4)\end{array}$ & $<0.001$ \\
\hline
\end{tabular}

Values in red and parenthesis are relative percentages within columns Values in black and parentheses are relative percentages within rows.

Insurance Status: For insurance status a statistically significant but smaller percentage of women with TNBC were insured (11.92\%) than uninsured (16.56\%) (Table 20). 
Tables 18, 19 and 20 all show comparative frequencies for TNBC and NTNBC status together with certain specific variables with p-values for test of significant differences of proportions within and between TNBC and NTNBC substes.

\section{ii. Survival Analysis Results}

The mean survival time for TNBC is statistically less than that for NTNBC (Table 21). The overall mean survival time ( \pm S.D.) for TNBC is $15.60( \pm 10.29)$ months compared to 16.01 ( \pm 10.18$)$ with a mean disparity difference of 0.410 months (95\% CI: 0.251 , $0.570, \mathrm{p}<0.0001)$

Cox Regression Analysis: The results of the overall model in the Cox regression analysis are shown in Table 22. The model yields an equation for the hazard as a function of predicted variables. This multivariate Cox proportional hazards model for various factors found that in TNBC patients, young age at diagnosis, African American race, unmarried status, high tumor grade, lack of treatment (surgery and radiation), as well as, uninsured status all had significantly higher hazard rates of death and poorer outcome than NTNBC patients. Among race/ethnicity groupings, white race, Hispanic origin and “Other” races defined as American Indian/Alaska Native, Asian/Pacific Islander, compared to African American women had comparatively lower hazard rates of death and higher survival. A Cox model that compares separately TNBC with NTNBC as a function of the predictive variables will be reported in Table 25 . That model was generated by analyzing survival in TNBC alone (without NTNBC) with respect to other predictive variables. Another model was generated from the same sample population by analyzing NTNBC without TNBC with respect to other predictive variables and reported in the same Table 25. 
Molecular Subtype: With NTNBC as the reference, the Cox regression model demonstrated that overall breast cancer survival is significantly less for the TNBC subset of patients. In that analysis, estimated hazard or risk of death for a TNBC woman increases 2.285 times that of a NTNBC patient and is a statistically significant difference in survival (hazard ratio 2.285, 95\% CI: 2.144, 2.434).

Age: Regarding age at diagnosis, the estimated risk of death increases by 1.033 times and is a statistically significant difference, hazard ratio $=1.033,(95 \%$ CI 1.033, 1.041). Compared to a woman $>80$ years old, a woman $<40$ years old has a 1.211 times higher risk of death, hazard ratio $=1.211,(95 \%$ CI: $0.759,1.688)$, which achieved statistical significance.

Race: With white women as reference, the estimated risk of death for an African American increases 1.2 times that of a white woman. This increase although small had a 95\% CI $(1.117,1.289)$ that did not include 1 and achieved statistical significance.

Marital Status: With a married woman as reference, an unmarried woman with TNBC the estimated risk of death decreases 0.697 times that of a married woman which was statistical significant. Unmarried status seemingly conferring a protective status for risk of death in women compared to married women.

Histological Grade: For a woman who had higher histological grade tumor (grade IV), her estimated risk of death was 2.81 times higher than that of a woman who had a lower grade tumor (Grade I), a difference that was statistically significant (hazard ratio 2.812, 95\% CI: 2.159, 3.661).

Health Insurance: For an uninsured woman, the estimated hazard or risk of death 
increased 1.717 times that of a woman with health insurance which is a statistically significant difference in survival (hazard ratio $=1.717,95 \%$ CI: 1.481, 1.992).

Treatment Status: The results for surgery indicates that for a woman who did not have surgery for whatever reason, had an estimated 8.633 times higher risk of death than a woman who had surgery. The beta coefficient for this relationship is a positive value indicating that the hazard is increased or survival is decreased.

Table 21: Survival Time for NTBC and TNBC.

\begin{tabular}{|l|r|r|r|r|r|}
\hline & \multicolumn{5}{|c|}{ Survival time (months) } \\
\hline
\end{tabular}

This decrease in survival is statistically significant, $p \leq 0.001$ (hazard ratio $=8.633,95 \%$ CI: 8.152, 9.143). Similarly, but to a lesser extent, for radiation treatment, a woman with breast cancer who did not have radiation therapy had an estimated 2.285 higher hazard or risk of death than a woman who had radiation therapy. This finding of lower survival among women with breast cancer not receiving/ receiving radiation was a statistically significant difference in survival, $\mathrm{p} \leq 0.001$ (hazard ratio $=2.285,95 \%$ CI: 1.535, 1.732). 
The results of this complete model with all independent variables and the survival outcome variable are shown in Table 22. The tabulation includes values of the $\beta$ coefficient, hazard ratios with associated 95\% confidence intervals and p-values.

Table 22: Cox regression survival analysis of variables.

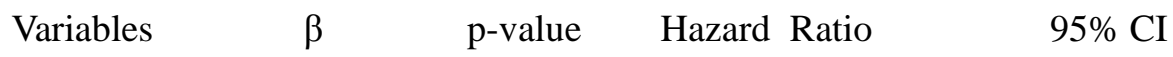

\begin{tabular}{|c|c|c|c|c|}
\hline \multicolumn{5}{|l|}{ Histological } \\
\hline $\begin{array}{l}\text { Grade } \\
\text { Grade I }\end{array}$ & & & & \\
\hline Grade I & Reference. & & & \\
\hline Grade II & 0.326 & $<0.0001$ & 1.385 & $1.271,1.508$ \\
\hline Grade III & 0.887 & $<0.0001$ & 2.428 & $2.228,2.646$ \\
\hline Grade IV & 1.034 & $<0.0001$ & 2.812 & $2.159,3.661$ \\
\hline Age (Years) & & & & \\
\hline$\geq 80$ & Reference & & & \\
\hline$<40$ & 0.124 & 0.543 & 1.132 & $0.759,1.688$ \\
\hline $40-49$ & -0.170 & 0.287 & 0.844 & $0.617,1.153$ \\
\hline $50-59$ & -0.251 & 0.041 & 0.778 & $0.612,0.990$ \\
\hline $60-69$ & -0.262 & 0.003 & 0.769 & $0.647,0.915$ \\
\hline $70-79$ & -0.165 & 0.004 & 0.848 & $0.759,0.948$ \\
\hline Treatment & Reference & & & \\
\hline No Surgery & 2.156 & $<0.0001$ & 8.633 & $8.152,9.143$ \\
\hline No Radiation & 0.489 & $<0.0001$ & 1.630 & $1.535,1.732$ \\
\hline Subtypes & & & & \\
\hline NTNBC & Reference & & & \\
\hline TNBC & 0.826 & $<0.0001$ & 2.285 & $2.144,2.434$ \\
\hline $\begin{array}{l}\text { Age at } \\
\text { Diagnosis }\end{array}$ & 0.033 & $<0.0001$ & 1.033 & $1.026,1.041$ \\
\hline Ethnicity & & & & \\
\hline Non-Hispanic & Reference & & & \\
\hline Hispanic & -0.064 & 0.169 & 0.938 & $0.855,1.028$ \\
\hline Race & & & & \\
\hline White & Reference & & & \\
\hline Black & 0.182 & $<0.0001$ & 1.200 & $1.117,1.289$ \\
\hline Other & -0.300 & $<0.0001$ & 0.741 & $0.661,0.830$ \\
\hline $\begin{array}{l}\text { Insurance Statt } \\
\text { Insurance }\end{array}$ & Reference & & & \\
\hline
\end{tabular}


$\begin{array}{llll}\text { No Insurance } & 0.541<0.0001 & 1.717 & 1.481,1.992\end{array}$

Marital Status

Married

Unmarried

\section{Reference}

$-0.362<0.0001 \quad 0.697$

$0.658,0.737$

Figure 6: Survival curve function by breast cancer subtypes (TNBC and NTNBC).

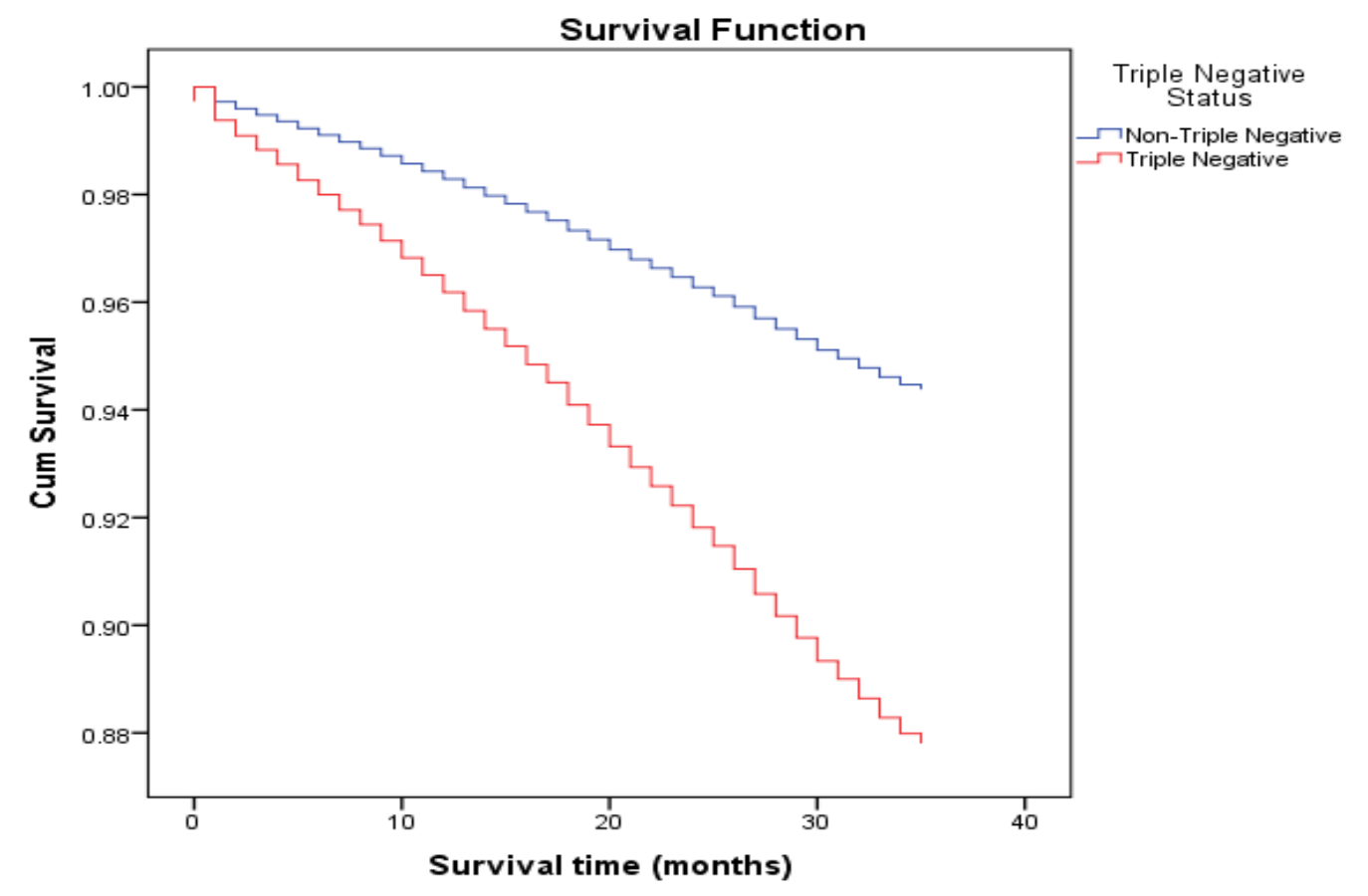

Legend: NTNBC (blue), TNBC (red)

The Cox regression results in Table 22 show that there are significant disparities in survival for various outcome variables, with statistically lower survival for TNBC than NTNBC status, higher histological tumor grades (Grades III and IV), lower age at diagnosis, chronological age for the age groups $\geq 50$ years up to $>79$ years (compared to the reference age $>80$ years), married women, African American race, uninsured status, and no treatment administered for both surgical and radiation treatment. The survival curve (Figure 6) illustrates the change in cumulative survival on the y-axis versus time in months in the x-axis. This survival function curve is generated from a 
comparison of the survival function for both TNBC (red) and NTNBC (blue) over time, and illustrates the survival differences of both subsets diverging over time up to the limit of the 36 month duration of the study.

Table 23: Logistic regression analysis for no surgery vs. surgery and other variables.

\begin{tabular}{|c|c|c|c|c|}
\hline Variables & $\boldsymbol{\beta}$ & p-Value & Odds Ratio & $95 \% \mathrm{CI}$ \\
\hline \multicolumn{5}{|l|}{ Age Categories } \\
\hline$<40$ years & Reference & & & \\
\hline 40-49 years & -0.921 & $<0.0001$ & .398 & $0.352,0.450$ \\
\hline 50-59 years & -1.223 & $<0.0001$ & .294 & $0.251,0.345$ \\
\hline 60-69 years & -1.734 & $<0.0001$ & 0.177 & $0.143,0.218$ \\
\hline 70-79 years & -2.050 & $<0.0001$ & 0.129 & $0.098,0.169$ \\
\hline$\geq 80$ years & -1.660 & $<0.0001$ & 0.190 & $0.136,0.266$ \\
\hline \multicolumn{5}{|l|}{ Receptor Status } \\
\hline NTNBC & Reference & & & \\
\hline TNBC & 0.102 & 0.001 & 1.107 & $1.042,1.177$ \\
\hline \multicolumn{5}{|l|}{ Hispanic Origin } \\
\hline Non- Hispanic & Reference & & & \\
\hline Hispanic & 0.174 & $<0.0001$ & 1.190 & $1.112,1.273$ \\
\hline \multicolumn{5}{|l|}{ Race } \\
\hline White & Reference & & & \\
\hline Black & 0.590 & $<0.0001$ & 1.804 & $1.702,1.912$ \\
\hline Other & 0.019 & 0.637 & 1.019 & $0.942,1.103$ \\
\hline Age at Diagnosis & 0.051 & $<0.0001$ & 1.053 & 1.046, 1.059 \\
\hline \multicolumn{5}{|l|}{ Insurance Status } \\
\hline Insured & Reference & & & \\
\hline Uninsured & 1.268 & $<0.0001$ & 3.552 & $3.206,3.937$ \\
\hline Constant & 4.508 & $<0.0001$ & .011 & \\
\hline
\end{tabular}

A statistically significant difference in survival time for TNBC and NTNBC patients was reported previously. With NTNBC as the reference, the Cox regression model also 
demonstrated that overall breast cancer survival is significantly less for the TNBC subset of patients. The estimated hazard or risk of death for a TNBC woman increases 2.285 times that of a NTNBC patient (hazard ratio 2.285, 95\% CI: 2.144, 2.434).

Table 24: Logistic regression analysis for radiation vs no radiation and other variables.

\begin{tabular}{|c|c|c|c|c|}
\hline Variables & $\boldsymbol{\beta}$ & p-value & Odds Ratio & $95 \%$ CI \\
\hline \multicolumn{5}{|l|}{ Age category } \\
\hline$<40$ years & Reference & & & \\
\hline 40-49 years & -0.329 & $<0.0001$ & 0.720 & $0.674,0.769$ \\
\hline 50-59 years & -0.710 & $<0.0001$ & 0.492 & $0.450,0.537$ \\
\hline $60-69$ years & -0.987 & $<0.0001$ & 0.373 & $0.331,0.419$ \\
\hline 70-79 years & -0.840 & $<0.0001$ & 0.432 & $0.372,0.501$ \\
\hline$\geq 80$ years & -0.218 & $<0.023$ & 0.805 & $0.667,0.970$ \\
\hline \multicolumn{5}{|l|}{ Status } \\
\hline NTNBC & Reference & & & \\
\hline TNBC & 0.140 & $<0.0001$ & 1.151 & $1.113,1.190$ \\
\hline \multicolumn{5}{|l|}{ Hispanic origin } \\
\hline Non- Hispanic & Reference & & & \\
\hline Hispanic & 0.229 & $<0.0001$ & 1.258 & $1.214,1.303$ \\
\hline \multicolumn{5}{|l|}{ Race } \\
\hline \multicolumn{5}{|l|}{ White } \\
\hline Black & 0.122 & $<0.0001$ & 1.130 & $1.091,1.170$ \\
\hline Other & 0.164 & $<0.0001$ & 1.179 & $1.134,1.225$ \\
\hline Age at diagnosis & 0.020 & $<0.0001$ & 1.020 & $1.017,1.024$ \\
\hline \multicolumn{5}{|l|}{ Insurance status } \\
\hline Insured & & & & \\
\hline Uninsured & 0.276 & $<0.0001$ & 1.318 & $1.217,1.429$ \\
\hline Constant & -0.682 & $<0.0001$ & 0.505 & \\
\hline
\end{tabular}

The logistic regression analysis modeling "no surgery" results in Table 23 and "no radiation" in Table 24 showed that TNBC, African American, uninsured, are less likely to receive surgery or radiation treatment. For TNBC it was 10\%, African American $80 \%$ and uninsured 355\% less likely to get surgery. While for radiation, it was 15\% (TNBC), 
13\% (African American) and (uninsured) 31.8\% less likely to receive radiation. So for the dichotomous treatment variables, comprising the binary outcomes of surgery/no surgery and radiation/no radiation indicate a significant treatment effect for both 'no surgery' and ‘no radiation’ versus surgery and radiation respectively, and predictive variables age at diagnosis, African American race, uninsured status and TNBC versus NTNBC.

The overall Cox model previously described under Survival Analysis Results provided information on all the variables acting in concert. To separately assess the model for the effect of TNBC alone on the other variables and repeating the process for the effect of NTNBC alone on the other variables, the model was executed with TNBC and the other variables but without NTNBC and the results reported. It was again executed, this time with NTNBC and the other variables but without TNBC and the results reported.

The results are shown in Table 25 and the resulting survival curves shown in Figure 6 and Figure 7. This modified split models show that for the variable race, African American, white and the "other" racial groups, there is a statistically significant difference in survival for each of TNBC and NTNBC subsets when the model was executed separately. The survival findings that distinguish various racial groups will be described in the next section.

Race: The estimated hazard or risk of death for the combined "other" racial groups show a decreased risk of death for patients with both TNBC and NTNBC when compared to both African American and white races. For African American women with TNBC, risk of death was 1.219 times that of white women with TNBC. In African American women 
with NTNBC, the risk of death was 1.341 times that of a white woman with NTNBC. Results were statistically significant for both TNBC and NTNBC. In this divided model, for an African American woman with TNBC when compared to a white woman with TNBC, the difference in survival did achieve statistical significance $(p=0.001)$ as was the case for NTNBC where the survival difference also achieve statistical significance (hazard ratio $=1.341$ 95\% CI: 1.234, 1.458, $\mathrm{p}<0.0001$ ).

Age at diagnosis: Another variables that achieved statistical significance for this divided model was age at diagnosis (hazard ratio $=1.033,95 \%$ CI: 1.026, 1.041, $\mathrm{p}<0.0001$ ). Treatment status: For the treatment status of patients who had no surgical treatment compared to those who had surgical treatment, the survival difference achieved statistical significance, with those not receiving surgery having a lower survival (hazard ratio = 8.633, 95\% CI: 8.152, 9.143, p < 0.0001). A woman who did not have surgery had 8.633 times increased risk of death than a woman who had surgery. Those who had no radiation treatment had a statistically lower survival compared to those who had radiation treatment (hazard ratio $=1.630,95 \% \mathrm{CI}: 1.535,1.732, \mathrm{p}<0.0001)$. A woman who had no radiation treatment had 1.630 times increased risk of death than a woman who had radiation treatment a difference that was statistically significant.

Tumor grade: Patients who had higher tumor histological grades (Grade II, III and IV compared to Grade I) tended to have lower survival than those who had a lower tumor grade. In fact the analysis demonstrated a gradient in decreased survival going from lower grade to higher grade, with the worst survival progressing from Grade II to Grade IV, all differences being statistically significant (Grade II, hazard ratio $=1.385$, 95\% CI: 1.271, 1.508, $\mathrm{p}<0.0001$ ), (Grade III, hazard ratio $=2.428,95 \%$ CI: 2.228, 2.646, $\mathrm{p}<$ 
0.0001), (Grade IV, hazard ratio $=2.812,95 \%$ CI: 2.159, 3.661, $\mathrm{p}<0.0001$ ). In this schema a woman who had Grade IV had 3.661 times higher risk of death than a woman who had a Grade I tumor, which was a statistically significant difference in survival.

Table 25: Cox proportional hazard results TNBC and NTNBC.

\begin{tabular}{|c|c|c|c|c|c|c|}
\hline & & TNBC & & & NTNBC & \\
\hline Variable & $\beta$ & $\begin{array}{l}\text { Hazard Ratio } \\
(95 \% \text { CI })\end{array}$ & p-value & $\beta$ & $\begin{array}{l}\text { Hazard Ratio } \\
\text { (95\% CI) }\end{array}$ & p-value \\
\hline $\begin{array}{l}\text { Age at } \\
\text { Diagnosis }\end{array}$ & 0.036 & $\begin{array}{c}1.037 \\
(1.022,1052)\end{array}$ & $<0.0001$ & 0.034 & $\begin{array}{c}1.033 \\
(1.024,1.041)\end{array}$ & $<0.0001$ \\
\hline \multicolumn{7}{|l|}{ Race } \\
\hline White & & Reference & & & Reference & \\
\hline Black & 0.198 & $\begin{array}{c}1.219 \\
(1.066,1.369)\end{array}$ & 0.001 & 0.293 & $\begin{array}{c}1.341 \\
(1.145,1.367)\end{array}$ & $<0.0001$ \\
\hline Other & -0.377 & $\begin{array}{c}0.686 \\
(0.550,0.856)\end{array}$ & 0.003 & -0.289 & $\begin{array}{c}0.753 \\
(0.660,0.859)\end{array}$ & $<0.0001$ \\
\hline \multicolumn{7}{|l|}{ Ethnicity } \\
\hline Non-Hispanic & & Reference & & & Reference & \\
\hline Hispanic & -0.057 & $\begin{array}{c}0.945 \\
(0.803,1.111)\end{array}$ & 0.272 & -0.050 & $\begin{array}{c}0.949 \\
(0.850,1.058)\end{array}$ & 0.349 \\
\hline \multicolumn{7}{|l|}{ Treatment } \\
\hline \multicolumn{7}{|l|}{ Status } \\
\hline Surgery & & Reference & & & Reference & \\
\hline No Surgery & 2.208 & $\begin{array}{c}9.094 \\
(8.148,10.149)\end{array}$ & $<0.0001$ & 2.157 & $\begin{array}{c}8.647 \\
(8.116,9.214)\end{array}$ & $<0.0001$ \\
\hline Radiation & & Reference & & & Reference & \\
\hline No Radiation & 0.280 & $\begin{array}{c}1.323 \\
(1.191,1.471)\end{array}$ & $<0.0001$ & 0.582 & $\begin{array}{c}1.790 \\
(1.668,1.920)\end{array}$ & $<0.0001$ \\
\hline \multicolumn{7}{|l|}{ Grade } \\
\hline Grade I & & Reference & & & Reference & \\
\hline Grade II & 0.680 & $\begin{array}{c}1.974 \\
(1.265,3.075)\end{array}$ & 0.003 & 0.283 & $\begin{array}{c}1.347 \\
(1.234,1.470)\end{array}$ & $<0.0001$ \\
\hline Grade III & 0.979 & $\begin{array}{c}2.662 \\
(1.728,4.102)\end{array}$ & $<0.0001$ & 0.917 & $\begin{array}{c}2.515 \\
(2.301,2.749)\end{array}$ & $<0.0001$ \\
\hline Grade IV & 1.299 & $\begin{array}{c}3.666 \\
(2.109,6.372)\end{array}$ & $<0.0001$ & 1.091 & $\begin{array}{c}2.802 \\
(1.984,3.957)\end{array}$ & $<0.0001$ \\
\hline \multicolumn{7}{|l|}{ Age } \\
\hline$<40$ year & & Reference & & & Reference & \\
\hline $40-49$ & 0.384 & 1.099 & 0.769 & -0.207 & $\begin{array}{c}0.813 \\
(0.641,1.031)\end{array}$ & 0.087 \\
\hline $50-59$ & -0.686 & $\begin{array}{c}(0.585,2.067) \\
0.843\end{array}$ & 0.493 & -0.154 & 0.857 & 0.219 \\
\hline
\end{tabular}




$\begin{array}{llcllll} & & (0.517,1.374) & & & (0.660,1.114) & \\ 60-69 & -0.863 & 0.731 & 0.082 & -0.149 & 0.862 & 0.348 \\ & & (0.514,1.040) & & & (0.631,1.176) & \\ 70-79 & -0.852 & 0.755 & 0.18 & -0.033 & 0.997 & 0.988 \\ & & (0.599,0.952) & & & (0.686,1.449) & \\ \geq 80 & -. .489 & 0.613 & & 0.172 & 1.188 & 0.456 \\ & & (0.285,1.323) & & & (0.756,1.867) & \end{array}$

iii. Survival Curves

Figures 6, 7 and 8 are all survival curves that illustrate the plot of cumulative survival versus survival time for the two breast cancer subsets, TNBC and NTNBC.

Figure 6 is a survival plot for the overall model that shows statistically significant survival differences among TNBC and NTNBC.

Figure 7: Survival function curves for TNBC and race.

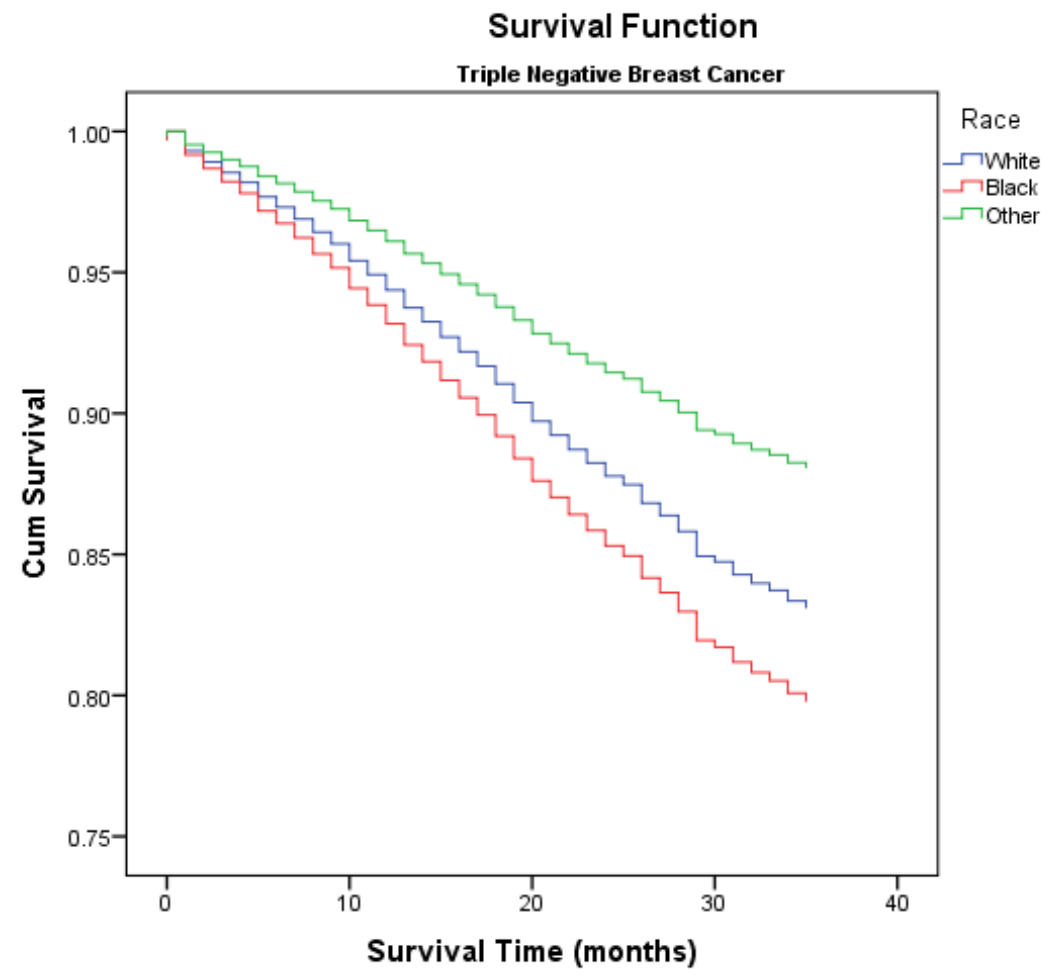

These

results illustrates the findings that the data satisfies the second hypothesis of this 
dissertation outlined previously. Figure 7 illustrates the significant differences in survival for female racial groups, white, African American and “other” among for TNBC. While Figure 8 shows similar differences in survival for the same racial groups among NTNBC patients. The findings satisfy the first hypothesis posited previously in this dissertation regarding survival among racial groups. This hypothesis states that survival is lower in African American patients compared with Non-Hispanic white women among TNBC patients. The results shown in Table 25 confirms this main hypothesis of this study and is illustrated in Table 6 that there is a statistically significant difference in survival between white women and African American women with TNBC.

Figure 8: Survival function curves for NTNBC and race.

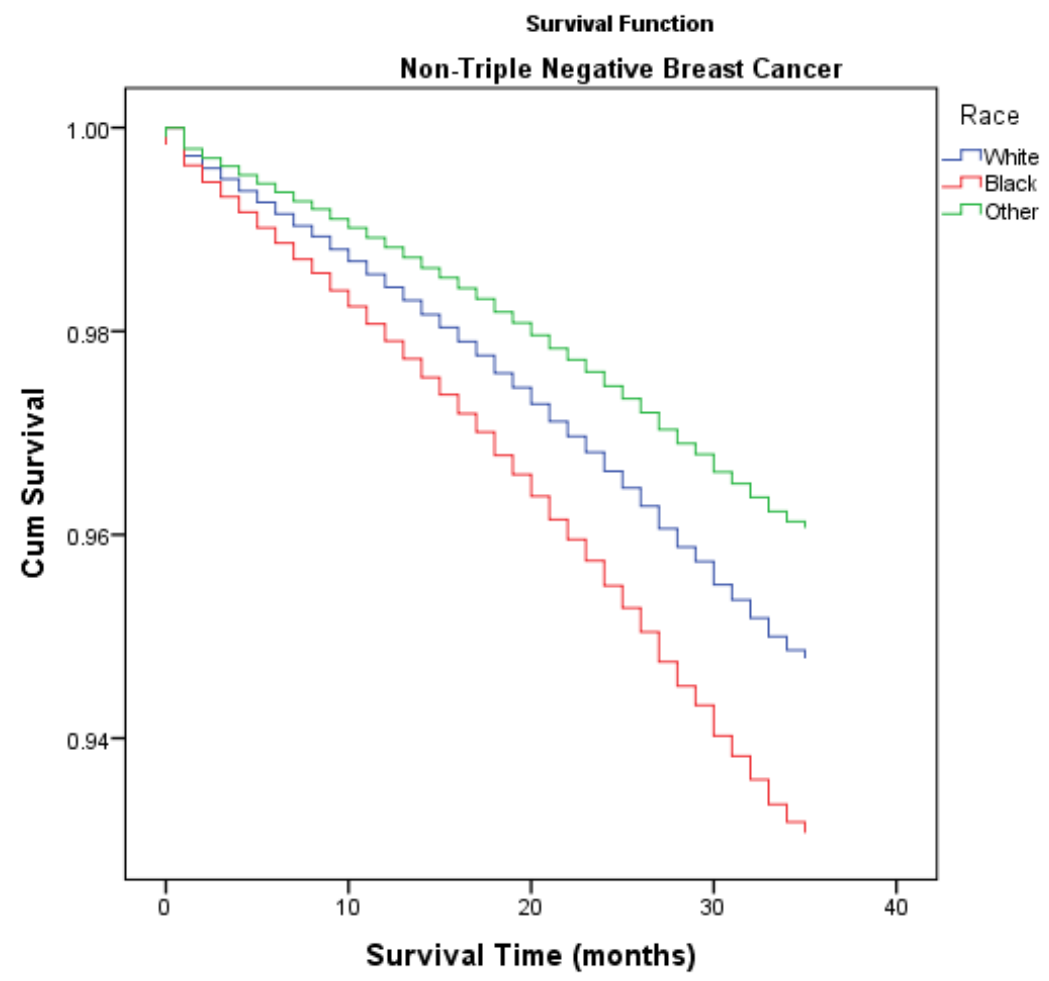




\section{CHAPTER V \\ DISCUSSION}

\section{i. Discussion}

The main goal of this study was to help close the epidemiological knowledge gaps regarding TNBC. In this direction, this large population study found that TNBC represented $11.71 \%$ of all molecular subsets of breast cancer compared to $88.29 \%$ of NTNBC subset. This $11.71 \%$ is at the lower end of the range of estimates found in the limited available literature on TNBC. This estimate is probably close to the actual estimate in the general population since the SEER population is closely representative of the general population. Despite this relatively small frequency, the epidemiological analysis of this subset, yield results which help to explain significant prognostically unfavorable aspects of breast cancer overall.

The TNBC intrinsic and extrinsic determinants (factors which broadly determine the frequency and impact of disease in the population) that were examined in this study include, age , race, ethnicity, marital status, health insurance status, histological tumor grade, and treatment received or not received, all have been shown to impact survival to varying extents in patients with breast cancer. A geographic-locality variable was excluded in the analysis because of the complex number of variables associated with it in the SEER database. The results, however, demonstrate a number of disparities that hitherto, were not definitively established in studies of this size, and in some instances were previously unknown prior to this undertaking:

Determinants and Disparities: This study has clearly demonstrated that age at diagnosis is a significant determinant of survival in TNBC patients. For categories of age, younger 
age is significantly less in TNBC versus NTNBC patients. The results also show that there is a significant disparity and higher hazard rate in survival regarding age at diagnosis. The survival data showed that TNBC patients, less than age 40 years have $12.4 \%$ lower survival rate as compared to women older than age 80 years. This is indicative of the lethality of TNBC in younger women such that octogenarians have $12.4 \%$ better survival than younger, premenopausal women with the disease subset. The lower survival age-disparity among TNBC compared to NTNBC has not been previously demonstrated in any studies of this population size. While the disparity in age has been implicated in other smaller studies, with age and specifically younger age as a risk factor for TNBC (Dent et al, 2007; Dolle et al., 2009, Bauer et al., 2007), this is the first study of this size and design to demonstrate the magnitude of this adverse survival effect.

Why the disparity in age and survival among TNBC populations? This is a subject of great speculation. Clearly, biological (especially genetics), environmental and social factors may play a role. One previous study offered the intriguing prospect in answer to this question, in the example of oral contraceptive use. Dolle et al. 2009, previously demonstrated an increased risk of oral contraceptive use among TNBC compared to controls in women, at or less than 40 years old (Dolle et al., 2009).

However, correlation does not imply causation. Moreover, the latency between carcinogenic exposure and cancer development is probably in the magnitude of many years (Clapp et al., 2008), so other putative factors may better explain the younger age predilection for TNBC than NTNBC and will have to be explored in other studies. Not surprisingly, this study revealed that race was a determinant of survival and significant disparities in race and survival among both TNBC and NTNBC exists. In terms of 
frequencies among the breast cancer subsets, less white women (over 8\% point) had TNBC than NTNBC while twice as many African American women had TNBC than NTNBC. The survival data confirmed the expected poorer survival among African American than white women with TNBC. The estimated hazard or risk of death for an African American woman with TNBC increases $34 \%$ that of a white woman with TNBC. Even the combined "Other” races had a 30\% decreased risk of death after the adjustment for the same variables in the model.

The study also showed that histological tumor grade was a determinant of survival in TNBC but the gradient with Grade III exhibiting greater disparity compared to survival in Grade I and II was quite surprising. What was also surprising were the frequencies of the tumor grades observed in this study with 79\% of TNBC patients having grade II while only $27 \%$ of NTNBC patients had grade II. $25.3 \%$ of NTNBC patients had grade I while only $2.2 \%$ of TNBC patients. The findings indicate that a greater proportion of TNBC patients tend to have a poorly differentiated breast cancer cellular profile at the time of diagnosis while fewer NTNBC do.

This goes to the observed greater lethality of this subset at the time of diagnosis and the resulting poorer survival seen in TNBC patients overall. It speaks to biology as a major contributor to the disparity seen in the mortality between TNBC and NTNBC patients. Disparities in those receiving surgical and radiation treatment were observed among African American, uninsured, and TNBC patients compared to white, insured and NTNBC patients. This treatment disparity may in part explain the poor survival seen in TNBC patients, although poorer survival in TNBC is likely due to other factors as well. While this study does shed light, not only on the determinants of survival, but also 
possible answers as to why these determinants may be causally related to the poor survival in TNBC and NTNBC. Future studies using other designs will be needed to further elucidate causation.

Still, the presence or absence of quality treatment is expected to independently predict survival in breast cancer (Odle, 2014). Disparities in quality of treatment have been shown to adversely affect survival in other health conditions (Bradley, Given \& Roberts, 2002). Surgical and radiation treatments, while part of standard treatment for breast cancer, are probably not by themselves the most effective treatment modalities for TNBC. Currently, the addition of systemic chemotherapy to surgery and locoregional radiation therapy should be a major part of the standard armamentarium against TNBC. While this may change in the future as a result of more effective treatment modalities such as biological therapy, the available forms of treatment today are not as effective for treating TNBC as it is for NTNBC. This also goes to the possible intrinsic biological aggressiveness and resistance to current forms of treatment for TNBC as opposed to NTNBC.

This study did not evaluate the merits of one form of treatment versus another in TNBC. That would be the remit of clinical trials. Its focus was on treatment in currently available forms, as a possible determinant of survival in the various subsets of breast cancer under study here.

Health insurance was also shown to be a significant determinant of survival in TNBC. As an index of socioeconomic status, health insurance status has hitherto been one explanation for poorer prognosis and survival in a number of health conditions. It has been shown previously in selected patient populations that quality of care or lack thereof 
is linked to the availability or non-availability of health insurance (Lillie-Blanton \& Hoffman, 2005). In a changing social environment during the years of this study, 2010 2012, fewer and fewer patients were without health insurance, so this factor was expected to play a smaller role in predicting survival in breast cancer subsets.

A small but statistically significant disparity difference in frequency of $0.8 \%$ was observed among the uninsured for TNBC (2.6\%) and NTNBC (1.8\%). The disparity of TNBC survival seen in this study among those with and without health insurance is a new finding and not previously reported. In the Cox model, the estimated hazard or risk of death for a patient without health insurance and TNBC increases 1.72 times that of an insured patient which is a statistically significant difference in survival. This and other such findings help confirm the study hypotheses that there are specific determinants and disparities in survival among TNBC and NTNBC patients.

\section{ii. Limitations}

One major limitation of this study is that some factors affecting survival remain illdefined or unknown and consequently are not reflected in this dissertation or some current database registries. TNBC is only one of many yet unknown breast cancer subsets contributing to current breast cancer mortality and its impact on survival is still to be determined. Another limitation is that databases themselves are limited in scope and the availability of a large menu of study variables that may affect outcome is still few and not well quantifiable. In particular, a complete menu of treatment modalities currently administered to patients with breast cancer that would help to better explain survivaltreatment disparities between TNBC and NTNBC is lacking. 


\section{iii. Implications}

These findings may have implications for policy changes that may refocus emphasis and priorities regarding screening, treatment and research on breast cancer subsets in African American women. Further studies focused on African American women may alter and direct mammographic screening guidelines specifically for this racial group, and especially towards younger age groups, such that current screening guidelines may have to be modified for African American women to better detect breast cancer at an earlier age, stage and grade. Earlier detection in this younger age group in particular may alter the current dismal mortality trajectory. As a result of this early screening intervention, African American women, if treated earlier in the course of their disease, may have a better long-term prognosis than currently exists.

Earlier treatment for at-risk populations as a result of earlier screening may be developed given the disparity data found here. For instance, new chemotherapy and biological therapies specific to TNBC patients may be tailored to this at-risk population with resultant improvement in efficacy - more equitable treatment approaches for all racial groups may thus lead to decreases in mortality for breast cancer in general and TNBC in particular, especially among African American women.

These findings could signal a new impetus do more frequent molecular typing in this at risk population subset. While not evaluated in this study, but on the basis of other study results, perhaps BRCA mutational studies can also be targeted for screening in this at-risk population. Undoubtedly, large methodologically sound studies will needed to 
better evaluate the impact of BRCA mutation and other as yet unknown biological markers for screening in this at-risk group.

These findings may also have implications for genetic research and the development of biomarkers specific for TNBC and especially among women of African American ancestry.

The findings might also provide the momentum to develop treatment modalities that de-emphasizes endocrinological measures in this racial group and instead emphasizes systemic therapy to a greater extent. For instance, new chemotherapy and biological therapies specific to TNBC patients may be tailored to this at-risk population with the resultant improved efficacy and outcomes.

The implications of socioeconomic factors and their impact on TNBC incidence, treatment, and mortality in the population, may gather greater thrust for study and action based on the present findings. While insurance status is only one indicator of socioeconomic status in the population, other studies using other indicators, such as income, education, housing, etc. should be undertaken with respect to TNBC outcomes and disparities, so as to better explain the impact of socioeconomic status on this subset in the population that may alter its prognostic trajectory.

The present findings have established that the higher histologic grade at diagnosis, and by implication the more aggressive and lethal nature of TNBC, have implications for cell receptor biology and identifies the need for further work to be undertaken regarding unique biological parameters operating in this population subset. 
Finally, the present findings has implications for primary and secondary prevention research. More population studies inclusive of minority women needs to be undertaken, specifically with regards to prevention strategies in at-risk groups.

\section{CHAPTER VI}

\section{RECOMMENDATIONS AND CONCLUSION}

\section{i. Recommendations}

This is the first large scale population study to demonstrate that, despite the small proportion of the population affected by this breast cancer subset, TNBC has a disproportionally larger impact on the survival rates of African American women than white women or women of "other" races in the United States. The lack of proven effective treatment modalities and the poorer survival outcome reported in this study makes TNBC a significant disease entity requiring substantially greater and concerted measures, involving the primary and secondary prevention of breast cancer, to be implemented in this population.

For this, it is recommended that among the substantive preemptive measures for curbing this lethal condition are primary prevention against known and unknown environmental and carcinogenic exposures including alcohol abuse and radiation exposure; increasing educational and behavior modification measures directed towards obesity reduction, with tailored diet and exercise programs; implementation of modifiable reproductive risk reduction measures, including endogenous endocrine interventions directed at altering timing of menarche, menopause, age at first birth and breast feeding choices. 
Intensification of research efforts on newer genetic screening procedures that are effective for detecting TNBC and other subsets and the utilization of innovative genomic techniques in the assessment of women at-risk for breast cancer subtypes are also strongly recommended in this public health policy schema.

Given the present findings, innovative breast cancer screening techniques should be initiated at a younger age ( $\leq$ age 40 years) for TNBC and African American women in particular, based on risk-benefit assessment studies. It is recommended that research on, and ushering in of, targeted biologic markers for both primary and secondary prevention of breast cancer subsets should be prioritized, as well as, the introduction of timely and more widespread histopathological typing for breast cancer subsets in institutions nationwide. The development of prophylactic agents for TNBC, analogous to the selective estrogen receptor modulators (SERMs), such as tamoxifen and raloxifene for Luminal A and Luminal B subsets, is critically important for TNBC patients and similar subsets. As a result of the data presented here, there should be new impetus for research on the epidemiology and public health impact of TNBC and other breast cancer subsets.

In summary, the main recommendation of this study is that greater public health attention and action for breast cancer and its subsets than is currently exhibited, needs to be introduced. Such an introduction, together with a range of supplementary actions, will significantly impact on the disproportionate survival rates of African American women. These supplementary actions should include changing public policy with regards to breast cancer prevention, diagnosis, treatment and quality of life for these patients; refocusing primary and secondary prevention strategies towards TNBC, other subsets and at-risk populations, specifically with regards to environmental, biological and 
socioeconomic interventions and research efforts, focused on both treatment and public health interventions that are especially directed towards TNBC patients in general and African American women in particular as particular at-risk groups for this disease and its and prognostically unfavorable sequelae.

\section{ii. Conclusion}

African American race, younger age at diagnosis, uninsured status, higher grade at diagnosis, inadequate treatment are independent predictors of poor survival among breast cancer patients; importantly, TNBC had a lower survival than that of NTNBC patients. The survival disparity in African American women with breast cancer may partially be explained by disproportionately higher TNBC cases among them, as well as, higher rates of not receiving standard treatments.

The main aim of this dissertation was to determine if there are variables that predict survival among TNBC and NTNBC patients and, if so, did disparities in survival exist for these same variables separately for TNBC and for NTNBC populations. The results showed that this aim was achieved; the research questions answered and affirmed; and the hypotheses supported by the data. 


\section{LIST OF REFERENCES}

Ambrosone, C.B, Zirpoli, G., Hong, C-C., Yao, S., Troester, M.A., Bandera, E.V.,

Schedin, P...\& Palmer, J.R. (2015). Important role of menarache in development of estrogen receptor-negative breast cancer in African American women. JNCI Journal of the National Cancer Institute, 107 (9): djv172

DOI: $\underline{10.1093 / j n c i / d j v 172}$

American Cancer Society (ACS). Cancer Facts and Figures 2010. Atlanta GA. 2010. Retrieved from: http://www.cancer.org/docroot/STT/content/STT_1x_Cancer_Facts_and_Fi gures_2008.asp?from=fast

American Cancer Society (ACS). Cancer Facts and Figures for African Americans 20092010. Atlanta. ACS. 2011.

American Cancer Society (ACS). Cancer Facts and Figures. 2013-2014. Atlanta GA. 2015. Retrieved from:

http://www.cancer.org/research/cancerfactsstatistics/index

American Cancer Society (ACS). Stages of Breast Cancer. Retrieved from: http://www.breastcancer.org/symptoms/diagnosis/staging

American Cancer Society (ACS). Treatment of Breast Cancer by stage. Cancer. Retrieved from: http://www.cancer.org/cancer/breastcancer/detailedguide/breast-cancer-treatingby-stage

Aebi, S., Davidson, T., Gruber, G. \& Cardoso, F (2008). Primary breast cancer: ESMO clinical practice guidelines for diagnosis, treatment and follow-up. Annals of Oncology, 22(6), v112-vi24.

Altekruse, S.F., Kosary, C.L., Krapcho, M., Neyman, N., Aminou, R., Waldron W... \& Edwards BK (Eds). SEER Cancer Statistics Review, 1975-2007, National Cancer Institute. Bethesda, MD. Retrieved from: http://seer.cancer.gov/csr/1975_2007/, based on November 2009 SEER data submission, posted to the SEER web site, 2010 .

Altundag, K., Harputluoglu, H., Aksoy, S. \& Gullu, I.H. (2007). Potential chemotherapy options in triple-negative subtype of breast cancer. Journal of Clinical Oncology, 25(10), 1294-1295. 
Amadou, A., Ferrari, P., Muvonge, R., Moskala, A., Biessy, C., Romieu, I. \& Hainaut, P. (2013). Overweight, obesity and risk of premenopausal breast cancer according to ethnicity: a systematic review and dose-response meta-analysis. Obesity Review, 14(8), 665-678. doi: 10.1111/obr.12028.

Amir, E., Freedman, O.C., Seruga, B. \& Evans D.J. Assessing women at high risk of breast cancer: a review of risk assessment models. Journal National Cancer Institute, 102, 1-12, 2010.

Amirikia, K.C., Mills, O., Bush, J. \& Newman, L.A. (2011). Higher population-based incidence rates of triple negative breast cancer among young African-American women: implications for breast cancer screening recommendations. Cancer, 117 (12), 2747-275. doi: 10.1002/cncr.25862.

Anders, C. \& Carey L.A. (2008). Understanding and treating triple-negative breast cancer. Oncology (Williston Park), 22(11), 1233-1239.

Anders, K.C. \& Carey L.A. (2009). Biology, metastatic patterns, and treatment of patients with triple-negative breast cancer. Clinical Breast Cancer, 9 (Supplement 2), S7381.

Anderson, S.J., Wapnir, I., Dignam, J.L., Fisher, B., Mamounas, E.P, Jeong, J.H...\& Wolmark, N. Prognosis after ipsilateral breast tumor recurrence and locoregional recurrences in patients treated by breast-conserving therapy in five National Surgical Adjuvant Breast and Bowel Project protocols of node-negative breast cancer. Journal of Clinical Oncology, 27(15), 2466-2473, 2009.

Anderson, W.F., Chu K.C., Chatterjee N., Brawley O. \& Briton LA. (2001). Tumor Variants by Receptor Expression in White patients with node-negative breast cancer from SEER database. Journal of Clinical Oncology, 19(1), 18 - 27.

Anderson, W.F., Chattergee, N., Ershler, W.B. \& Brawley O.W. (2002). Estrogen receptor breast cancer phenotypes in SEER database. Breast Cancer Research, 76(1), 27 36.

Anderson, W.F, Jatoi, I., Tse, J. \& Rosenberg P.S. (2010). Male breast cancer: a population-based comparison with female breast cancer. Journal of Clinical Oncology, 28(2), 232-239.

Andya, A.A., Enewold, L., Horner, M.J., Jatoi, I., Shriver, C.D. \& Zhu K. (2012). Socioeconomic disparities and breast cancer hormone receptor status. Cancer Causes and Control, 23(6), 51-958. doi: 10.1007/s10552-012-9966-1. 
Armstrong, K., Long, J.A. \& Shea, J.A. (2004). Measuring adherence to mammography screening recommendations among low income women. Preventive Medicine, 38(6), $754-760$.

Bauer, K.R., Brown, M., Cress, R.D., Parise, C.A. \& Caggiano, A. (2007). Descriptive analysis of estrogen receptor (ER)-negative, progesterone receptor (PR)-negative, and HER2-negative invasive breast cancer, the so-called triple-negative phenotype: A population-based study from the California Cancer Registry. Cancer, 109(9), 1721-1728.

Bayraktar, S., Gutierrez, A.M., Liu D., Tasbas, T., Akar, U., Litton, J.K...\& Arun B.K. (2011). Outcome of triple-negative breast cancer in patients with or without deleterious BRCA mutations. Breast Cancer Research and Treatment, 130 (1), 145-153. doi: 10.1007/s10549-011-1711-z.

Bertucci, F., Finetti, P., Cervera, N., Esterni, B., Hermitte, F., Viens, P. \& Birnbaum, D. (2008). How basal are triple-negative breast cancer. International Journal of Cancer, 123(1), 236-240. doi: 10.1002/ijc.23518.

Billar, J.A., Dueck, A.C., Stucky, C-C H., Gray, R.J., Wasif, N., Northfelt, D.W... \& Pockaj B.A. (2010). Triple-Negative breast cancers: unique clinical presentations and outcomes. Annals of Surgical Oncology, 17(3 Supplement), 384-390.

Bonadonna, G., Brusamolino, E., Valagussa, P. \& Veronesi, U. (1976). Combination chemotherapy as adjuvant treatment in operable breast cancer. New England Journal of Medicine, 294(8), 405-410.

Boyle, P. \& Boffetta, P. (2009). Alcohol consumption and breast cancer risk. Breast Cancer Research, 11(supplement 3), S3.

Boyle, P. (2012). Triple Negative Breast Cancer: Epidemiological Considerations and Recommendations. Annals of Oncology, 23, (Supplement 6), vi7-12.

Breast. In: Edge, S.B., Byrd, D.R., Compton, C.C., Fritz, A.G., Greene, F.L., \& Trotti, A. eds. (2010): AJCC Cancer Staging Manual and Handbook, 7th Ed. New York, NY: Springer, pp 347-76.

Breen, N., Cronin, K.A., Meissner, H.I., Taplin, S.H., Tangka, F.K., Tiro, J.A. \& McNeel, T.S. (2007). Reported drop in mammography: Is this cause for concern. Cancer, 109(12), $2405-2409$.

Burnstein, H.J., Temin, S., Anderson, H., Buchholz, T.A., Davidson, N.E...\& Griggs, J.J. (2014). Adjuvant endocrine therapy for women with hormone receptor-positive breast cancer: American Society of clinical oncology clinical practice guidelines focused update. Journal of Clinical Oncology, 32(21), 2255-2269. 
Buxant, F., Engohan-Aloghe, C. \& Noel, J.C. (2010). Estrogen receptor, progesterone receptor, and glucocorticoid receptor in breast tissue, breast in situ carcinoma, and invasive breast cancer. Applied Immunohistochemistry Molecular Morphology, 18(3), 254-257.

Calle, E.E, Rodriguez, C., Walker-Thurmond, K., \& Thun, M.J. (2003). Overweight, Obesity and mortality from cancer in a prospectively studied cohort of U.S. adults. New England Journal of Medicine, 348(17), 1625-1638.

Cameron, D., Brown, J., Dent, R., Jacjisch, C., MacKey, J., Pivot, X...\& Bell, R. (2013). Adjuvant bevacizumab-containing therapy in triple-negative breast cancer (BEATRICE): primary results in a randomized, phase 3 trial. The Lancet Oncology, 14(10), 933-942.

Campeau, P.M., Foulkes, W.D. \& Tischkowitz, M.D. (2008). Hereditary breast cancer: New genetic developments, new therapeutic avenues. Human Genetics, 124(1), 31-34.

Cao, J.Q., Olson, R. A., \& Tyldesley, S. K. (2013). Comparison of recurrence and survival rates after breast-conserving therapy and mastectomy in young women with breast cancer. Current Oncology, 20(6), e593-e601. doi:10.3747/co.20.1543.

Cardoso, F., Costa, A., Norton, L., Cameron, D., Cuffer, T...\& Winer, E. (2012). First international consensus guidelines for advanced breast cancer (ABC 1). Breast, 21(3), 242-252.

Carey, L.A., Perou, C.M., Livasy, C.A., Dressler, L.G., Conway, K., Karaca, G...\& Millikan, R.C. (2006). Race, breast cancer subtypes, and survival in the North Carolina Breast Cancer Study. Journal of the American Medical Association, 29(2), $2492-2502$.

Carmichael, A.R. \& Bates, T. (2004). Obesity and Breast Cancer: A Review of the Literature. Breast, 13(2), 85 - 92.

CDC. Breast Cancer Statistics, 2014. Retrieved from http://www.cdc.gov/cancer/breast/statistics/

CDC. Breast Cancer Rates by Race and Ethnicity. 1999 - 2011. Retrieved from: http://www.cdc.gov/cancer/breast/statistics/race.htm

Chavez-Macgregor, M., Clarke, C.A., Lichtensztajn, D., Hortobagyi, G.N. \& Giordano S.H. (2013). Male breast cancer according to tumor subtype and race: a population-based study. Cancer, 119(9), 1611-1617. doi: 10.1002/cncr.27905. 
Chen, S.L., Hoehne, F.M. \& Giuliano, A.E. (2007). Prognostic significance of micrometastasis: SEER population based study. Annals of Surgical Oncology, 14, 3378 -3384 .

Chen, Y., Thompson, W., Semenciw, R. \& Mao, Y. (1999). Epidemiology of contralateral breast cancer. Cancer Epidemiology Biomarker Prevention, 8(10), 855-861.

Chew HK. (2001). Adjuvant therapy for breast cancer. Who should get what? Western Journal of Medicine, 174(4), 284-287.

Chlebowski, R., Chen, Z., Anderson, G., Rohan, T., Aragaki, A. \& Lane, D. (2005). Ethnicity and breast cancer: Factors influencing differences in incidence and outcome. Journal of the National Cancer Institute, 97, 439-448.

Chlebowski, R.T, Hendrix, S.L., Langer, R.D., Stefanick, M.L., Gass, M., Lane, D., WHI Investigators. (2003). Influence of estrogen plus progestin on breast cancer and mammography in healthy postmenopausal women. Journal of the American Medical Association, 289, 3243-3253.

Choo, J.R. \& Nielsen, T.O. (2010). Biomarkers for Basal-like Breast Cancer. Cancers, 2(2), 1040- 1065. doi:10.3390/cancers2021040.

Clapp, R. W., Jacobs, M. M., \& Loechler, E. L. (2008). Environmental and Occupational Causes of Cancer New Evidence, 2005-2007. Reviews on Environmental Health, 23(1), 1-37.

Clarke, C.A., Keegan, T.H., Yang, J., Press, D.J., Kurian, A.W., Patel, A.H. \& Lacey, J.V. (2012). Age-specific incidence of breast cancer subtypes: understanding the black-white crossover. Journal of the National Cancer Institute, 104(14), 10941001.

Clarke, M., Collins, R., Darby, S., Davies, C., Elphinstone, P., Evans, E., Goodwin, J., Gray, R... \& Wang, Y. (2005). Effects of radiotherapy and of differences in the extent of surgery for early breast cancer on local recurrence and 15-year survival: an overview of the randomised trials. Lancet, 366(9503), 2087-2106.

Clarke, T., Soler-Vila, H., Fleming, L.E., Christ, S.L., Lee, D.L \& Arheart, K.L. (2012). Trends in adherence to recommended cancer screening: the US population and working cancer survivors. Frontiers in Oncology, 2, 190. doi: 10.3389/fonc.2012.00190.

Cleator, S., Heller, W. \& Coombes, R.C. (2007). Triple-negative Breast cancer: therapeutic options. The Lancet Oncology, 8 (3), 235 - 244.

Clegg, L.X., Li, F.P., Hankey, B.F., Chu, K. \& Edwards, B.K. (2002). Cancer survival 
among US whites and minorities: a SEER (Surveillance, Epidemiology, and End Results) Program population-based study. Archives of Internal Medicine, 162, 1985-1993.

Cohn, B.A., La Merrill, M., Krigbaum, N.Y., Yeh, G., Park, J.S, Zimmermann, L. \& Cirillo, P.M. (2015). DDT exposure in utero and breast cancer. Journal of Clinical Endocrinology \& Metabolism, 100(8), 2865-2872. doi: 10.1210/jc.2015-1841.

Cox, D.R. Regression model and life tables (with discussion). (1972). Journal of the Royal Society Statistical Society. Series B (Methodological), 34(2), 187-220.

Crosbie, J., Kilbreath, S.L., Dylke, E., Refshauge, K.M., Nicholson, L.L... \& White, K. (2010). Effects of mastectomy on shoulder and spinal kinematics during bilateral upper-limb movement. Physical Therapy, 90(5), 679-692.

Crown, J., Oshaughnessy, J., \& Gullo, G., (2012). Emerging targeted therapies in triplenegative breast cancer. Annals of Oncology, 23 (Supplement 6), vi56-65. doi: 10.1093/annonc/mds196.

Curtis, E., Quale, C., Haggstrom, D. \& Smith-Bindman, R. (2008). Racial and ethnic differences in breast survival: how much is explained by screening, tumor severity, biology, treatment, comorbidities and demographics. Cancer, 112(1), 171 -180 .

Cuzick, J., Sestak, I., Forbes, J.F., Dowsett, M., Knox, J., Cawthorn, S...\& IBIB-II investigators. (2014). Anastrozole for prevention of breast cancer in high risk postmenopausal women (IBIS-II): an international, double-blind, randomised placebo-controlled trial. Lancet. 383, 1041-1048, 2014. Erratum in: Lancet, 383(9922), 1040.

Dawson, S.J, Provenzano, E. \& Caldas, C. (2009). Triple negative breast cancers: Clinical and prognostic implications. European Journal of Cancer, 45, 27-40.

De Haes, J.C., Van Oostrom, M.A. \& Welvaart, K. (1986). The effect of radical and conserving surgery on the quality of life of early breast cancer patients. European Journal of Surgical Oncology, 12, 337-342.

Delozier, T., Julien, J.P., Juret, P., Veyret, C., Couette, J.E, Graic, Y...\& de Ranieri, E. (1986). Adjuvant tamoxifen in postmenopausal breast cancer: preliminary results of a randomized trial. Breast Cancer Research and Treatment, 7(2), 105-109.

Dent, R., Trudeau, M., Pritchard, K., Hanna, W.M. Kahn, H.K., Sawka, C.A, Lickley, L.A, Rawlinson, E., Sun, P. \& Narod, S.A. (2007). Triple Negative breast cancer: clinical features and patterns of recurrence. Clinical Cancer Research, 13(15 Pt 1), $4429-4434$. 
De Ruijter, T.C., Veeck, J., de Hoon, J.P., van Engeland, M. \& Tijan-Heijnen, V.C. (2011). Characteristics of triple-negative breast cancer. Journal of Cancer Research and Clinical Oncology, 137(2), 183 - 192. doi: 10.1007/s00432-010-0957-x.

Desantis, C., Jemal, A. \& Ward, E (2010). Disparities in breast cancer prognostic factors by race, insurance status, and education. Cancer Causes and Control, 21(9), 1445-50. doi: 10.1007/s10552-010-9572-z.

Diab, S.G., Elledge, E.M. \& Clark, G.M. (2000). Tumor characteristics and clinical outcome of elderly women with breast cancer. National Cancer Journal, 92(7), $550-556$.

Dietz, E.C., Sistrunk, C., Miranda-Carboni, G., O’Regan, R. \& Seewaldt, V.L. (2015). Triple-negative breast cancer in African American women: disparities versus biology. National Review of Cancer, 15(40, 248-254.

Dolle, J.M., Dalling, J.R., White, E., Brinton, L.A., Doody, D.R ... \& Malone, K.E. (2009). Risk Factors for triple-negative breast cancer in women under age 45 years. Cancer Epidemiological Biomarkers \& Prevention, 18(4), 1157-1166. doi: 10.1158/1055-9965.

Edge, S.B. \& Compton, C.C. (2010). The American Joint Committee on Cancer: $7^{\text {th }}$ Edition of AJCC Cancer staging Manual and Future of TNM. Annals of Surgical Oncology, 17(6), 1471-1474. doi: 10.1245/s10434-010-0985-4.

Elston, C.W. \& Ellis, I.O. (1991). Pathological prognostic factors in breast cancer I. The value of histological grade in breast cancer: experience from a large study with long-term follow-up. Histopathology, 19, 403-410.

Esposito, A., Criscitiello, C. \& Curigliano G. (2015). Highlights from the $14^{\text {th }}$ St Gallen international breast cancer conference 2015 in Vienna: Dealing with classification, prognostication, and prediction refinement to personalize the treatment of patients with early breast cancer. Ecancermedicalscience, 9, 518. doi: 10.3332/ecancer.2015.518.

Evans, D.G., Howell, A., Ward, D., Lalloo, F., Jones J.L. \& Eccles, D.M. (2011). Prevalence of BRCA1 and BRCA2 mutations in triple-negative breast cancer. Journal of Medical Genetics, 48, 520-522. doi: 10.1136/jmedgenet-2011-100006.

Finison, K.S., Wellins, C.A., Wennberg, D.E. \& Lucas, F.L. (1999). Screening mammography rates by specialty of the usual care physician. Effective Clinical Practice, 2 (2), 120 - 125.

Fisher, B., Anderson, S., Bryant, J., Margolese, R.G., Deutsch, M., Fisher, E.R...\& 
Wolmark, N. (2002). Twenty-year follow-up of a randomized trial comparing total mastectomy, lumpectomy, and lumpectomy plus irradiation for the treatment of invasive breast cancer. New England Journal of Medicine, 347, 1233-1241.

Fisher, B., Carbone, P., Economou, S.G., Frelick, R., Glass, A., Lerner H...\& Fisher, E.R. (1975). l-Phenylalanine mustard (L-PAM) in the management of primary breast cancer: a report of early findings. New England Journal of Medicine, 292, 117122.

Fisher, B., Montague, E., Redmond, C., Barton, B., Borland, D., Fisher, E.R... \& Lawton, R. (1977). Comparison of radical mastectomy with alternative treatments for primary breast cancer. A first report of results from a prospective randomized clinical trial. Cancer, 39 (6 Supplement), 2827-2839.

Freedman GM, Anderson PR, Li T \& Nicolaou N. (2009). Locoregional recurrence of triple-negative breast cancer after breast-conserving surgery and radiation. Cancer, 115, 946-951.

Fostira, F., Tsitlanthi, M., Papadimitrou, C., Pertesi, M., Timotheadu, E., Stavropoulou, A.V... \& Skarlos, P. (2012). Prevalence of BRCA1 mutation among 403 women with triple-negative breast cancer: implications for genetic screening selection criteria: a Hellenic Cooperative Cancer Group Study. Breast Cancer Research and Treatment, 134(1), 353-362. doi: 10.1007/s10549-012-2021-9.

Foulkes, W.D., Smith, I.E. \& Reis-Filho, J.S. (2010). Triple-Negative Breast Cancer. New England Journal of Medicine, 368, 1938-1948.

Gartel, A.L. (2006). Is p21 an oncogene? Molecular Cancer Therapeutics, 5, 385.

Gaudet, M.M., Press, M.F., Haile R.W., Lynch, C.F, Glaser, S.L...\& Bernstein, J.L. (2011). Risk factors by molecular subtypes of breast cancer across a populationbased study of women 56 years or younger. Breast Cancer Research and Treatment, 130(2), 587-97. doi: 10.1007/s10549-011-1616-x.

Gazinska, P., Grioriadis, A., Brown, J.P., Mills, R.R., Mera, A...\& Pinder, S.E. (2013). Comparison of basal-like triple negative breast cancer defined by morphology, immunohistochemistry and transcriptional profiles. Modern Pathology, 26(7), 955-966. doi: 10.1038/modpathol.2012.244

Gierach, G.L., Burke, A. \& Anderson, W.F. (2010). Epidemiology of Triple Negative Breast Cancer. Breast Diseases, 32, 5 - 24.

Gluz, O., Liedtke, C., Gottschalk, N., Pusztai, L. \& Harbeck, N. (2009). Triple-negative 
breast cancer--current status and future directions. Annals of Oncology, 20(12), 1913-1927.

Goldhirsh, A., Wood, W.C., Coats, A.S., Gelber, R.D., Thurlimann, B., Senn, H.J..., \& Panel Members. (2011). Strategies for subtypes - dealing with the diversity of breast cancer: highlights of the St. Gallen International Expert Consensus on primary therapy of early breast cancer 2011. Annals Oncology, 22(8), 1737 -1747. doi: 10.1093/annonc/mdr304.

Gonzales-Angulo, A.M., Timms, K.M., Liu, S., Chen, H., Litton, J.K ...\& MericBernstam, F. (2011). Incidence and outcome of BRCA mutation in unselected patients with triple-negative breast cancer. Clinical Cancer Research, 17, 1082. doi: 10.1158/1078-0432.CCR-10-2560.

Goowin, P.J. (2008). Host-related factors in breast cancer: an underappreciated piece of the puzzle? Journal of Clinical Oncology, 26(20), 3299-3300.

Gown, A.M. (2008) Current issues in ER and HER2 testing by IHC in breast cancer. Modern Pathology, 21, S8-S15.

Greenup, R., Buchanan, A., Lorizio, W., Rhoads, K., Chan, S...\& Shelley Hwang, E. (2013). Prevalence of BRCA mutations among women with triple-negative breast cancer (TNBC) in a genetic counselling cohort. Annals of Surgical Oncology, 20(10), $3254-3258$.

Guray, M. \& Sahin, A.A. (2006). Benign Breast diseases: classification, diagnosis, and management. Oncologist, 11(5), 435-449.

Haffty, B.G., Yang, Q., Reiss, M., Kearney, T, Higgins, S.A...\& Toppmeyer, D. (2006). Locoregional relapse and distant metastasis in conservatively managed triplenegative early-stage breast cancer. Journal of Clinical Oncology, 24, 5652-5657.

Henson, D.E., Reis, L., Freedman, L.S. \& Carriaga, M. (1991). Relationship among outcome, stage of disease, and histologic grade for 22,616 cases of breast cancer. The basis for a prognostic index. Cancer, 68, 2142-2149.

Hershman, D., McBride, R., Jacabson, J.S., Lameroto, L., Roberts, K., Grann, V.R. \& Neugut, A.I. (2005). Racial Disparities and survival among women with early stage breast cancer. Journal of Clinical Oncology, 23, 6639 - 6646.

Hicks, D.G., Short, S.M., Prescott, N.L., Tarr, S.M., Coleman, K.A...\& Weil, R.J. (2006). Breast cancers with brain metastases are more likely to be estrogen receptor negative, express the basal cytokeratin CK5/6, and over express HER2 or EGFR. American Journal of Surgical Pathology, 30, 1097-1104. 
Hortobagyi, G.N. (2001). Adjuvant systemic therapy for early breast cancer: progress and controversies. Clinical Cancer Research, 7, 1839 - 1842

Howlader, N., Altekruse, S., Li, C.I., Chen, V.W., Clarke, C.A., Ries, L.A \& Cronin. K.A. (2014). US Incidence of Breast Cancer Subtypes defined by joint hormone receptor and HER2 Status. Journal of the National Cancer Institute, 106(5), 1-8. doi: 10.1093/jnci/dju055.

Howlader, N., Noone, A.M., Krapcho, M., Garshell, J., Miller, D., Altekruse, E.J... \& Cronin, K.A. (eds) (2015). SEER Cancer Statistics Review, 1975-2012, National Cancer Institute. Bethesda, MD. Retrieved from: http://seer.cancer.gov/csr/1975_2012/, based on November 2014 SEER data submission, posted to the SEER web site, April 2015.

Hudis, C.A. \& Gianni, L. (2011). Triple-Negative Breast Cancer: An Unmet Medical Need. The Oncologist, 16 (Supplement 1), 1-11. doi: 10.1634/theoncologist.2011S1-01.

Humphrey, L.L., Helfand, M., Chan, B.K.S., Woolf SH. (2002). Breast Cancer Screening: A summary of the evidence for the US Preventative Task Force. Annals of Internal Medicine, 137(5), 347- 360.

Isakoff, S.J. (2010). Triple-negative breast cancer: role of specific chemotherapy agents. Cancer Journal, 16(1), 53-61. doi: 10.1097/PPO.0b013e3181d24ff7.

Kaae, S. \& Johansen, H. (1962). Breast cancer: five year results: two random series of simple mastectomy with postoperative irradiation versus extended radical mastectomy. American Journal of Roentgenology, 87, 82-88.

Kaae, S. \& Johansen, H. (1969). Simple mastectomy plus postoperative irradiation by the method of McWhirter for mammary carcinoma. Annals of Surgery, 170, 895-899.

Kabat, G.C., Kim, M., Phipps, A.I., Li, C.I., Messina, C. R., \& Rohan, T.E. (2011). Smoking and alcohol consumption in relation to risk of triple-negative breast cancer in a cohort of postmenopausal women. Cancer Causes and Control, 22(5), 775-783.

Kaplan, H.G., Malmgren, J.A. \& Atwood, M.K. (2008). Impact of triple negative phenotype on breast cancer prognosis. The Breast Journal, 14(5), 456-463.

Keam, S.A., Im, S.A., Han, S.W., Oh, D.Y., Kim, J.H... \& Bang, Y.J. (2011). Ki-67 can be used for further classification of triple-negative breast cancer into two subtypes with different response and prognosis. Breast Cancer Research, 13, R22. 10.1186/bcr2834. 
Keegen, T.H.M., DeRouen, M.C., Press D.J, Kurian, A.W. \& Clarke, C.A. (2012). Occurrence of Breast Cancer Subtypes in adolescent and young adult women. Breast Cancer Research, 14(2), R55. 1 - 9.

Key, J., Hodgson, S., Omar, R.Z., Jensen, T.K, Thompson, S.G, Boobis, A.R., Davis, D.S. \& Elliott, P. (2006). Meta-analysis of studies of alcohol and breast cancer with consideration of the methodological issues. Cancer Causes and Control, 17(6), 759-70.

Kilbourne, A. M., Switzer, G., Hyman, K., Crowley-Matoka, M., \& Fine, M. J. (2006). Advancing Health Disparities Research Within the Health Care System: A Conceptual Framework. American Journal of Public Health, 96(12), 2113-2121. http://doi.org/10.2105/AJPH.2005.077628

King, M.C., Marks, J.H., Mandell, J.B., \& New York Breast Cancer Study Group. (2003). Breast and ovarian cancer risks due to inherited mutations in BRCA1 and BRCA2. Science, 302 (5645), 643-646.

Kreiger, N. (2010). Decline in Breast Cancer rates after the Women's Health Initiative: Socioeconomic and racial/ethnic differentials. American Journal of Public Health, 100(Supplement 1), S132-S139.

Kreike, B., van Kouwenhove, M., Horlings, H., Weigelt, B., Peterse, H. Bartelink, H. \& van de Vijver, M.J. (2007). Gene expression profiling and histopathological characterization of triple-negative/basal-like breast carcinomas. Breast Cancer Research, 9(5), R65. doi: 10.1186/bcr1771.

Krismanich-Conniff, K.M. (2012). Triple-Receptor Negative Breast Cancer: Imaging and Clinical Characteristics. American Journal of Roentgenology, 199(2), 458 - 464.

Kurian, A.W., Fish, K., Shema, S.J. \& Clarke, C.A. (2010). Lifetime risks of specific breast cancer subtypes among women in four racial/ethnic groups. Breast Cancer Research, 12, R99. doi: 10.1186/bcr2780.

Kwan, M.L., Kushi, L.H., Weltzien, E., Maring, B., Kutner, S.E...\& Caan, B.J. (2009). Epidemiology of breast cancer subtypes in two prospective cohort studies of breast cancer survivors. Breast Cancer Research, 11: R31.

Lakhani, S.R., Reis-Filho, J.S., Fulford, L., Penault-Lliorca, F., van der Vijver, M...\& Breast Cancer Linkage Consortium. (2005). Prediction of BRCA1 status in patients with breast cancer using estrogen receptor and basal phenotype. Clinical Cancer Research, 11, 5175. 
Lange, C.A., Gioeli, D., Hammes, S.R. \& Marker, P.C. (2007). Integration of rapid signaling events with steroid hormone receptor action in breast and prostate cancer. Annual Review of Physiology, 69, 171-199.

Langlands, F.E., Horgans, K., Dodwell, D.D. \& Smith, L. (2013). Breast cancer subtypes: response to radiotherapy and potential radiosensitisation. British Journal of Radiology, 86 (1023), 20120601. doi: 10.1259/bjr.20120601

Langles-Agulo, A.M., Timms, K.M., Liu, S., Chen, H., Litton, J.K...\& Meric-Bernstam, F. (2011). Incidence and outcome of BRCA mutations in unselected patients with triple receptor-negative breast cancer. Clinical Cancer Research, 17(5), 1082 1089.

Lantz, P.M., Mujahid, M., Schwartz, K., Janz, N.K., Fagerlin, A, Salem, B...\& Katz, S.J. (2006). The influence of race, ethnicity, and individual socioeconomic factors on breast cancer stage at diagnosis. American Public Health, 96(12), 2173-2178.

Lara-Medina, F.E, Perez-Sanchez, V., Saavedra-Perez, D., Blake-Cerda, M., Arc, C...\& Arrieta, O. (2011). Triple-negative breast cancer in Hispanic patients. Cancer, 117(16), 3658-3669. doi: 10.1002/cncr.25961.

Lee, E., McKean-Cowdin, R., Ma, H., Spicer, D.V., Van den Berg, D., Bernstein, L. \& Ursin, G. (2011). Characteristics of triple-negative breast cancer in patients with a BRACA1 mutation: Results from a population-based study of young women. Journal of Clinical Oncology, 29(33), 4373-4380.

Lee, E.H., Park, S.K., Park, B., Kim, S.W., Lee, M.H., Ahn, S.H...\& Korean Breast Cancer Society. (2010). Effect of BRCA1/2 mutation on short-term and long-term breast cancer survival: a systematic review and meta-analysis. Breast Cancer Research Treatment, 122, 11-25. doi: 10.1007/s10549-010-0859-2.

Lemmon, M.A. \& Schlessinger, J. (2010). Cell signaling by receptor-tyrosine kinases. Cell, 141 (7), 1117-1134.

Leserman, J., Cilenti, D., Hall, S.P., Hamby, S.L., Murphy, C.E. \& Berkman N.D. (1993). In sickness and in health: the status of women's health in North Carolina. International Journal of Health Service, 23, 555 - 584.

Lew, J.Q., Freedman, N.D., Leitzmann, Brinton, L.A., Hoover, R.N., Hollenbeck, A.R... \& Park Y. (2009). Alcohol and risk of breast cancer by histologic type and hormone receptor status in postmenopausal women. The NIH-AARP diet health study. American Journal of Epidemiology, 170(3), 308-317. doi: 10.1093/aje/kwp120. 
Li, C.I., Beaber, E.F., Tang, M.T.C., Porter, P.L., Daling, J.R. \& Malone, M.E. (2013). Reproductive factors and risk of estrogen receptor positive, triple-negative, and HER2-neu overexpressing breast cancer among women 20-44 years of age. Breast Cancer Research and Treatment, 137(2), 579-587.

Li, C.I., Malone, K.E. \& Daling, J.R. (2002). Differences in Breast Cancer Hormone Receptor Status and Histology by Race and Ethnicity among Women 50 Years of Age and Older. Cancer Epidemiology Biomarkers and Prevention, 11, 601-607.

Lin, N.U. \& Claus, E. (2008). Sites of distant recurrence and clinical outcomes in patients with metastatic triple-negative breast cancer. Cancer, 113(10), 2638 - 2645.

Liedtke, C., Mazouni, C., Hess, K.R., Andre, F., Tordai, A...\& Pusztai L. (2008). Response to neoadjuvant therapy and long-term survival in patients with triplenegative breast cancer. Journal of Clinical Oncology, 26(8), 1276 - 1281.

Lizarraga, I., Schroeder, M.C., Weigel, R. J \& Thomas, A. (2015). Surgical management of breast cancer in 2010 - 2011 SEER registries hormone and HER2 receptor status. Annals of Surgical Oncology, May 9, Volume 0(1).

Lodish, H., Berk, A., Zipurski, S.L., Matsudaira, P., Baltomore, D. \& Darnell, J. (2000). Molecular Cell Biology. $4^{\text {th }}$ Edition. NY, WH Freeman. Section 3.4.

Loukas, M., Tubbs, R.S, Mirzayan, N., Shirak, M., Steinberg, A. \& Shoja, M.M. (2011). The history of mastectomy. The American Surgeon, 77(5), 566-571.

Love, R.R. \& Philips, J (2002). Oophorectomy for breast cancer: history revisited. Journal of the National Cancer Institute, 94, 1433-1434.

Lund, M.J., Butler, E.N., Hair, B.Y., Ward, K.C., Andrews, J.H...\& Eley, J.W. (2010). Age/race differences in HER2 testing and in incidence rates for breast cancer triple subtypes: a population-based study and first report. Cancer, 116(11), 25492559.

Lynch, H.T., Lynch, P.M., Lanspa, S.J., Snyder, C.L. Lynch, J.F. \& Boland, C.R. (2009). Review of the Lynch syndrome: history, molecular genetics, screening, differential diagnosis, and medicolegal ramifications. Clinical Genetics, 76(1), 1 18.

Lund, M.J., Trivers, K.F., Porter, P.L., Coates, R.J., Leyland-Jones, B...\& Eley, J.W. (2009). Race and triple negative threats to breast cancer survival: a populationbased study in Atlanta, GA. Breast Cancer Research and Treatment, 113:357-370. doi: 10.1007/s10549-008-9926-3. 
McCarthy, E.P., Burns, R.B., Coughlin, S.S., Freund, K.M., Rice, J., Marwill, S.L...\& Moskowitz, M.A. (1998). Mammography use helps to explain differences in Breast Cancer stage at diagnosis between older Black and White women. Annals of Internal Medicine, 128(9), 729 - 736.

McDonald, J., Goyal, A. \& Terry, M.B. (2013). Alcohol intake and breast cancer: weighing the overall evidence. Current Breast Cancer Reports, 5(3), 10.1007/s12609-013-0114-z.

McPherson, K., Steel, C.M. \& Dixon, J.M. (2000). Breast cancer - epidemiology, risk factors, and genetics. British Medical Journal, 321(7261), 624-628.

Ma, X.J., Salunga, R., Tuggle, J.T., Gaudet, J., Enright, E., McQuary, P...\& Zhang, B.M. (2003) Gene expression profiles of human breast cancer progression. Proceedings of the National Academy of Science U S A, 100, 5974-5979. doi: 10.1002/cncr.25016.

Malin, D., Strekalova, E., Petrovic, V., Deal, A. M., Ahmad, A. A., Adamo, B... Cryns, V. L. (2014). $\alpha$ B-crystallin: a novel regulator of breast cancer metastasis to the brain. Clinical Cancer Research, 20(1), 56-67. doi:10.1158/1078-0432.CCR-13-1255

Malone, K.E., Daling, J.R., Doody, D.R., Hsu, L., Berbstein, L...\& Ostrander, E.A. (2006). Prevalence and predictors of BRCA1 and BRCA2 mutations in a population-based study of breast cancer in white and black American women ages 35 to 64 years. Cancer Research, 66(16), 8297 - 8308.

Margolis, G., Goodman, R.L. \& Rubin, A. (1990). Psychological effects of breastconserving cancer treatment and mastectomy. Psychosomatics, 31, 3-39.

Marimoto, L.M., White, E., Chen, Z., Chlebowski, R.T., Hays, J., Kuller, L...\& McTiernan, A. (2002). Obesity, Body Size and Risk of Postmenopausal Breast Cancer: The Women's Health Initiative (United States). Cancer Causes \& Control, 13, 741 - 751.

Martin, M., Segui, M.A., Anton, A., Ruiz, A., Ramos, M., Adrover, E...\& GEICAM 9805 Investigators. (2010). Adjuvant docetaxel for high-risk, node-negative breast cancer. New England Journal of Medicine, 363, 2200-2210.

Merrill, R.M., Capocaccia, R., Feuer, E.J. \& Mariotto, A. (2000). Cancer registry estimates based on tumour registry data in the Surveillance, Epidemiology and End Result (SEER) program. International Journal of Epidemiology, 29(2), 197 207. 
Metzger-Filho, O. \& de Azambuja, E. (2011). Neoadjuvant Chemotherapy and Targeted Therapies: a Promising Strategy. Journal of the National Cancer Institute. Monographs, (43), 116-119.

Miller, B.A., Hankey, B.F. \& Thomas, T.L. (2002). Impact of Sociodemographic Factors, Hormone Receptor Status, and Tumor Grade on Ethnic Differences in Tumor Stage and Size for Breast Cancer in US Women. American Journal of Epidemiology, 155, 534-545.

Millikan, R.C., Newman, B., Tse, C.K., Moorman, P.G., Conway, K., Dressler, L.G... \& Perou, C.M. (2008). Epidemiology of basal-like breast cancer. Breast Cancer Research and Treatment, 109, 123-129.

Mock, V. (1993). Body image in women treated for breast cancer. Nursing Research, 42(3), 153-157.

Moran, M.S., Yang, Q., Harris, L.N., Jones, B., Tuck, D.P. \& Haffty, B.G. (2008). Longterm outcomes and clinicopathologic differences of African-American versus white patients treated with breast conservation therapy for early-stage breast cancer. Cancer, 113, 2565-2574.

Morimoto LM, White E, Chen Z, Chlebowski T, Hays, J, Kuller, L...\& McTiernan, A. (2002). Obesity, body size, and risk of postmenopausal breast cancer: the Women's Health Initiative (United States). Cancer Causes and Control, 13 (8), 741-751.

Morris, G.J., Naidu, S., Topham, A.K., Guiles, F., Xu, Y. \& Mitchell, E.P. (2007). Differences in breast carcinoma characteristics in newly diagnosed AfricanAmerican and Caucasian patients. A single-institution compilation compared with the National Cancer Institute's Surveillance, Epidemiology, and end results database. Cancer, 110(4), 876-884.

Moyer, A. (1997). Psychosocial outcomes of breast-conserving surgery versus mastectomy: A meta-analytic review. Health Psychology, 16(3), 284-298.

Musolino, A., Bella, M.A., Bortesi, B., Michiara, M., Naldi, N...\& Ardizzoni, A. (2007). BRCA mutations, molecular markers, and clinical variables in early-onset breast cancer: a population-based study. Breast, 16(3), 280-292.

NCHS. Fact Sheet. May 2015. National Center for Health Statistics, 3311 Toledo Rd, Hyattsville, MD 20782-2064.

NCCN. From: http://www.nccn.org/professionals/physician_gls/f_guidelines.asp\#site 
NCI (National Cancer Institute). Breast Cancer Treatment (PDQ $\left.{ }^{\circledR}\right)$. Treatment Options for Triple Negative Breast Cancer. Retrieved from: http://www.cancer.gov/types/breast/patient/breast-treatment-pdq\#section/_367

NCI (National Cancer Institute). Breast Cancer Treatment (PDQ $\left.{ }^{\circledR}\right)$ Treatment by Stage. Retrieved from: http://www.cancer.gov/types/breast/patient/breast-treatment-pdq\#section/_222

NHIS. National Health Interview Survey. Mammography utilization, NHIS Website. retrieved from http://www.cdc.gov/nchs/nhis.htm.

Nielsen, T., Hsu, F., Jensen, K., Cheang, M., Karaca, G., Hu, Z...\& Perou, C.M. (2004). Immunohistochemical and clinical characterization of the basal-like subtype of invasive breast carcinoma. Clinical Cancer Research, 10(16), 5367-5374.

Nissen, M.J., Swenson, K.K., Ritz, L.J., Farrell, J.B., Sladek, M.L. \& Lally, R.M. (2001). Quality of life after breast carcinoma surgery: a comparison of three surgical procedures. Cancer, 91:1238-46.

Niu, J., Sangal, A. \& Quan, W. (2014). An evolving paradigm: addition of neoadjuvant chemotherapy in triple-negative breast cancer. Austin Journal of Medical Oncology, 1(1), 3.

Niwińska, A., Olszewski, W., Murawska, M. \& Pogoda, K. (2011). Triple-negative breast cancer with brain metastases: a comparison between basal-like and non-basal-like biological subtypes. Journal of Neuro-Oncology, 105(3), 547-553.

Nofech-Mozes, S., Trudeau, M., Kahn, H.K., Dent, R., Rawlinson, E...\& Hanna, W.M. (2009). Patterns of recurrence in the basal and non-basal subtypes of triple-negative breast cancers. Breast Cancer Research Treatment, 118, 131137. doi: 10.1007/s10549-008-0295-8.

Oakman, C., Viale, G. \& Di Leo, A. (2010). Management of triple negative breast cancer. Breast, 19, 312-321.

Odle T.G. (2014). Adverse effects of breast cancer treatment. Radiologic Technology. 85(3), 297M-319M.

Onitilo, A., Engel, J.M., Greenlee, R.T. \& Mukesh, B.N. (2009). Breast Cancer Subtypes Based on ER/PR and Her2 Expression: Comparison of Clinicopathologic Features and Survival. Clinical Medicine Research, 7(1-2): 4-13. Retrieved from: http://www.ncbi.nlm.nih.gov/pmc/articles/PMC2705275/ 
O’Shaughnessy, J., Osborne, C., Pippen, J.E., Yoffee, M., Patt, D., Rocha, C...\& Bradley, C. (2011). Iniparib plus chemotherapy in metastatic triple-negative breast cancer. New England Journal of Medicine, 364, 205-214.

Pal, S.K., Childs, B.H. \& Pegram, M. (2011). Triple negative breast cancer: unmet medical needs. Breast Cancer Research and Treatment, 125 (3), 627-636.

Palmer, J.R., Adams-Campbell, L.L., Boggs, D.A., Wise, L.A. \& Rosenberg, L. (2007). A Prospective study of body size and breast cancer in black women. Cancer Epidemiology Biomarkers \& Prevention, 16, 1795 - 1802.

Parker, C., Lin, H.Y. \& Shen, Y., (2014). Effect of hormone receptor status and local treatment on overall survival for early-stage breast cancer. Journal of Clinical Oncology, 32, (Suppl 26), abstract 60.

Patterson, S.K., Helvie, M.A., Joynt, L.K., Roubidoux, M.A., \& Strawderman, M. (1998). Mammographic appearance of breast cancer in African-American women: report of 100 consecutive cases. Academy of Radiology, 5, 2-8.

Penault-Llorca, F. \& Viale, G. (2012). Pathological and molecular diagnosis of triplenegative breast cancer: a clinical perspective. Annals of Oncology, 23 (Suppl 6), vi19 - vi22.

Perou, C.M., Sørlie, T., Eisen, M.B., van de Rijn, M., Jeffrey, S.S...\& Botstein D. (2000). Molecular portraits of human breast tumours. Nature, 406,747-752.

Phipps, A.I, Chlebowski, R.T, Prentice, R., McTiernan, A., Wactawski-Wende, J...\& Li, CI. (2011). Reproductive history and oral contraceptive use in relation to risk of triple-negative breast cancer. Journal of the National Cancer Institute, 103, 470477. doi: 10.1093/jnci/djr030.

Phipps, A.I \& Li, C.I (2014). Breastfeeding and triple-negative breast cancer: potential implications for racial/ethnic disparities. Journal National Cancer Institute, 106(10). doi: 10.1093/jnci/dju281

Pierobon, M. \& Frankenfeld, C.L. (2013). Obesity as a risk factor for triple-negative breast cancers: a systematic review and meta-analysis. Breast Cancer Research and Treatment, 137(1), 307-317.

Prat, A., Adamo, B., Cheang, M.C, Anders, C.K, Carey, L.A \& Perou, C. M (2012). Molecular Characterization of Basal-Like and Non-Basal-Like Triple-Negative Breast Cancer. The Oncologist, 18(2), 123 - 133.

Prasise, C.A. \& Caggiano, V. (2014). Breast cancer Survival Defined by the 
ER/PR/HER2 Subtypes and a Surrogate Classification according to Tumor Grade and Immuno-histochemical Biomarkers. Journal of Cancer Epidemiology, 2014. Retrieved from: http://www.hindawi.com/journals/jce/2014/469251/

Prowell, T.M. \& Davidson, N.E. (2004). What is the role of ovarian ablation in the management of primary and metastatic breast cancer today? The Oncologist, 9, 507-517.

Rahman, G.A. (2011). Breast conserving therapy: A surgical technique where little can mean more. Journal of Surgical Technique and Case Report, 3, 1-4.

Rakha, E.A., Reis-Filho, J.S., Baehner, F, Dabbs, D.J, Decker, T...\& Ellis, I. O. (2010). Breast cancer prognostic classification in the molecular era: the role of histological grade. Breast Cancer Research, 12, 207- 219.

Rankin J. (2006). William Stewart Halsted: a lecture by Dr Peter D. Olch. Annals of Surgery, 243(3), 418-25.

Rastelli, F. \& Crispino, S. (2008) Factors predictive of response to hormone therapy in breast cancer. Tumori, 94(3), 370-383.

Retsky, M., Demicheli, R., Gukas, I. \& Hrushesky, W. (2005). Enhanced surgery-induced angiogenesis among pre-menopausal women might partially explain excess breast cancer mortality of blacks compared to whites: An hypothesis. International Journal of Surgery, 5, 300-304.

Rhee, J., Han, S.W., Oh, D.Y., Kim, J.H., Im, S.A., Han, W...\& Kim, T.Y. (2008). The clinicopathologic characteristics and prognostic significance of triple-negativity in node-negative breast cancer. BMC Cancer, 8, 307. doi: 10.1186/1471-2407-8-307.

Ries, L. A. G., Eisner, M. P., Kosary, C. L., Hankey, B. F., Miller, B. A. \& Clegg, L. (Eds). (2004). SEER Cancer Statistics Review, 1975-2001. Bethesda, MD, National Cancer Institute.

Robertson, L., Hanson, H., Seal, S., Warren-Perry, M., Hughes, D., Howell, I...\& TNT Trial TMG; BCSC (UK). (2012). BRCA1 testing should be offered to individuals with triple-negative breast cancer diagnosed below 50 years. British Journal of Cancer, 106(6), 1234-1238. doi: 10.1038/bjc.2012.31.

Rosenburg, J., Chia, Y.L. \& Plevritis, S. (2005). The effect of age, race, tumor size, tumor grade, and disease stage on invasive ductal breast cancer survival in US SEER database. Breast Cancer Research and Treatment, 89, 47 - 54.

Rummel, S., Varner, E., Shriver, C.D., \& Ellsworth, R.E. (2013). Evaluation of BRCA1 
mutations in an unselected patient population with triple-negative breast cancer. Breast Cancer Research and Treatment, 137(1), 119-125.

Rushton, M.K., Zhang, T. \& Song, X. (2014). Survival Outcomes across ethnicities in Triple-Negative Breast cancer. Journal of Clinical Oncology, 32:5s, (supplement; abstract 1113).

Schwartz, G.F., Veronesi, U., Clough, K.B., Dixon, J.M., Fentiman, I.S... \& Consensus Conference Committee. (2006). Proceedings of the Consensus Conference on Breast Conservation, April 28 to May 1, 2005, Milan, Italy. Cancer, 107, 242250.

Schifeling, D.J. \& Hamlin, D.J. (1991). Early diagnosis of breast cancer. Universal screening is essential. Postgraduate Medicine, 89(3), 55-6, 59-60, 62.

SEER Cancer Statistics Factsheets: Breast Cancer. National Cancer Institute. Bethesda, MD. 2015. Retrieved from: http://seer.cancer.gov/statfacts/html/breast.html

Shih, T. \& Lindley, C. (2006). Bevacizumab: angiogenesis inhibitor for the treatment of solid malignancies. Clinical Therapeutics, 28(11), 1779-1802.

Shinde, S.S, Forman, M.R., Kuerer, H.M., Yan, K., Peintinger, F., Hunt, K. K...\& Symmans, W. F. (2010). Higher parity and shorter breastfeeding duration: association with triple-negative phenotype of breast cancer. Cancer, 116, 49334943. doi: 10.1002/cncr.25443.

Singh, G. (2012). Oophorectomy in breast cancer - controversies and current status. Indian Journal of Surgery, 74(3), 210-212.

Singletary, S.E., Allred, C., Ashley, P., Bassett, L.W., Bland, K.I...\& Greene F.L. (2002). Revision of the American Joint Cancer Committee on Cancer Staging for breast cancer. Journal of Clinical Oncology, 20 (17), 3628-3636.

Smith, G.L., Jiang, J., Buchholz, T.A., Xu Y., Hoffman, K.E...\& Smith, B.D. (2014). Benefit of adjuvant brachytherapy versus external beam radiation for early breast cancer: impact of patient stratification on breast preservation. International Journal of Radiation Oncology, Biology, and Physics, 88(2), 274-284.

Smith, I.E, Pierga, J.Y., Biganzoli, L., Cortes-Funes, H., Thomssen, C., Pivot, X... \& ATHENA Study Group. (2011). First-line bevacizumab plus taxane-based chemotherapy for locally recurrent or metastatic breast cancer: Safety and efficacy in an open-label study in 2,251 patients. Annals of Oncology, 3, 595-602. 
Smith-Warner, S.A., Spiegelman, D., Yaun, S.S., van den Brandt, P.A., Folsom A. R...\& Hunter, D.J. (1998). Alcohol and breast cancer in women: a pooled analysis of cohort studies. Journal of the American Medical Association, 279, 535-540.

Solin LJ. (2010). Breast conservation treatment with radiation: An ongoing success story. Journal of Clinical Oncology, 28(5), 709-711.

Solin, L.J., Hwang, W-T. \& Vapiwala N (2009). Outcome after breast conservation treatment with radiation for women with triple-negative early-stage invasive breast carcinoma. Clinical Breast Cancer, 9, 96-100.

Sotirlou, C., Neo, S.Y., McShane, L.M., Korn, E.L., Long, P.M...\& Liu, E.T. (2003). Breast Cancer classification and Prognosis based on gene expression profiles from a population-based study. Proceedings of the National Academy of Sciences, 100 (18), $10393-10398$.

Sorlie, T., Perou, C.M., Tibshirani, R., Aas, T., Geisler, S...\& Borrensen-Dale, A.L. (2001). Gene expression patterns of breast carcinomas distinguish tumor subclasses with clinical implications. Proceedings of the National Academy of Science U S A., 98, 10869-10874.

Sorlie, T., Tibshirani, R., Parker, J., Hastie, T., Marron, J.S...\& Botstein, D. (2003). Repeated observation of breast tumor subtypes in independent gene expression data sets. Proceedings of the National Academy of Science U S A., 100(14), 84188423.

Stark, A.T., Claud, S., Kapke, A., Lu, M. \& Griggs, J. (2005). Race modifies the association between breast carcinoma pathologic prognostic indicators and the positive status for HER-2/neu. Cancer, 104, 2189-2196.

Stark, A., Kleer, C.G., Martin, I., Awuah, B., Nsiah-Asare, A., Takyi, V...\& Newman, L. (2010). African ancestry and higher prevalence of triple-negative breast cancer. Cancer, 116, 4926-4932.

Stead, L.A., Lash, T.L., Sobieraj, J.E., Chi, D.D., Westrup, J.L...\& Rosenberg, C.L. (2009). Triple-Negative Breast Cancers are increased in black women regardless of age or body mass index. Breast Cancer Research, 11(2), R18. doi: 10.1186/bcr2242.

Steinberg, M.D., Juliano, M.A. \& Wise, L. (1985). Psychological outcome of lumpectomy versus mastectomy in the treatment of breast cancer. American Journal of Psychiatry, 142, 34-39.

Stewart, S.L., King, J.B., Thompson, T.D., Friedman, C. \& Wingo, P.A. (2004). Cancer 
Mortality Surveillance --- United States, 1990 - 2000. MMWR, 53 (SS03), 1 108.

Sturtz, L.A., Melley, J., Mamula, K., Shriver, C.D. \& Ellsworth, R.E. (2014). Outcome disparities in African American women with triple negative breast cancer: a comparison of epidemiological and molecular factors between African American and Caucasian women with triple negative breast cancer. BMC Cancer, 14, 62. doi: 10.1186/1471-2407-14-62.

Suba, Z. (2014). Triple-negative breast cancer risk in women is defined by the defect of estrogen signaling: preventive and therapeutic implications. Journal of OncoTargets and Therapy. 7, $147-151$.

Swede, H., Gregorio, D.I., Tannenbaum, S.H., Brockmeyer, J.A., Ambrosone, C...\& Runowicz, D. (2011). Prevalence and Prognostic role of triple-negative breast cancer by race: a surveillance study. Clinical Breast Cancer, 11(5), 332-341.

Tinoco G., Warsch S., Glück S., Avancha K., \& Montero AJ. (2013). Treating breast cancer in the $21^{\text {st }}$ century: emerging biological therapies. Journal of Cancer, 4(2):117-132. doi:10.7150/jca.4925

Tjonneland, A., Thomsen, B.L., Stripp, C., Christensen, J., Overvad, K...\& Olsen, J.H. (2003). Alcohol intake, drinking patterns and risk of postmenopausal breast cancer in Denmark: a prospective cohort study. Cancer Causes Control, 14(3), $277-284$.

Tot, T., Gere, M., Pekar M., Tarjan M., Hofmeyer S., Hellberg, D...\& Tabar, L. (2011). Breast cancer multifocality, disease extent, and survival. Human Pathology. 42(11), 1761 -1769. doi: 10.1016/j.humpath.2011.02.002.

Trivers, K.F., Lund, M.J., Porter, P.L., Liff, J.M., Flagg, E.W., Coates, R.J. \& Eley, J.W. (2009). The epidemiology of triple negative breast cancer, including Race. Cancer Causes Control, 20, 1071 - 1082.

Ueno, N.T. \& Zhang, D. (2011). Targeting EGFR in triple-negative breast cancer. Journal of Cancer, 2, 324-328.

USPSTF Procedure Manual. Overview of US Preventative Services Task Force Structure and Processes, 2009. Retrieved from: http://www.uspreventiveservicestaskforce.org/uspstf08/methods/procmanua $\underline{\text { l1.htm }}$

Valachis, A., Polyzos, N.P., Patsopoulos, N.A., Georgoulias, V., Mavroudis, D. \& Mauri D (2010). Bevacizumab in metastatic breast cancer: A meta-analysis of randomized controlled trials. Breast Cancer Research and Treatment. 122(1), 1-7. 
Veronesi, U., Zurrida, S., Viale, G., Galimberti, V. Arnone, P. \& Nole, F. (2009). Rethinking TMN: a breast cancer classification to guide treatment and facilitate Research. The Breast Journal, 15(3), 291 - 295.

Vogel, V.G. (2001). Reducing the risk of breast cancer with tamoxifen in women at increased risk. Journal of Clinical Oncology, 19(18 Supplement), 87S -92S.

Vona-Davis, L. \& Rose, D.P. (2009). The influence of socioeconomic disparities on breast cancer tumor biology and prognosis: a review. Journal of Womens Health, 18(6), 883-893.

Vona-Davis, L., Rose, D.P., Hazard, H., Howard-McNatt, M, Adkins, F., Partin, J. \& Hobbs, G. (2008). Triple-negative breast cancer and obesity in rural Appalachian population. Cancer Epidemiological Biomarkers Prevention, 17, 3319-3324.

Vu, T. \& Claret, F.X. (2012). Trastuzumab: Updated mechanisms of action and resistance in breast cancer. Frontiers in Oncology, 2, 62.

Wang, R.F., Miyahara, Y., Wang, H.Y. (2008). Toll-like receptors and immune regulation; implications for cancer therapy. Oncogene, 27, 181-189.

Ward, E., Jemal, A., Cockkinides, V., Singh, G., Cardinez, C., Ghafoor, A. \& Thun, M. (2004). Cancer disparities by race/ethnicity and socioeconomic status. CA Cancer Journal Clinics, 54, 78.

Wellisch, D.K., Dimatteo, R., Silverstein, M. (1989). Psychosocial outcomes of breast cancer therapies: lumpectomy versus mastectomy. Psychosomatics, 30, 365-73.

Yadav, B. S., Sharma, S. C., Chanana, P., \& Jhamb, S. (2014). Systemic treatment strategies for triple-negative breast cancer. World Journal of Clinical Oncology, 5(2), 125-133. doi:10.5306/wjco.v5.i2.125.

Yanagawa, M., Ikemot, K., Kawauchi, S., Furuya, T., Yamamoto, S, Oka, M...\& Sasaki, K. (2012). Luminal A and luminal B (HER2 negative) subtypes of breast cancer consists of a mixture of tumors with different genotypes. BMC Research Notes, 5 , 376, 2012.

Yang, X.R., Pfeiffer, R.M., Garcia-Closas, M., Rimm, D.L, Lissowska, J...\& Sherman, M.E. (2007). Hormonal markers in breast cancer: coexpression, relationship with pathologic characteristics, and risk factor associations in a population-based study. Cancer Research, 67, 10608-16017. 
Yang, X.R., Sherman, M.E., Rimm, D.L, Lissowska, J., Brinton, L.A...\& Garcia-Closas, M. (2007). Differences in risk factors for breast cancer molecular subtypes in a population-based study. Cancer Epidemiological Biomarkers \& Prevention, 16, 439-443.

Young, S.R., Pilarski, R.T., Donenberg, T., Shapiro, C., Hammond, L.S...\& Narod, S.A. (2009). The prevalence of BRCA1 mutations among young women with triplenegative breast cancer. Biomed Central Cancer, 9, 86. doi: 10.1186/1471-2407-986.

Zhou, W. \& Slingerland, J.M. (2014). Links between oestrogen receptor activation and proteolysis: relevance to hormone-regulated cancer therapy. Nature Reviews. Cancer, 14(1), 26-38.

Zhu, W., Perez, E.Z., Hong, R., Li, Q. \& Xu, B. (2015). Age-related disparity in immediate prognosis of patients with triple-negative breast cancer: a populationbased study from SEER cancer registries. PLoS One, 10(5). doi: 10.1371/journal.pone.0128345.

Zorka, I., Zegarac, M., Inic, M., Markovic, I., Kozomara, Z...\& Jancic, S. (2014). Differences between Luminal A and Luminal B subtypes according to Ki-67, tumor size, and progesterone receptor negativity providing prognostic information. Clinical Medical Insights Oncology, 8, 107-111. 


\section{APPENDICES}

\section{APPENDIX A}

\section{Cox Proportional Hazard Model}

The Cox proportional hazard model is a statistical or semi-parametric approach to survival analysis that uses marginal likelihood methods. It is a method that is used to evaluate the relationship between patient survival (or its inverse - hazard) and several other covariates. These covariates are also known as predictive or explanatory variables. The importance of these covariates can be assessed by the hazard function. Moreover, the quantitative impact of these covariates on survival measures can be assessed by the model. The more familiar non-parametric log-rank or Kaplan-Meir method can evaluate survival for one variable at a time. The Cox proportional hazard model can be used to simultaneously evaluate the effects of several variables on survival, where survival is taken to mean the time between which a patient enters and then exits a study either through death or some other defined endpoint or event.

The model can also provide an estimate of the effect of an intervention on survival after an adjustment for other covariates, while allowing for an estimate of risk of death for a patient in the light of their prognostic variables. The Cox model in this study is fitted to the available data in a regression equation for the hazard function involving the chosen covariates of age, race, marital status, etc. The coefficients of these covariates ( $\beta$ ) describes the model fit, such that a positive and large regression coefficient means that the hazard is higher and the prognosis worst, while a negative regression coefficient implies that the hazard is lower and the prognosis better for patients with higher magnitude of the associated covariates. 
Censoring: When the period of observation is cut off before the event of interest occurs (still alive or lost to follow up, say) the subject is considered censored. If the subject's survival time is greater than the duration of study observation, the subject is also considered censored.

Interpretation of Hazard Function

A hazard function $\mathrm{h}(\mathrm{t})$ is a ratio of counts per unit time, a "probability rate" that a subject will die within a finite period of time, such that the subject has survived at least up to the start of the interval duration; it is often considered the risk of dying at time t. (Note $h(t)$ is a rate or a ratio of the number of subjects dying (counts) at the beginning of interval $t$ over the product of the number of subjects surviving at time $\mathrm{t}(\mathrm{n}(\mathrm{t}))$ and interval duration, D), such that: $h(t)=f(t) / S(t)$, where $S(t)=n(t) .(D)$.

$$
h(t)=h_{0}(t) e^{(\beta x)} \text { where } h_{0}(t) \text { is the baseline hazard. }
$$

In general:

$$
h_{i}(t)=h_{0}(t) * e^{(\beta 1 x i 1+\beta 2 x i 2+\ldots+\beta k x i k)}
$$

The hazard function therefore describes the relative likelihood of the event occurring at time t, conditional on the subject surviving up to that time. It is counts per unit time (units time $^{-1}$ ). The relationship between the presence or absence of death/event and the covariate could be assessed with logistic regression at a particular time by hazard ratio, h:

$$
h=e^{(\beta 1 x i 1+\beta 2 x i 2+\ldots+\beta k x i k)}
$$

To statistically compare the difference between two survival curves requires survival analysis and use of hazard ratio (ratio of two functions). Note: the ratio eliminates the baseline hazard $h_{0}$. Here, the $\beta$ coefficient is considered a hazard risk or a risk of death (e.g. x-times greater risk of dying). 
The Kaplan-Meir plot is step wise because the estimated survival probabilities are constant (horizontal) between adjacent deaths times and then decreases after each and every death (vertical line). The Cox cumulative probabilities is more continuous and instantaneous.

The SPSS output shows a table in which B is the value of the coefficients, $\beta$. A positive coefficient indicates that the hazard increased and survival decreased. In that situation the hazard rate is increased in proportion for each unit of the reference variable. If negative the hazard is less than the reference.

Example: For breast cancer subtype status, where TNBC is being compared with NTNBC or reference group, B is 0.826, hazard ratio 2.285, 95\% CI (2.144, 2.434, $\mathrm{p}<$ 0.0001) indicates that the estimated hazard or risk of death for a TNBC patient increases 2.285 times that of a NTNBC patient. It indicates that there is an $83 \%$ increase in the risk of death after adjustment for the effects of the other variables in the model, which is a statistically significant difference in survival.

The value of the Wald statistic is indicative of the importance of the variable for the model. The greater the Wald value, the greater the importance of the variable to the model. The Wald statistic is calculated for the variables in the model to help in the selection of the variables for removal from the model. Exponent of B $[\operatorname{Exp}(\mathrm{B}]$ provides the exponential value of the beta coefficient, which is the Hazard ratio.

\section{Definitions in the Cox Model}

P-value: The probability of the data or more extreme data occurring by chance when the null hypothesis is true.

Standard Error: A measure of the uncertainty or variability of the data or its spread. 
Confidence Interval (CI): If the estimation is repeated many times, then $95 \%$ of the estimated intervals will contain the true value within the interval.

Principal Information Source

Walters SJ. What is a Cox Model? Hayward Group. 2009. 


\section{APPENDIX B}

Raw Computer Data

Table B 1: Survival data for NTNBC versus other variables

\begin{tabular}{|c|c|c|c|c|c|c|c|c|}
\hline & \multirow[b]{2}{*}{ B } & \multirow[b]{2}{*}{ SE } & \multirow[b]{2}{*}{ Wald } & \multirow[b]{2}{*}{ df } & \multirow[b]{2}{*}{ Sig. } & \multirow[b]{2}{*}{ OR } & \multicolumn{2}{|c|}{$\begin{array}{l}95.0 \% \text { CI for } \\
\operatorname{Exp(B)}\end{array}$} \\
\hline & & & & & & & Lower & Upper \\
\hline GRADE I & & & 560.396 & 3 & .000 & Ref. & & \\
\hline GRADE II & .298 & .045 & 44.174 & 1 & .000 & 1.347 & 1.234 & 1.470 \\
\hline GRADE III & .922 & .045 & 412.424 & 1 & .000 & 2.515 & 2.301 & 2.749 \\
\hline GRADE IV & 1.030 & .176 & 34.230 & 1 & .000 & 2.802 & 1.984 & 3.957 \\
\hline $\begin{array}{l}80 \text { years and } \\
\text { above }\end{array}$ & & & 16.110 & 5 & .007 & Ref. & & \\
\hline$<40$ years & -.122 & .242 & .253 & 1 & .615 & .886 & .552 & 1.422 \\
\hline 40-49 years & -.343 & .185 & 3.451 & 1 & .063 & .710 & .494 & 1.019 \\
\hline $50-59$ years & -.300 & .142 & 4.486 & 1 & .034 & .741 & .561 & .978 \\
\hline 60-69 years & -.248 & .101 & 5.982 & 1 & .014 & .780 & .639 & .952 \\
\hline 70-79 years & -.133 & .064 & 4.279 & 1 & .039 & .875 & .771 & .993 \\
\hline \begin{tabular}{|l} 
Surgery \\
performed
\end{tabular} & & & & & & Ref. & & \\
\hline No-Surgery & 2.135 & .034 & 3952.924 & 1 & .000 & 8.458 & 7.913 & 9.040 \\
\hline Radiation given & & & & & & ref & & \\
\hline No-Radiation & .578 & .037 & 242.159 & 1 & .000 & 1.783 & 1.658 & 1.918 \\
\hline $\begin{array}{l}\text { Age at } \\
\text { Diagnosis }\end{array}$ & .032 & .004 & 56.748 & 1 & .000 & 1.033 & 1.024 & 1.041 \\
\hline Non-Hispanic & & & & & & Ref. & & \\
\hline Hispanic & -.053 & .056 & .897 & 1 & .344 & .949 & .850 & 1.058 \\
\hline White & & & 47.395 & 2 & .000 & Ref. & & \\
\hline Black & .224 & .045 & 24.659 & 1 & .000 & 1.251 & 1.145 & 1.367 \\
\hline Other & -.284 & .067 & 17.679 & 1 & .000 & .753 & .660 & .859 \\
\hline Insurance & & & & & & Ref. & & \\
\hline \begin{tabular}{|l} 
No Insurance \\
\end{tabular} & .486 & .096 & 25.498 & 1 & .000 & 1.627 & 1.347 & 1.965 \\
\hline Married & & & & & & Ref. & & \\
\hline Unmarried & .365 & .034 & 116.175 & 1 & .000 & 1.440 & 1.347 & 1.538 \\
\hline
\end{tabular}


Table B 2: Survival data for TNBC versus other variables

\begin{tabular}{|l|l|l|l|l|l|l|l|l|}
\hline \multicolumn{2}{|c|}{} & & & & & & & $95.0 \%$ CI for Exp(B) \\
\hline & B & SE & Wald & df & Sig. & OR & Lower & Upper \\
\hline GRADE I & & & 29.544 & 3 & .000 & Ref. & & \\
\hline GRADE II & .681 & .233 & 8.577 & 1 & .003 & 1.976 & 1.253 & 3.116 \\
\hline GRADE III & .926 & .226 & 16.773 & 1 & .000 & 2.524 & 1.621 & 3.932 \\
\hline GRADE IV & 1.147 & .297 & 14.885 & 1 & .000 & 3.148 & 1.758 & 5.637 \\
\hline $\begin{array}{l}80 \text { years and } \\
\text { above }\end{array}$ & & & & & & & & \\
\hline <40 years & .392 & .407 & .931 & 1 & .335 & 1.480 & .667 & 3.284 \\
\hline 40-49 years & .095 & .322 & .087 & 1 & .769 & 1.099 & .585 & 2.067 \\
\hline $50-59$ years & -.171 & .249 & .470 & 1 & .493 & .843 & .517 & 1.374 \\
\hline 60-69 years & -.313 & .180 & 3.028 & 1 & .082 & .731 & .514 & 1.040 \\
\hline $70-79$ years & -.281 & .118 & 5.645 & 1 & .018 & .755 & .599 & .952 \\
\hline $\begin{array}{l}\text { Surgery } \\
\text { performed }\end{array}$ & & & & & & & & \\
\hline No-Surgery & 2.198 & .059 & 1408.631 & 1 & .000 & 9.008 & 8.032 & 10.104 \\
\hline Radiation given & & & & & & Ref. & & \\
\hline No-Radiation & .274 & .055 & 24.378 & 1 & .000 & 1.315 & 1.180 & 1.466 \\
\hline Age at Dx & .032 & .008 & 17.274 & 1 & .000 & 1.033 & 1.017 & 1.049 \\
\hline Non-Hispanic & & & & & & Ref. & & \\
\hline Hispanic & -.096 & .087 & 1.209 & 1 & .272 & .909 & .766 & 1.078 \\
\hline White & & & 13.752 & 2 & .001 & Ref. & & \\
\hline Black & .109 & .062 & 3.046 & 1 & .081 & 1.115 & .987 & 1.260 \\
\hline Other & -.348 & .117 & 8.906 & 1 & .003 & .706 & .562 & .887 \\
\hline Insurance & & & & & & Ref. & & \\
\hline No Insurance & .618 & .123 & 25.180 & 1 & .000 & 1.854 & 1.457 & 2.360 \\
\hline Married & & & & & & Ref. & & \\
\hline Unmarried & .345 & .054 & 40.594 & 1 & .000 & 1.413 & 1.270 & 1.571 \\
\hline a. Triple Negative $=$ Triple Negative & & & & & \\
\hline
\end{tabular}


VITA

MICHAEL C. BELCON

$1969-1973$

B.Sc., Chemistry

McMaster University

$1973-1976$

M.D.

College of Medicine

Howard University

1983

M.Sc., Health Science

McMaster University

2006

M.P.H

Florida International University

Board Certifications

American Board of Internal Medicine

1982

1998

2009

Internal Medicine

Rheumatology

Public Health

\section{PUBLICATIONS}

Belcon MC, Rooney PJ, Tugwell P. Aspirin and Gastrointestinal Hemorrhage: A Methodologic Assessment. Journal of Chronic Diseases. 38, 101-111, 1985.

Ahmed NU, Smith GI, Haber G, Belcon MC. Are women with functional limitations at risk of underutilization of mammography screening? Women's Health Issues. 19, 79-87, 2009.

Belcon MC, Ahmed NU, Younis MZ. Analysis of national healthcare systems: searching for a model for developing countries - Trinidad and Tobago as a test case. Public Administration \& Management. 13(3), 40-74, 2009.

Belcon MC, Ahmed NU. Disparities in triple-negative breast cancer. Submitted to Journal of Health Disparities Research and Practice.

Belcon MC, Ahmed NU. Risk-factors for triple-negative breast cancer: An Epidemiological Analysis. In preparation.

Belcon MC, Saxena A, Ahmed NU. Higher tumor histological grades at the time of diagnosis: A unique distinguishing feature between triple-negative and non-triplenegative breast cancer. In preparation. 